\title{
Amide Directed Intramolecular Co(III)-Catalyzed C-H Hydroarylation of Alkenes for the Synthesis of Dihydrobenzofurans with a quaternary center
}

Asier Carral-Menoyo, Nuria Sotomayor* and Esther Lete*

Departamento de Química Orgánica II, Facultad de Ciencia y Tecnología, Universidad del País Vasco / Euskal Herriko Unibertsitatea UPV/EHU. Apdo. 644. 48080 Bilbao (Spain)

Table of contents

1. Synthesis of substrates 1aa-1fa, 3aa

2. Copies of ${ }^{1} \mathrm{H}$ and ${ }^{13} \mathrm{C}$ spectra of compounds 1-6 


\section{Synthesis of substrates 1aa-1fa, 3aa}

Substrates 1aa, ${ }^{1} \mathbf{1 a b}, \mathbf{1 a d}-\mathbf{1 a g}, \mathbf{1 a i}, \mathbf{1 a k}^{2}{ }^{2} \mathbf{1 b a}, \mathbf{1 d a}, \mathbf{1 e a}, \mathbf{5 a a}$ and $\mathbf{3 a a}{ }^{1}$ were prepared according to literature procedures, and 1ac, 1ah, 1aj, 1al, 1am, 1an, $\mathbf{1 b f}, \mathbf{1} \mathbf{b g}, \mathbf{1 b j}, \mathbf{1 c a}, \mathbf{1 d g}, \mathbf{1 f a}$ using analogous synthetic routes (Schemes S1 and S2)

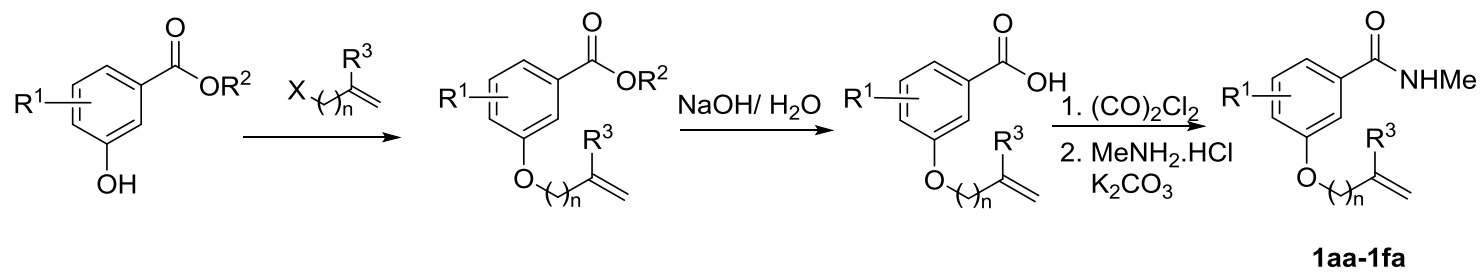

Scheme S1. Synthesis of 1aa-1fa.

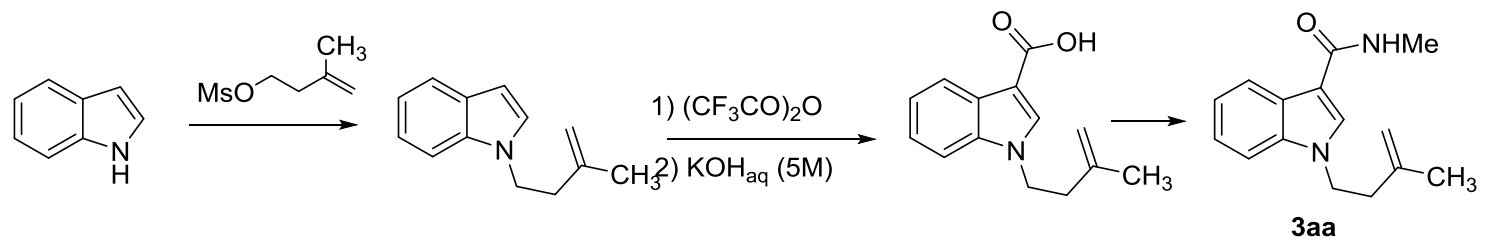

Scheme S2. Synthesis of 3aa.

\footnotetext{
${ }^{1}$ Davis, T. A.; Hyster, T. K.; Rovis, T. Rhodium(III)-Catalyzed Intramolecular Hydroarylation, Amidoarylation, and Heck-type Reaction: Three Distinct Pathways Determined by an Amide Directing Group. Angew. Chem. Int. Ed. 2013, 52, 14181-14185.

${ }^{2}$ Rit, R. K.; Ghosh, K.; Mandal, R.; Sahoo, A. K. Ruthenium-Catalyzed Intramolecular Hydroarylation of Arenes and Mechanistic Study: Synthesis of Dihydrobenzofurans, Indolines, and Chromans. J. Org. Chem. 2016, 81, 8552-8560.
} 
2. Copies of ${ }^{1} \mathrm{H}$ and ${ }^{13} \mathrm{C}$ spectra of compounds $1-6$
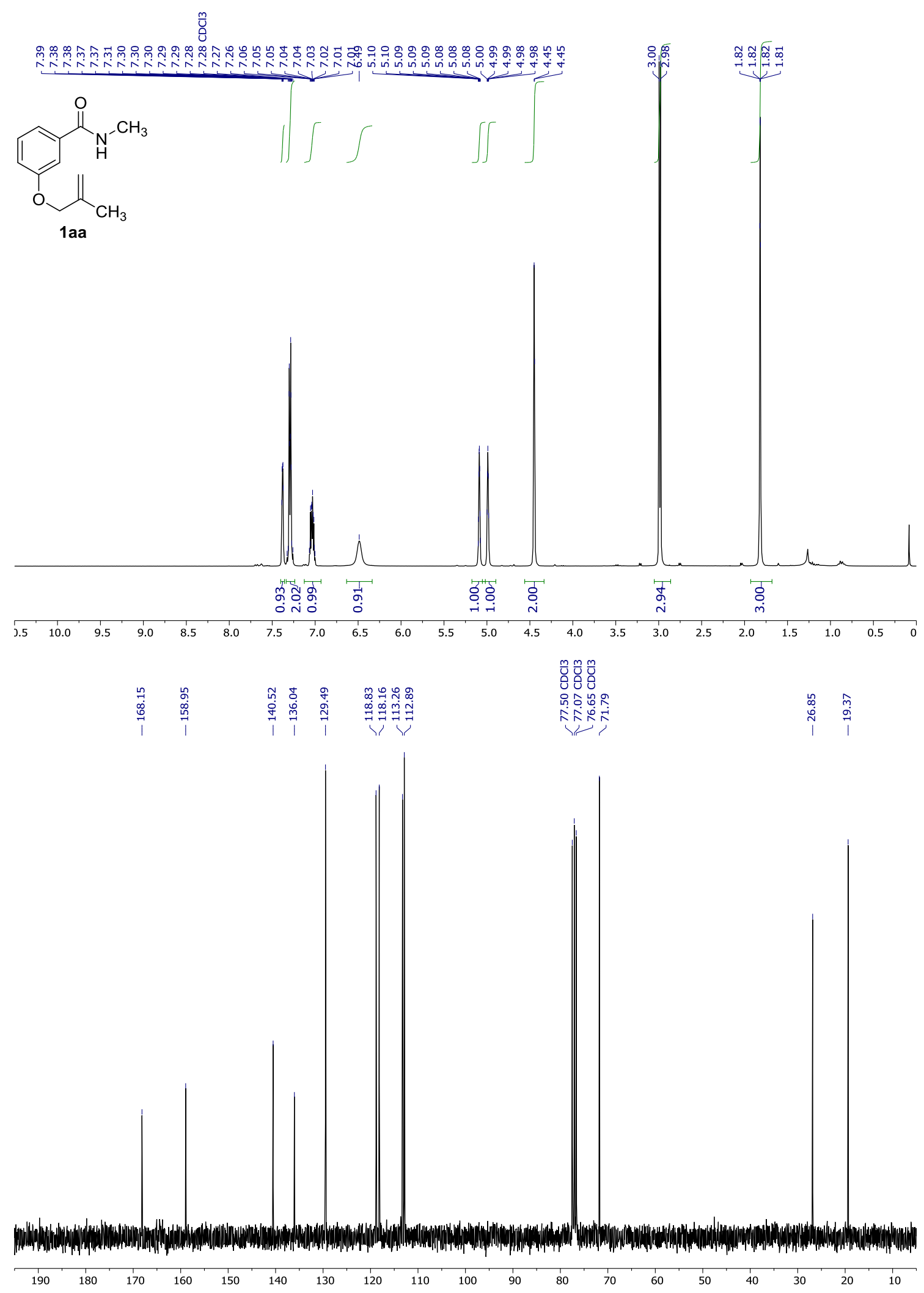

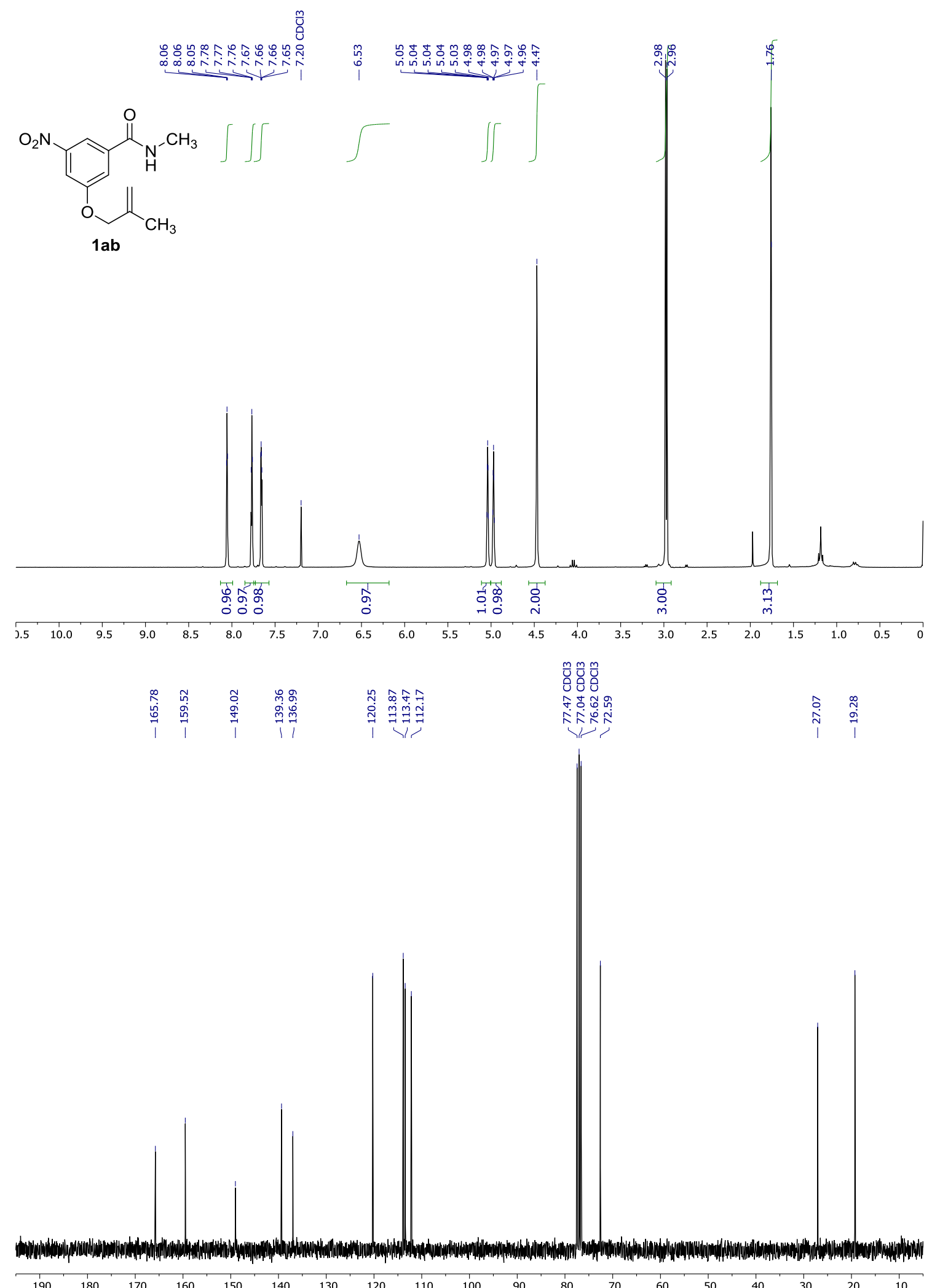

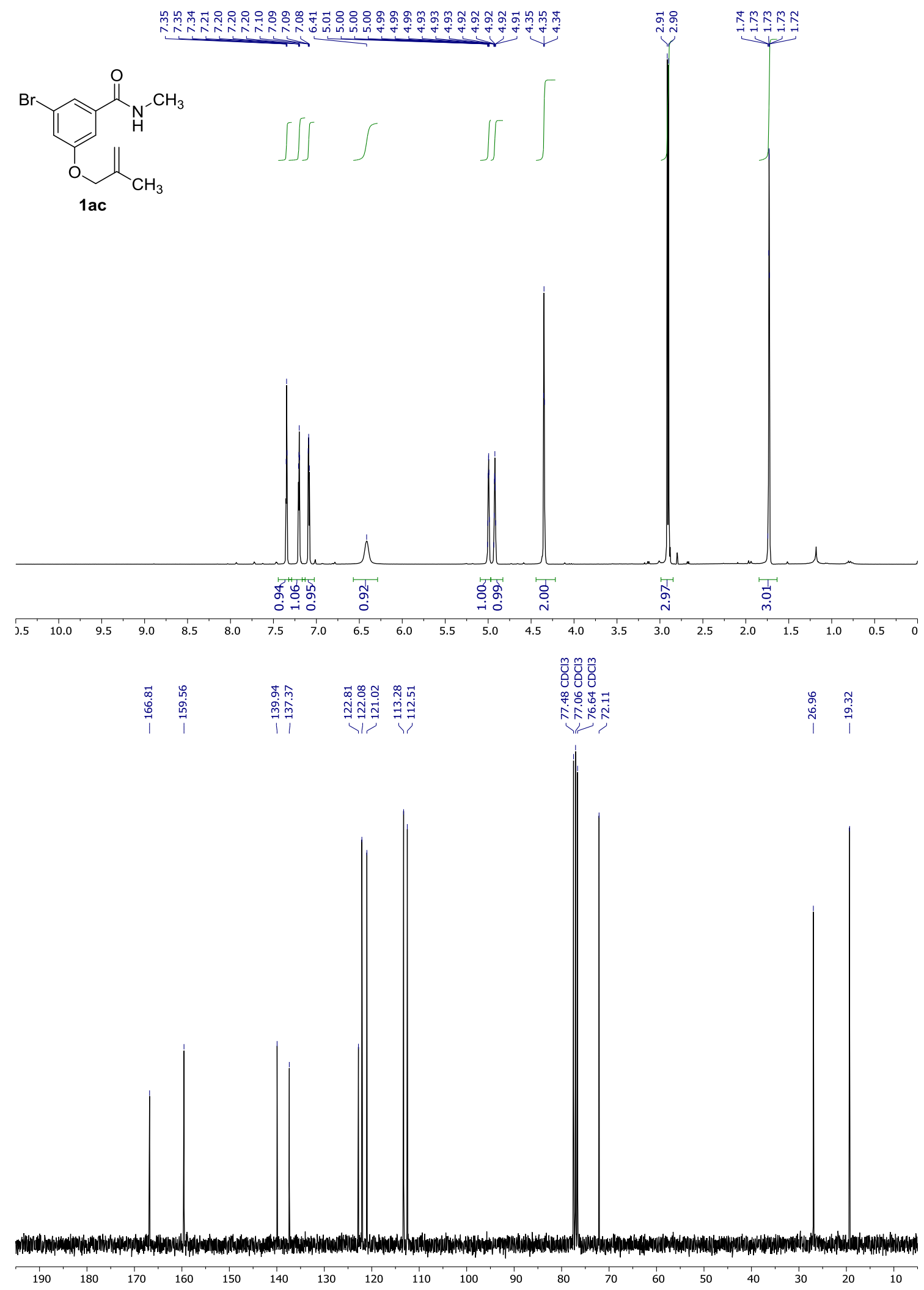

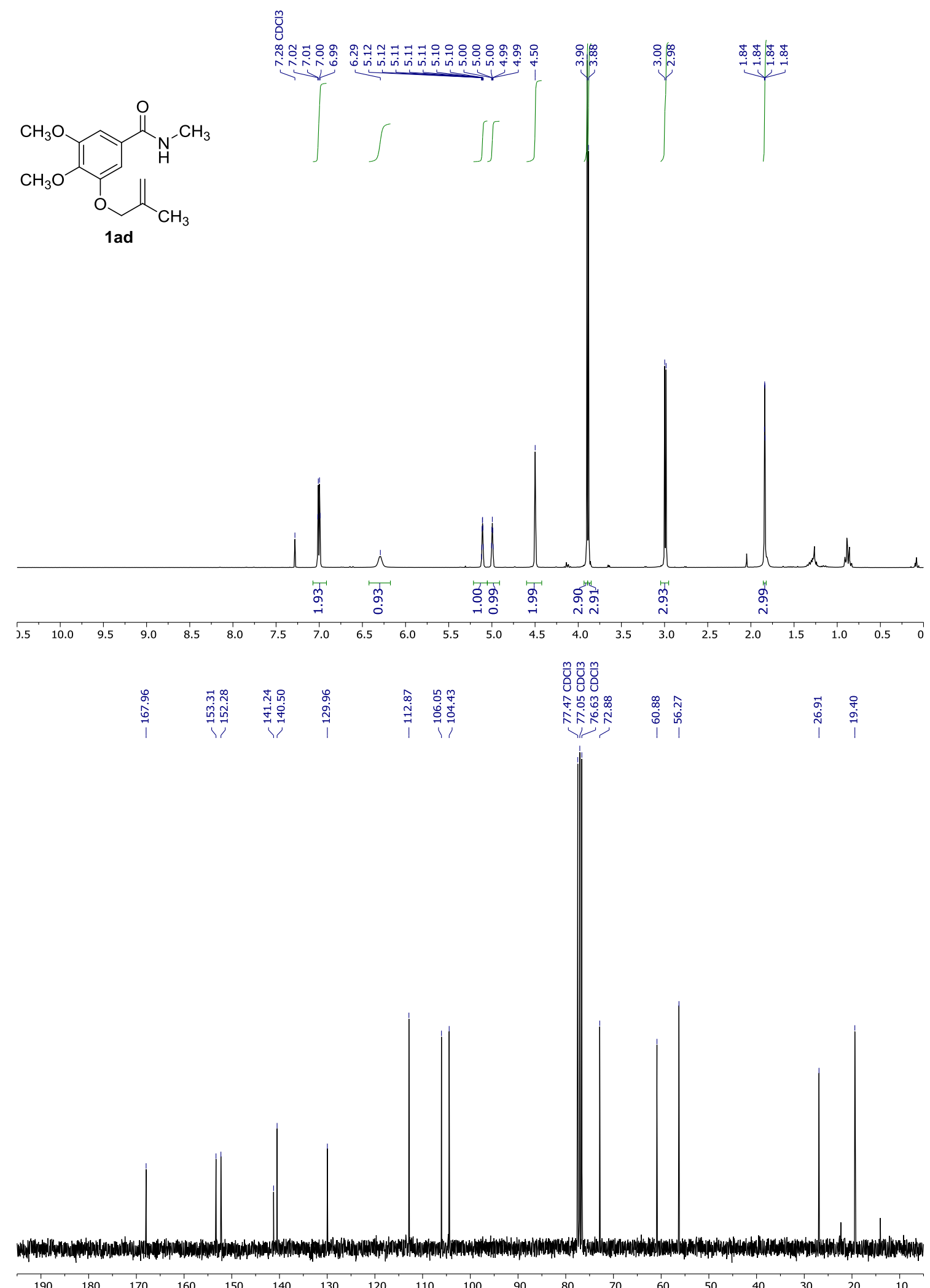

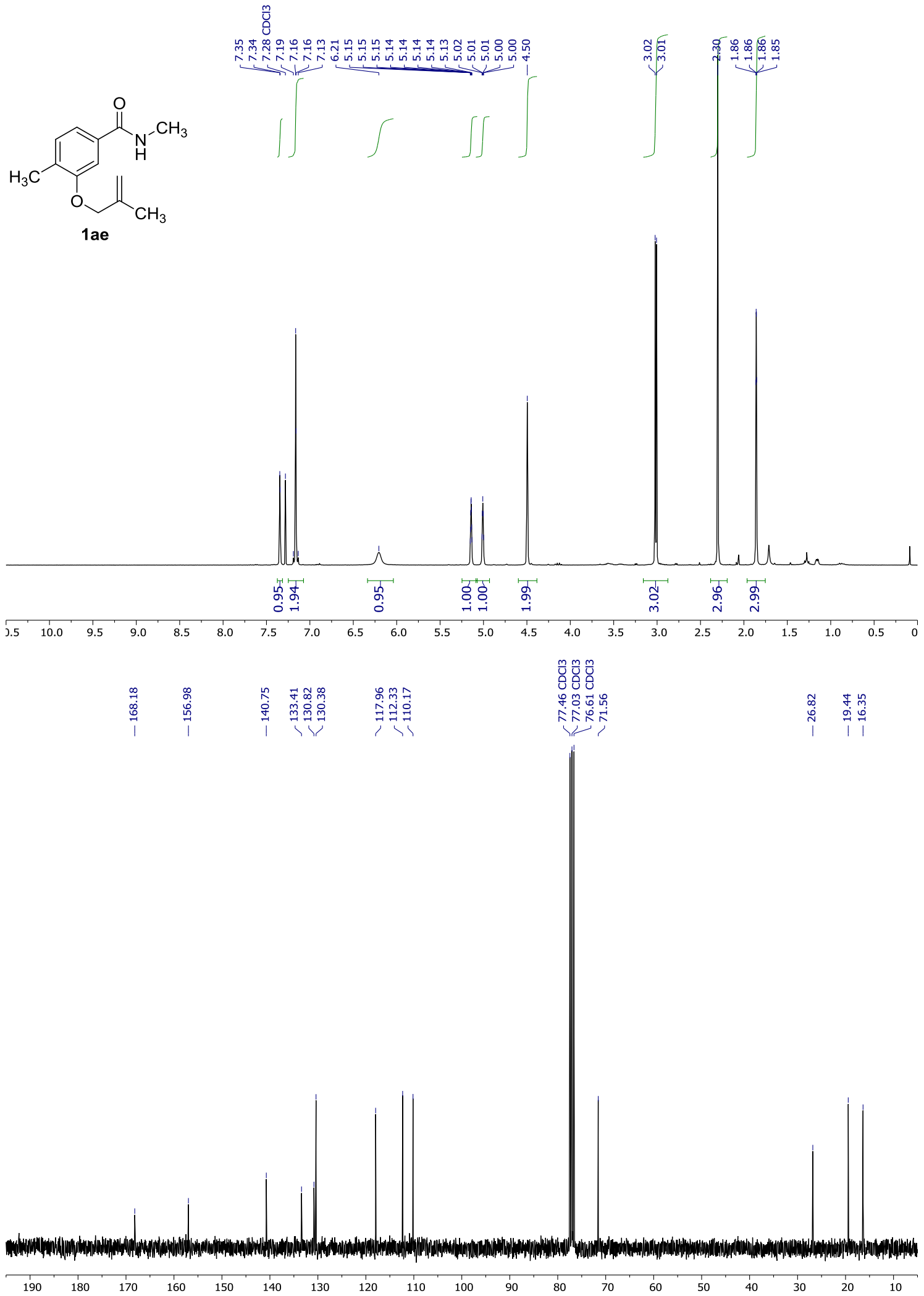

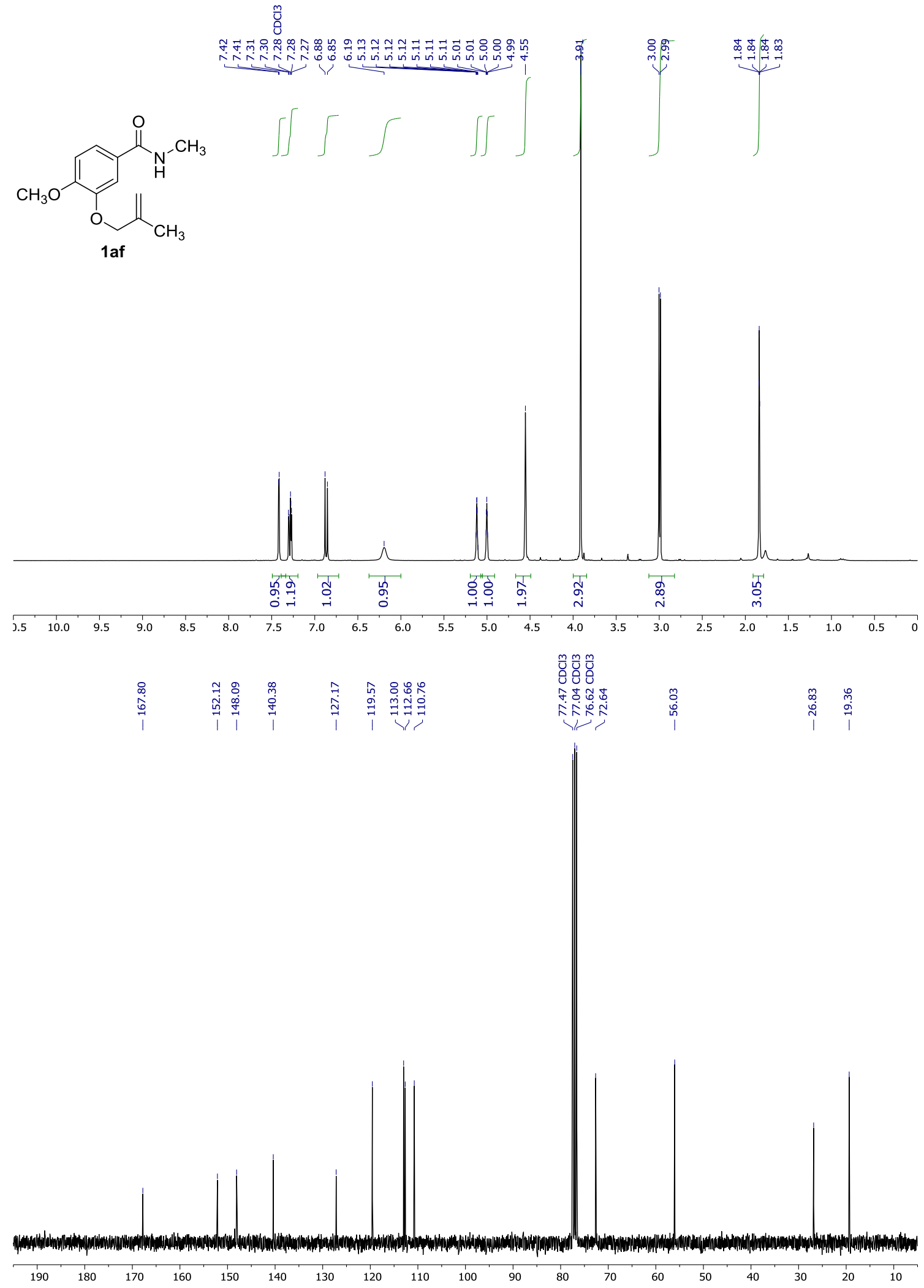

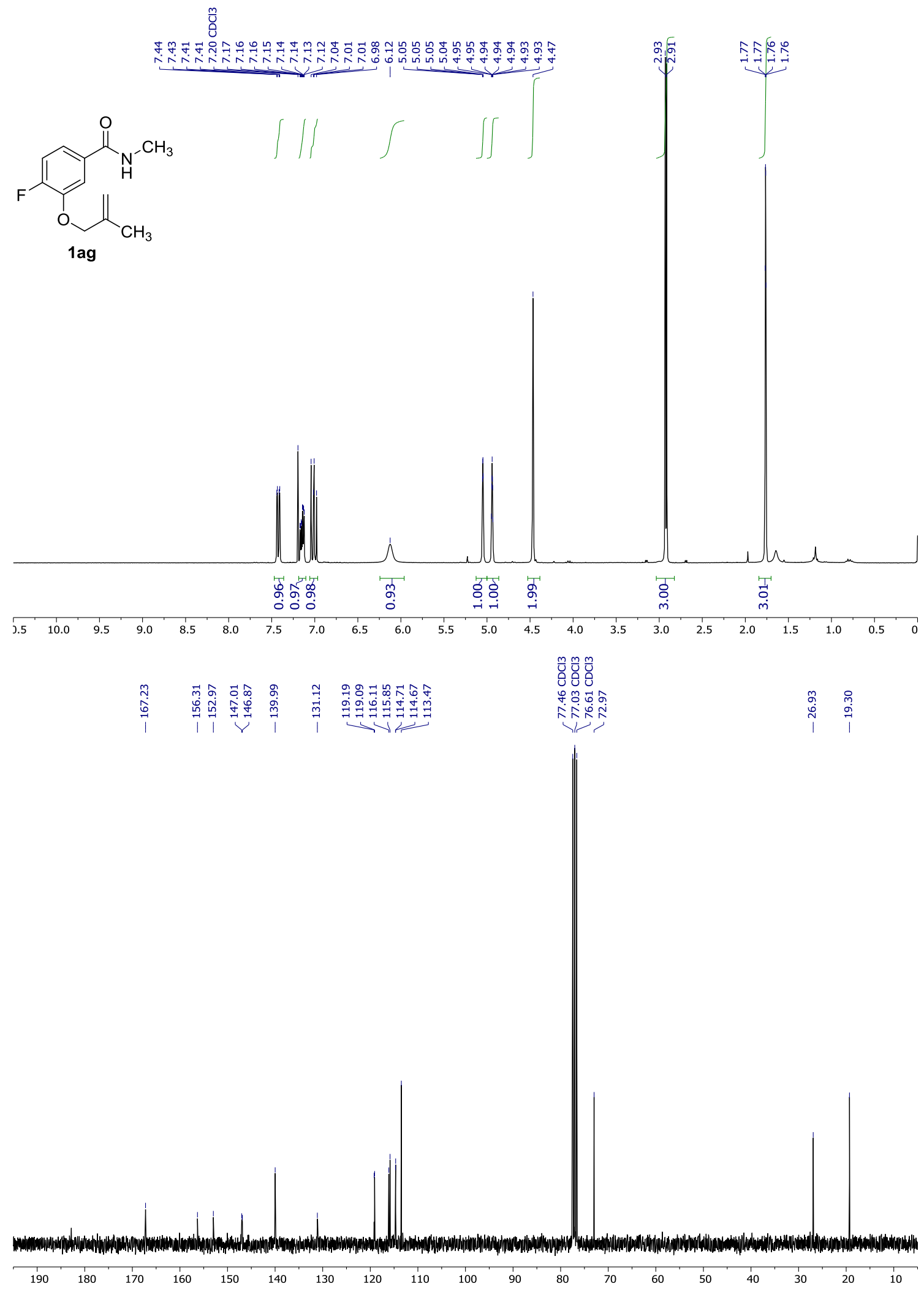

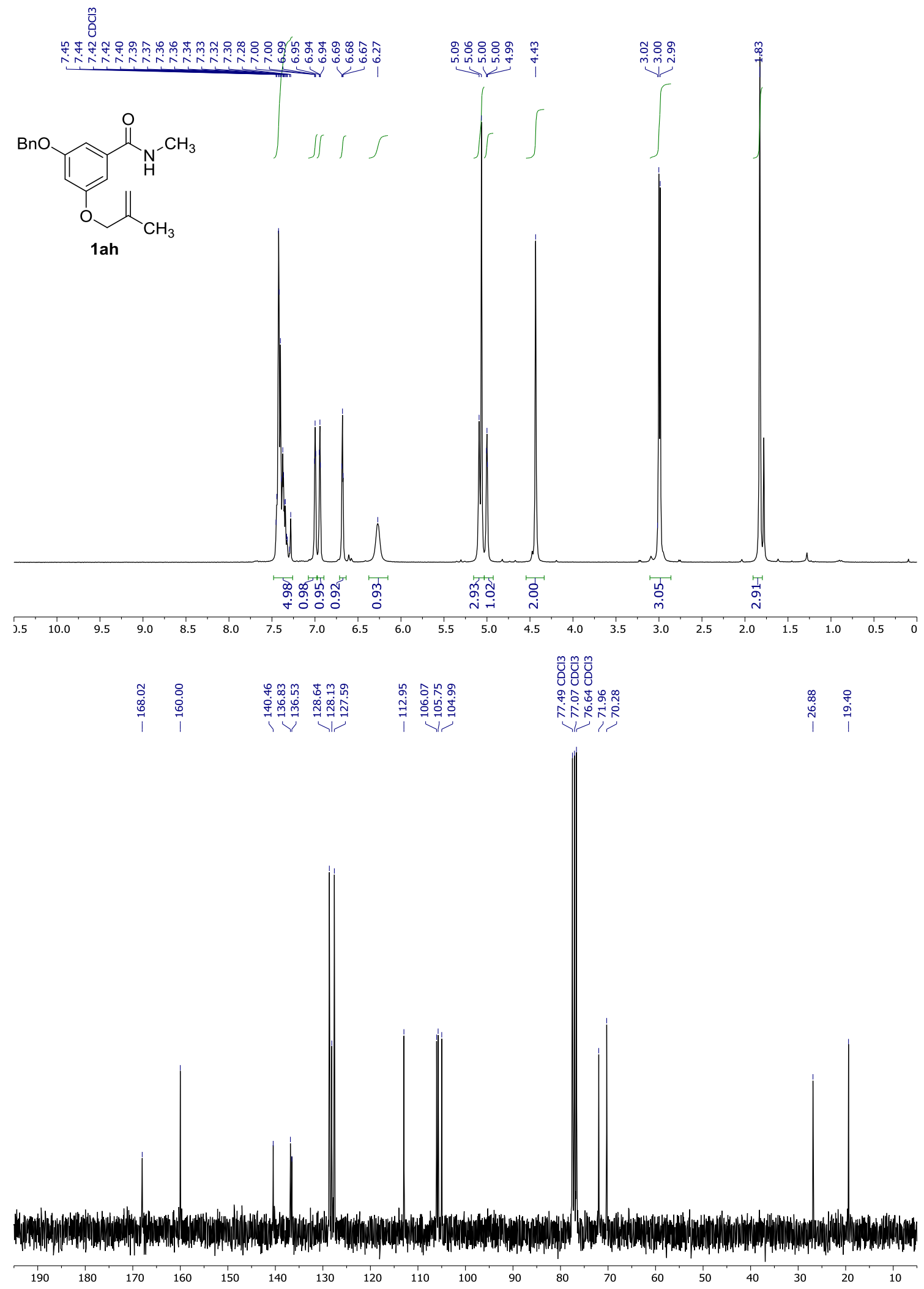


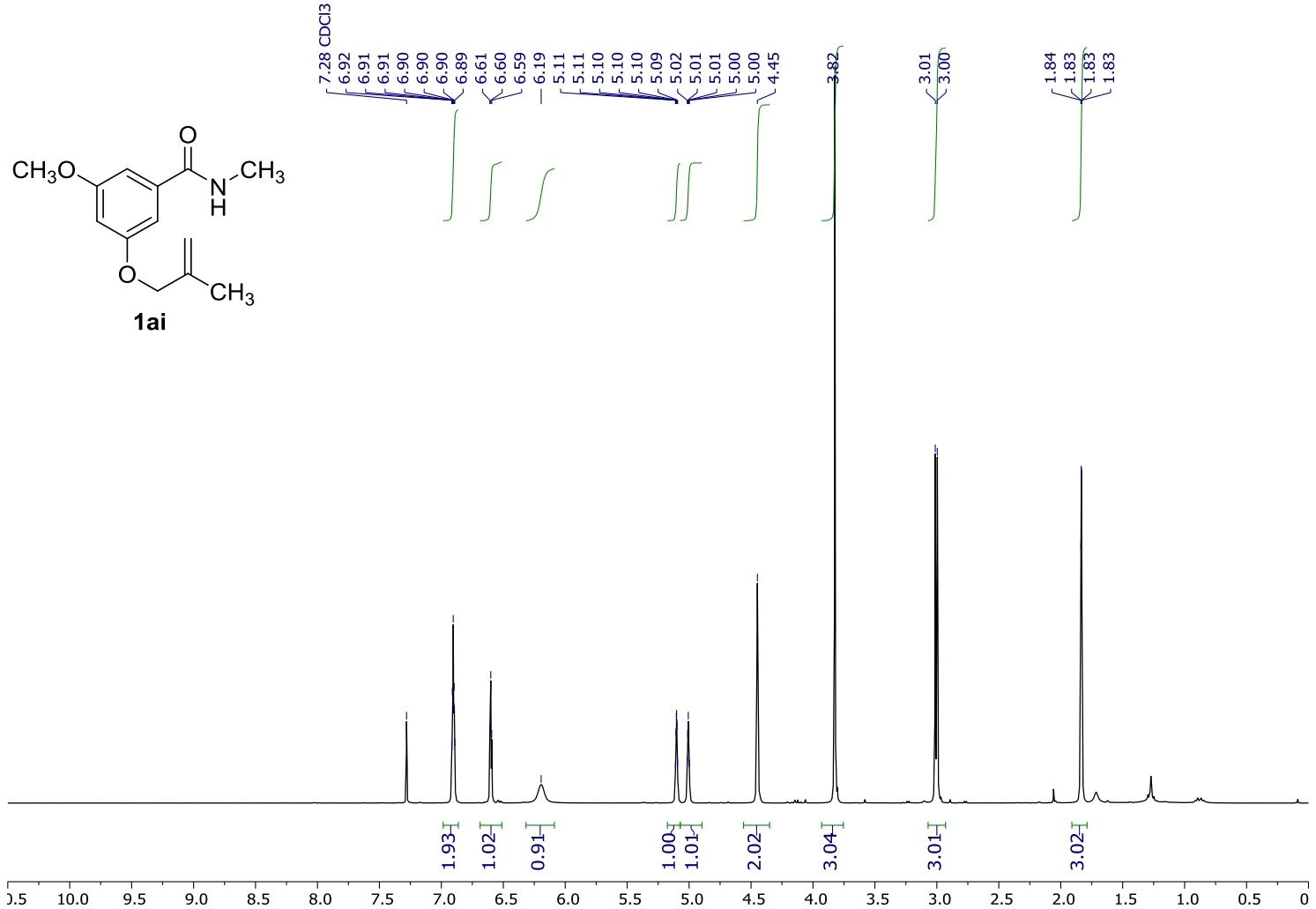

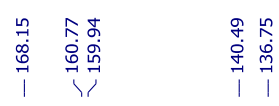

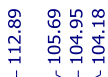

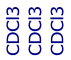

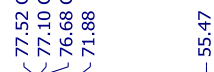

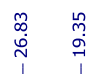

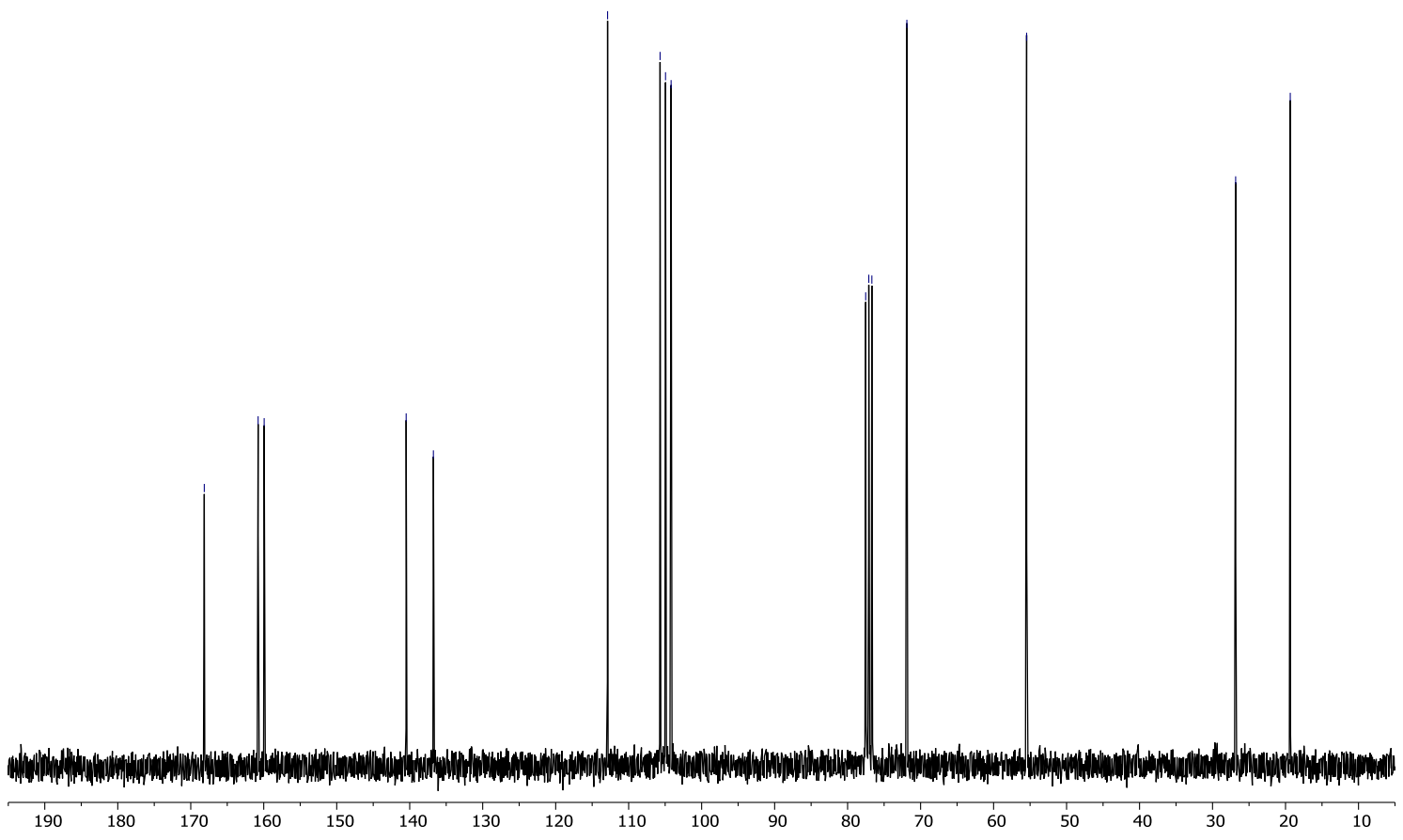



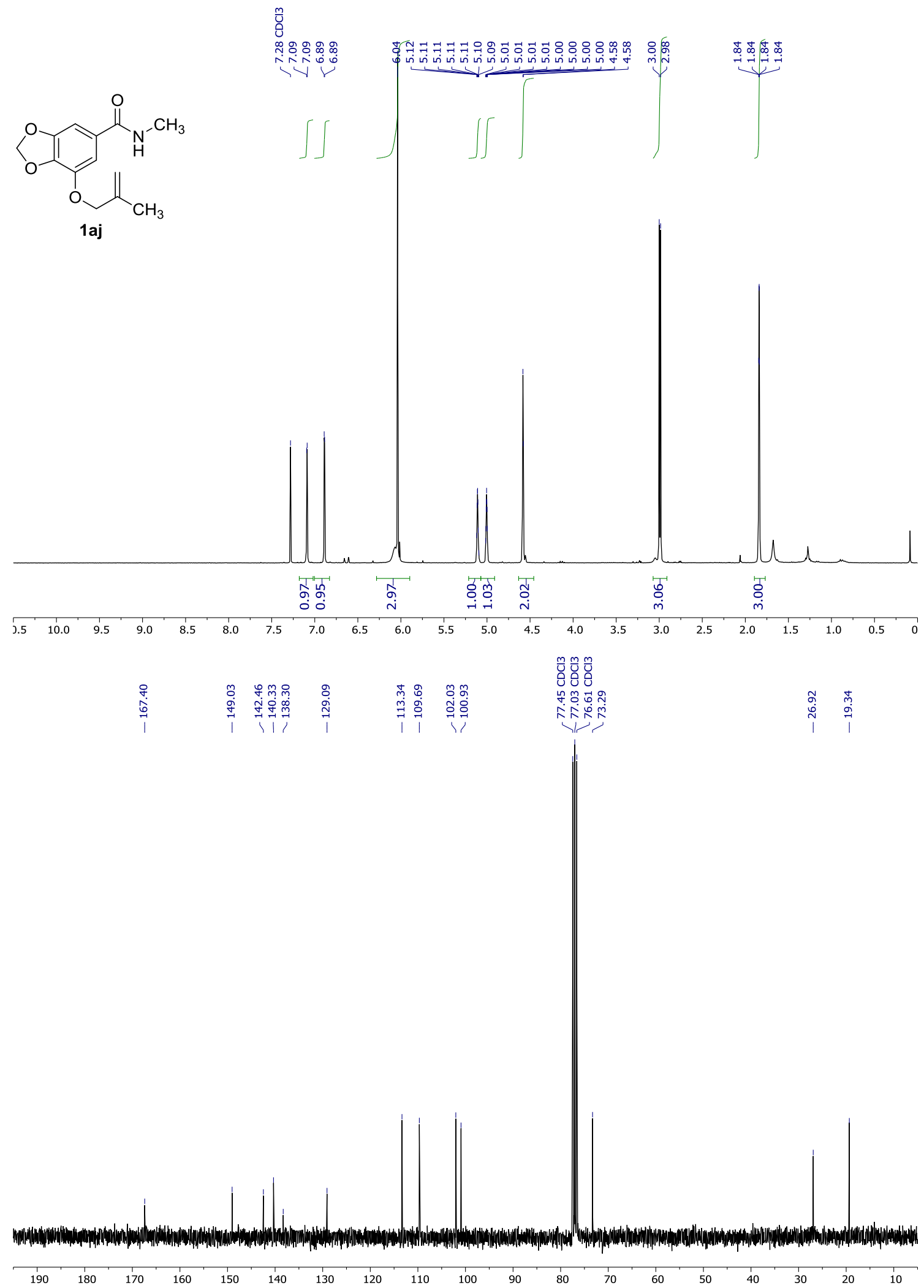

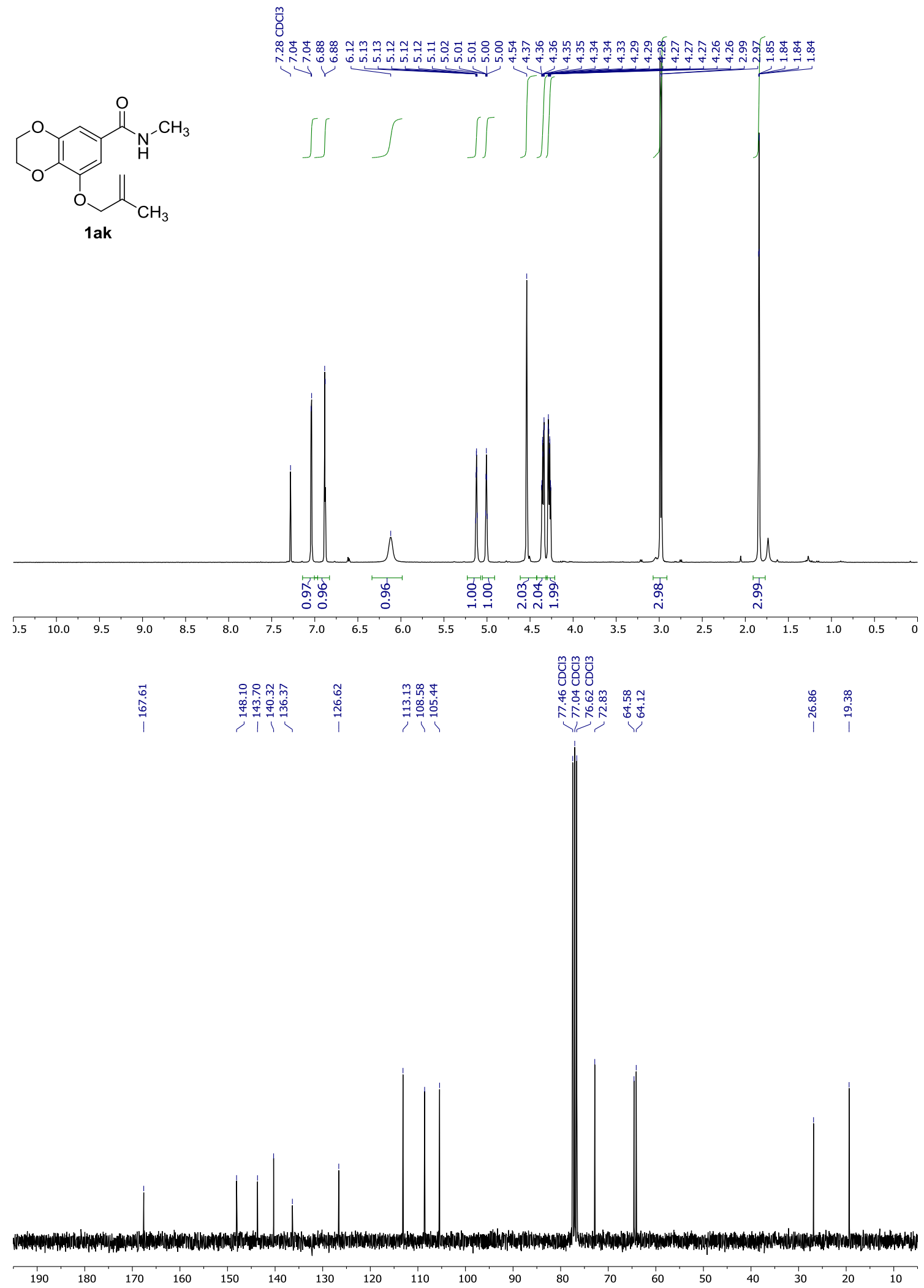
<smiles>C=CCOc1cccc(C(=O)NC)c1</smiles><smiles>c1ccccc1</smiles><smiles>[C]1C=CC=C1</smiles>

1al

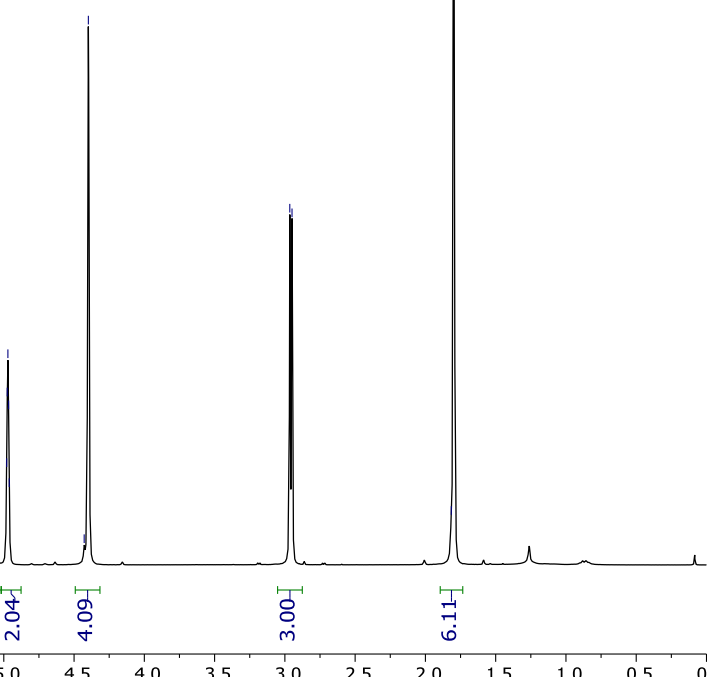

\begin{tabular}{llllllllllllllllllllllll}
\hline .5 & 1 & 10.0 & 9.5 & 9.0 & 8.5 & 8.0 & 7.5 & 7.0 & 6.5 & 6.0 & 5.5 & 5.0 & 4.5 & 4.0 & 3.5 & 3.0 & 2.5 & 2.0 & 1.5 & 1.0 & 0.5 & 0
\end{tabular}

\begin{tabular}{|c|c|c|c|c|}
\hline 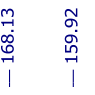 & 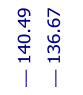 & 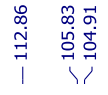 & 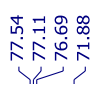 & \\
\hline
\end{tabular}

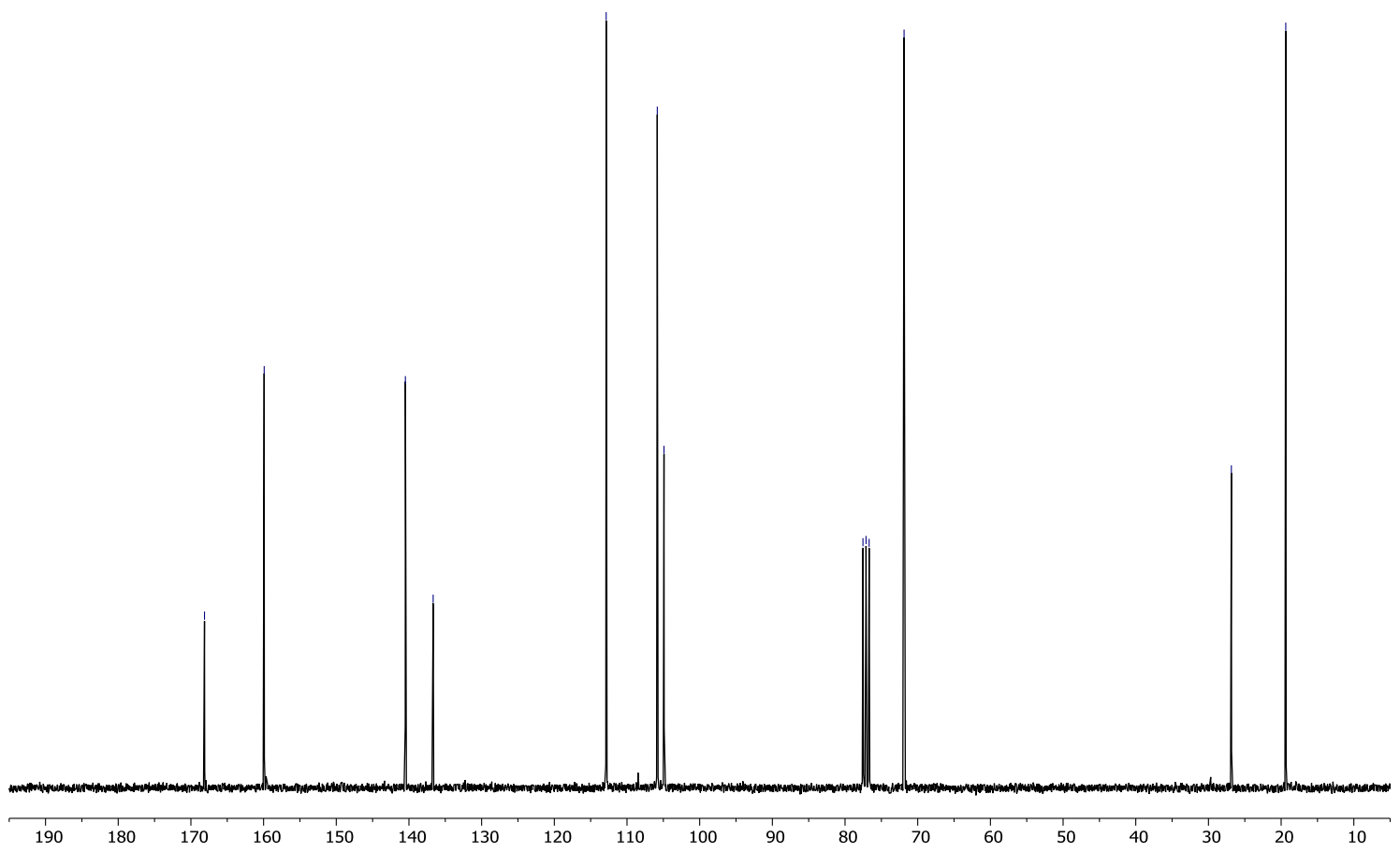



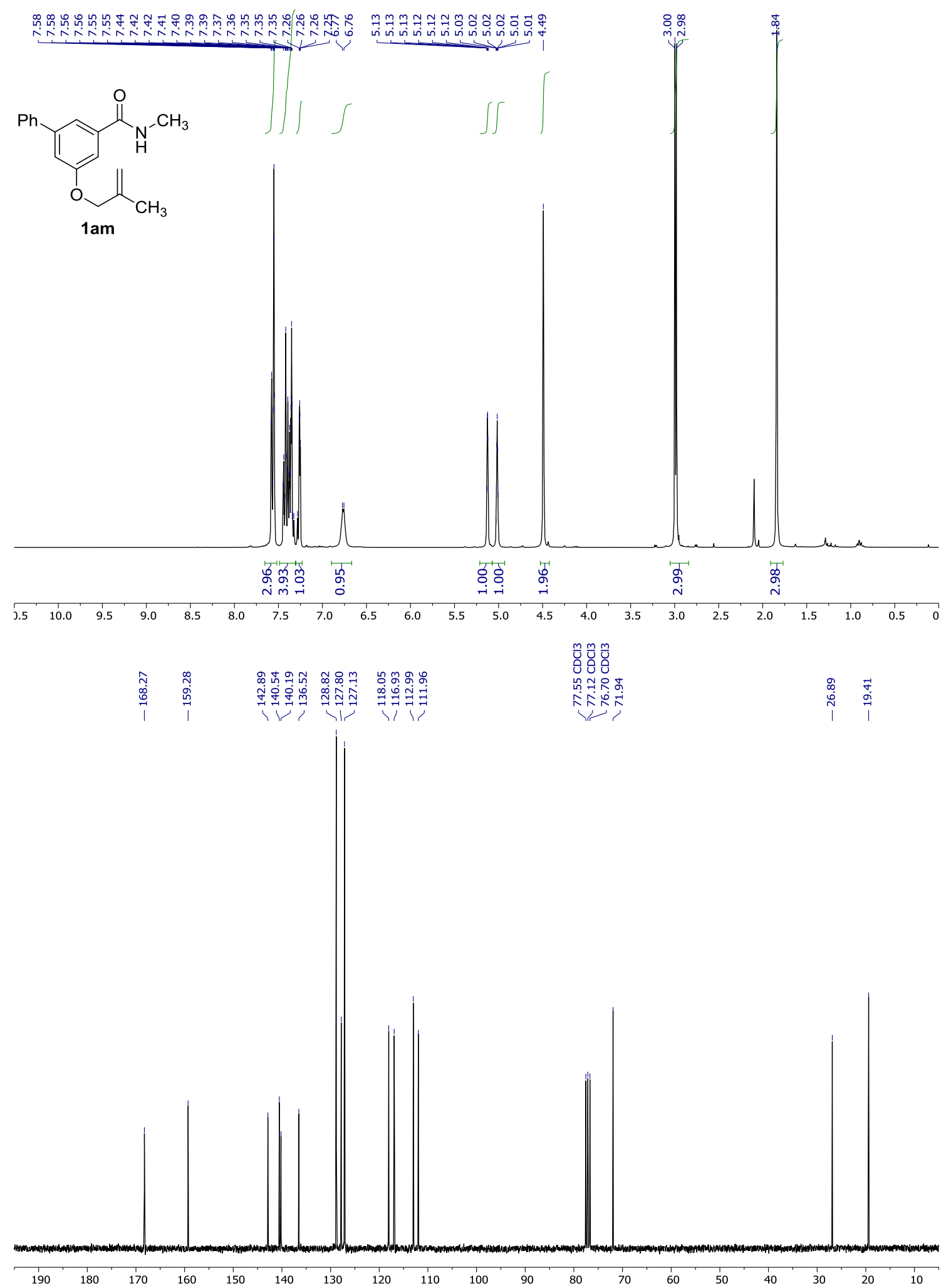


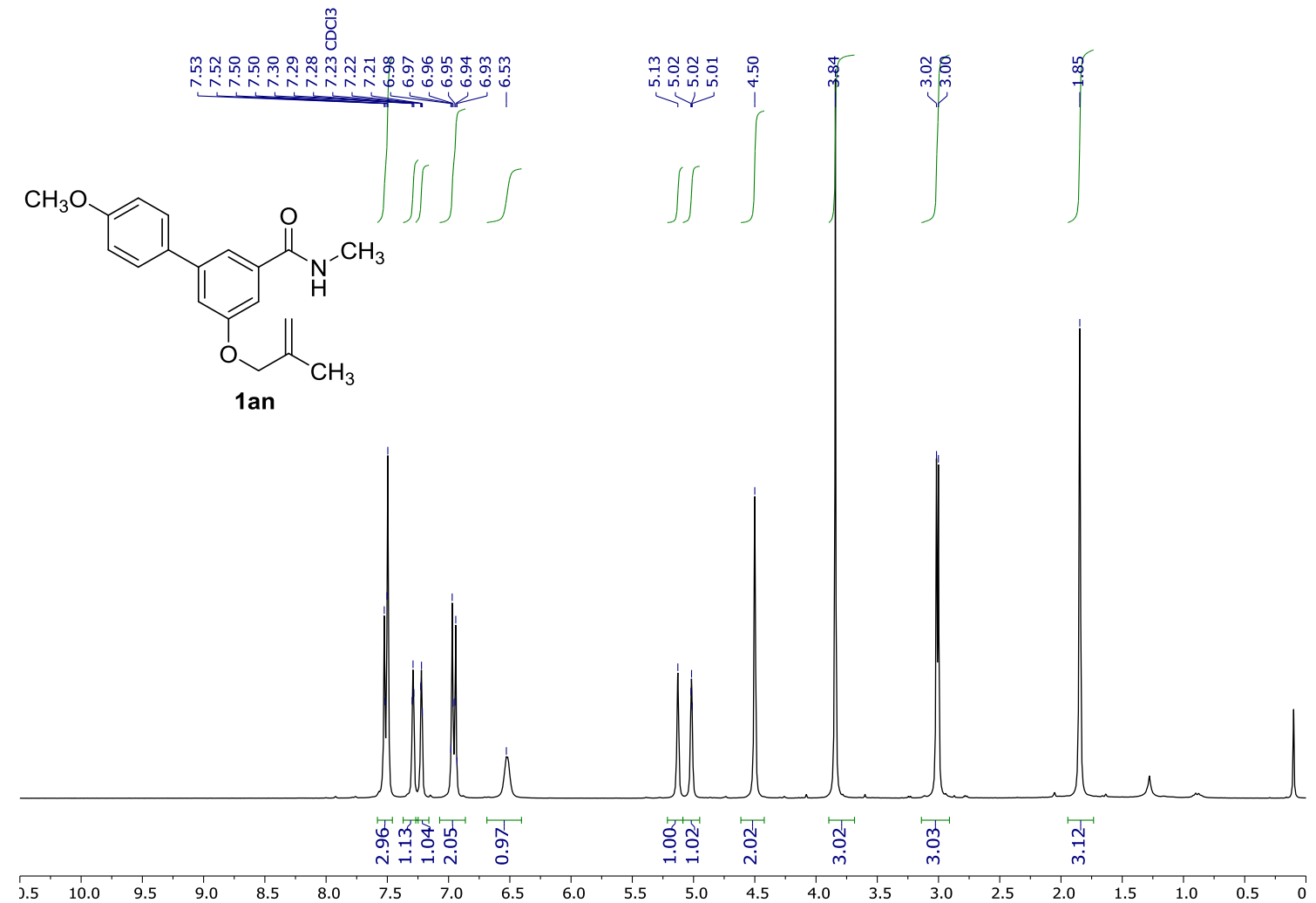

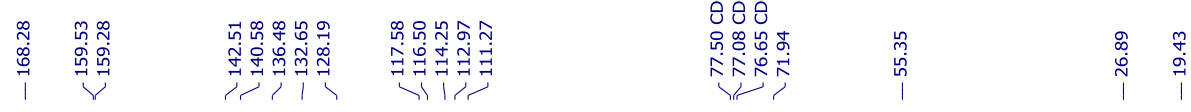

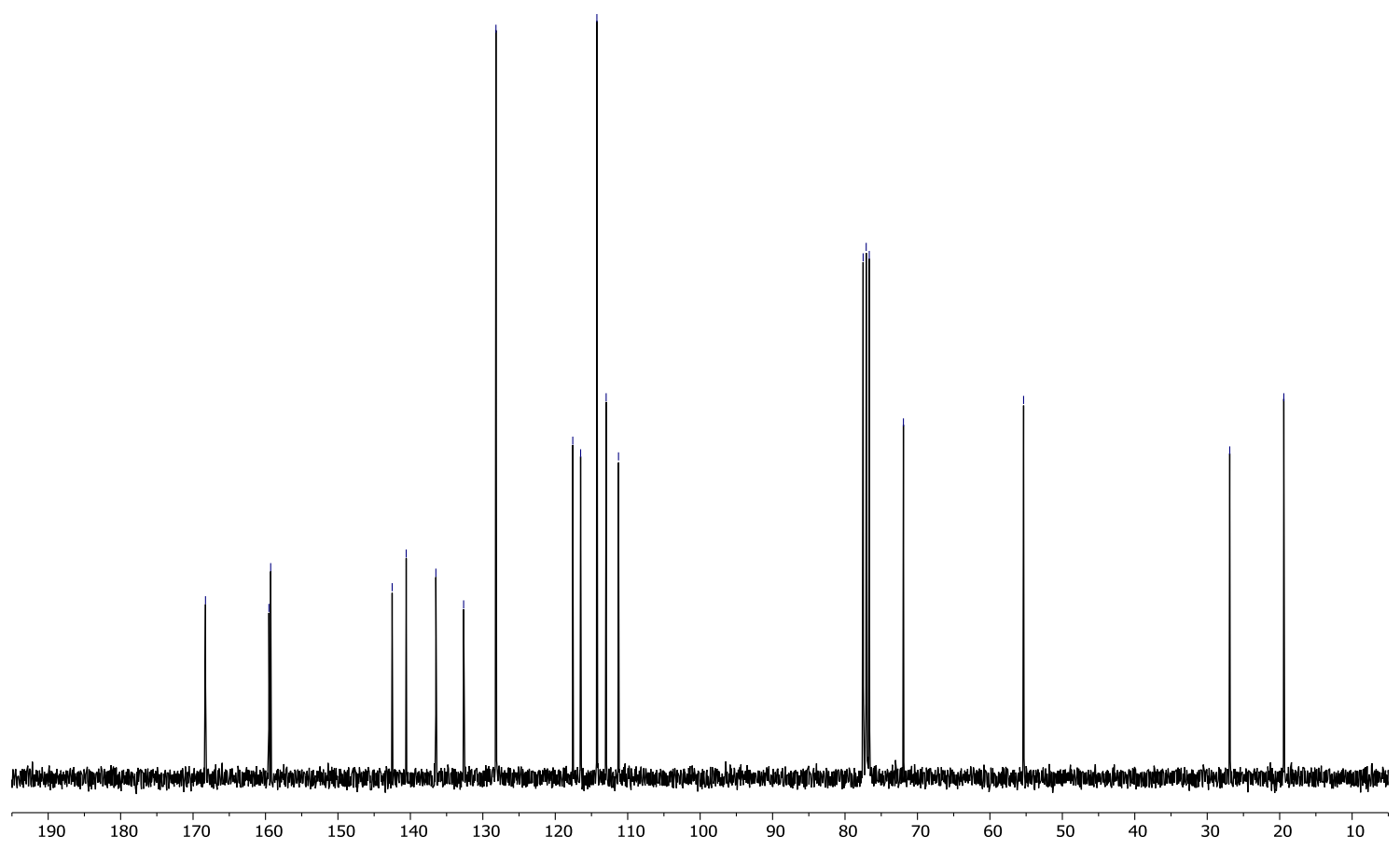




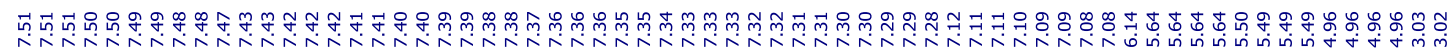<smiles>C=C(COc1ccccc1)c1ccccc1</smiles>

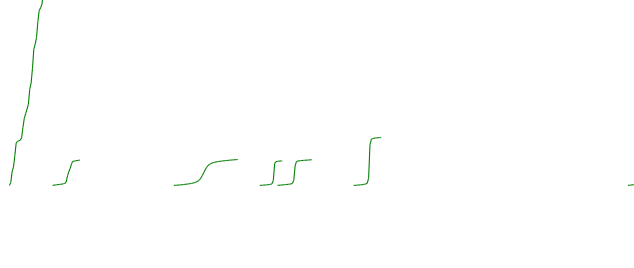

$1 \mathrm{ba}$

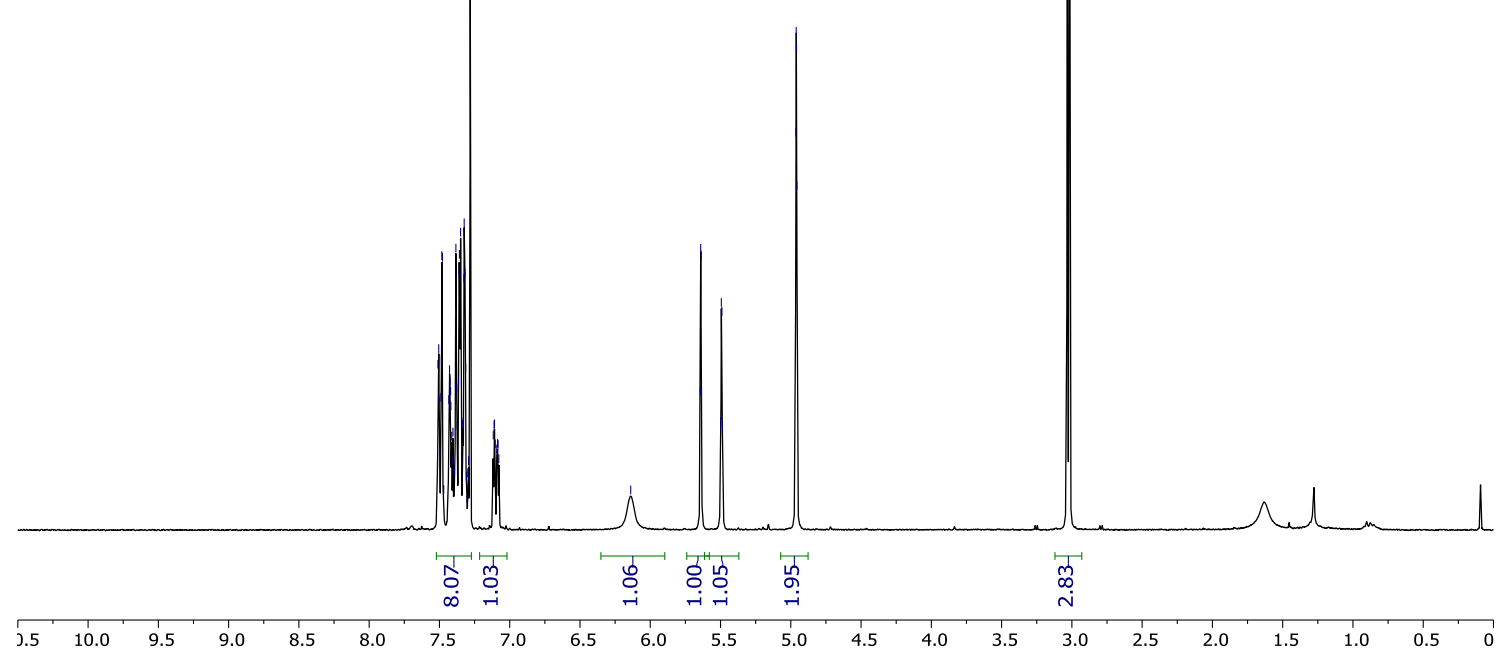

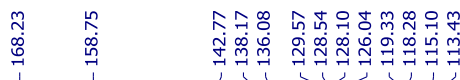

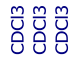

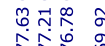

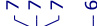

$\underset{\infty}{\infty}$

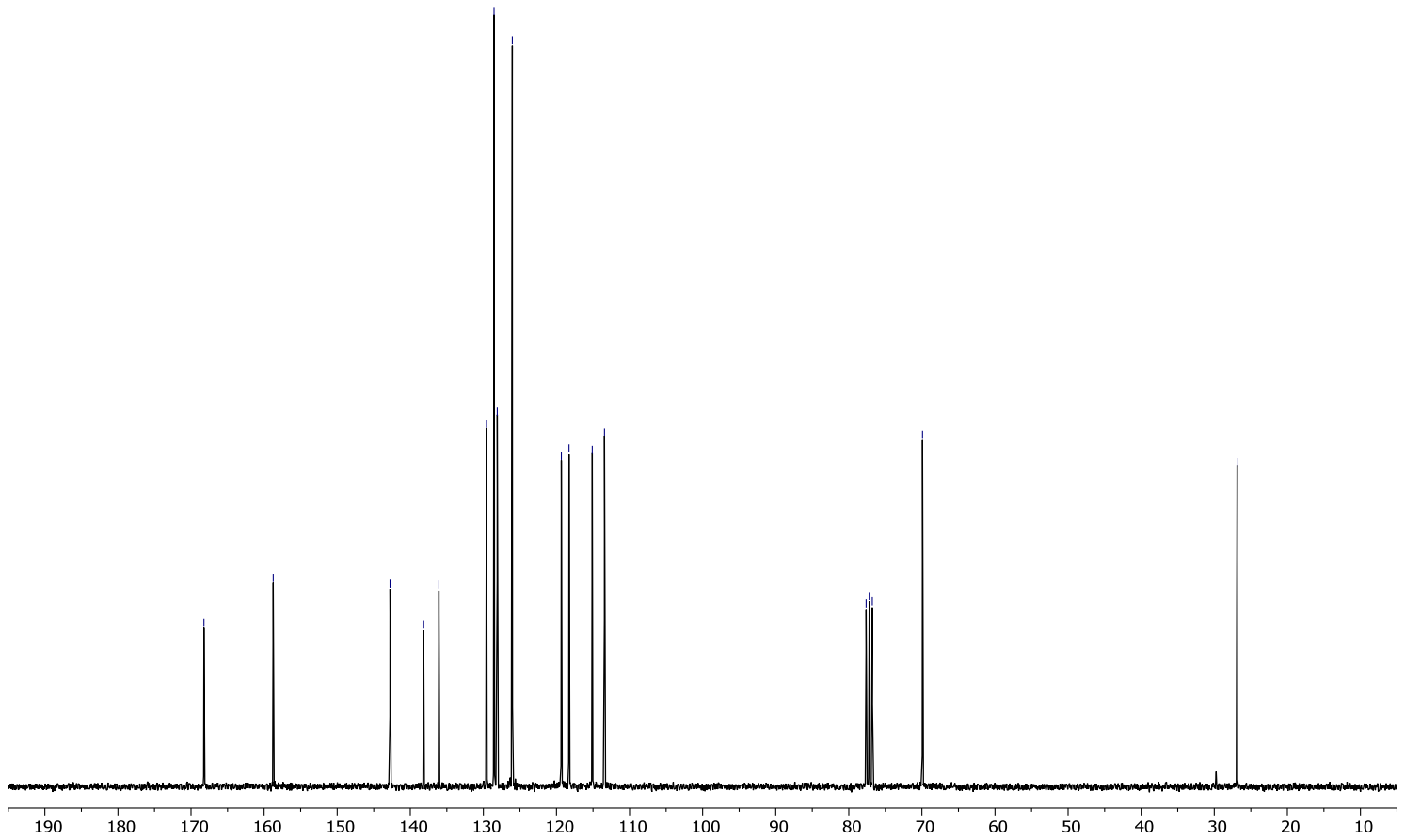



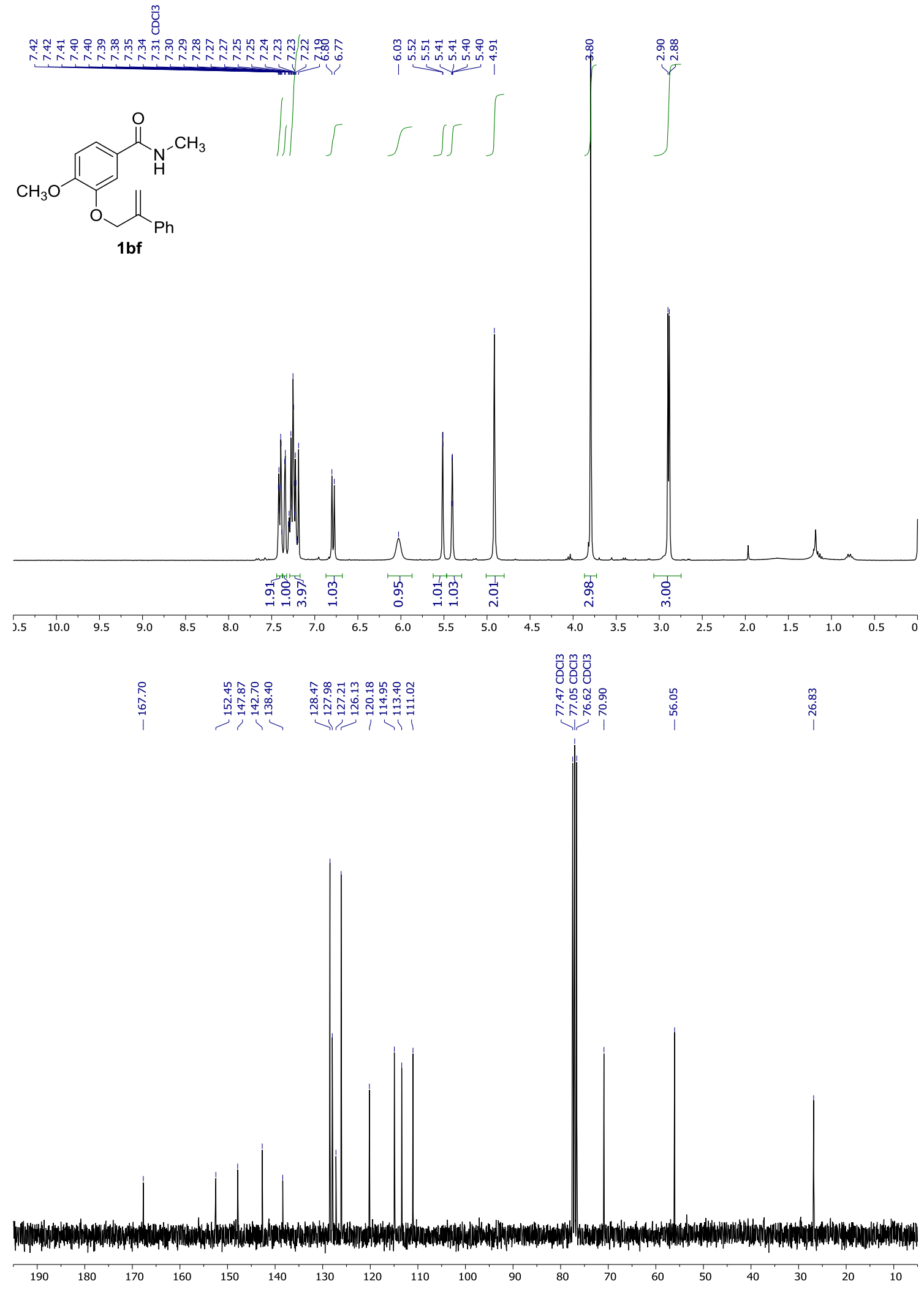

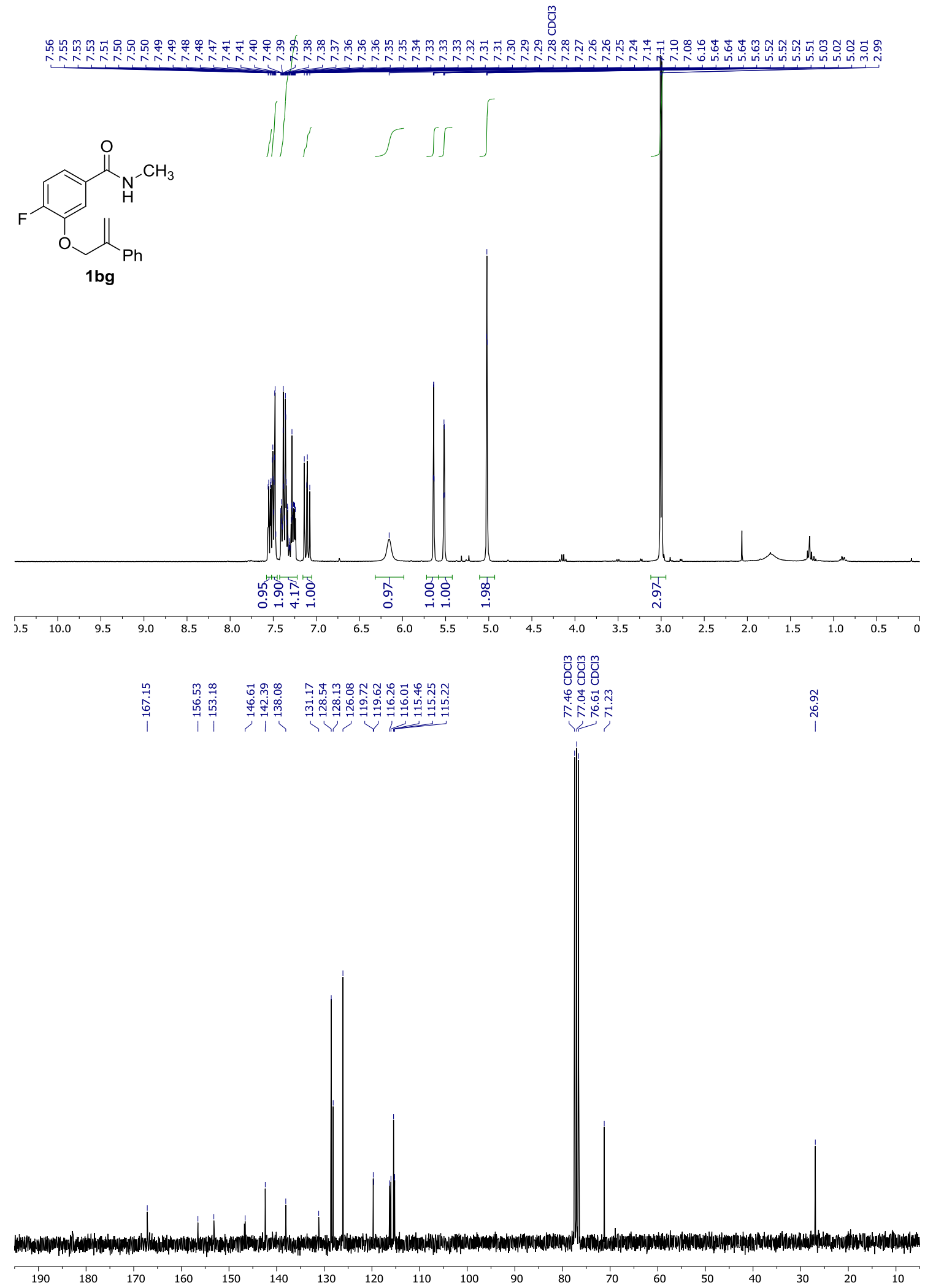


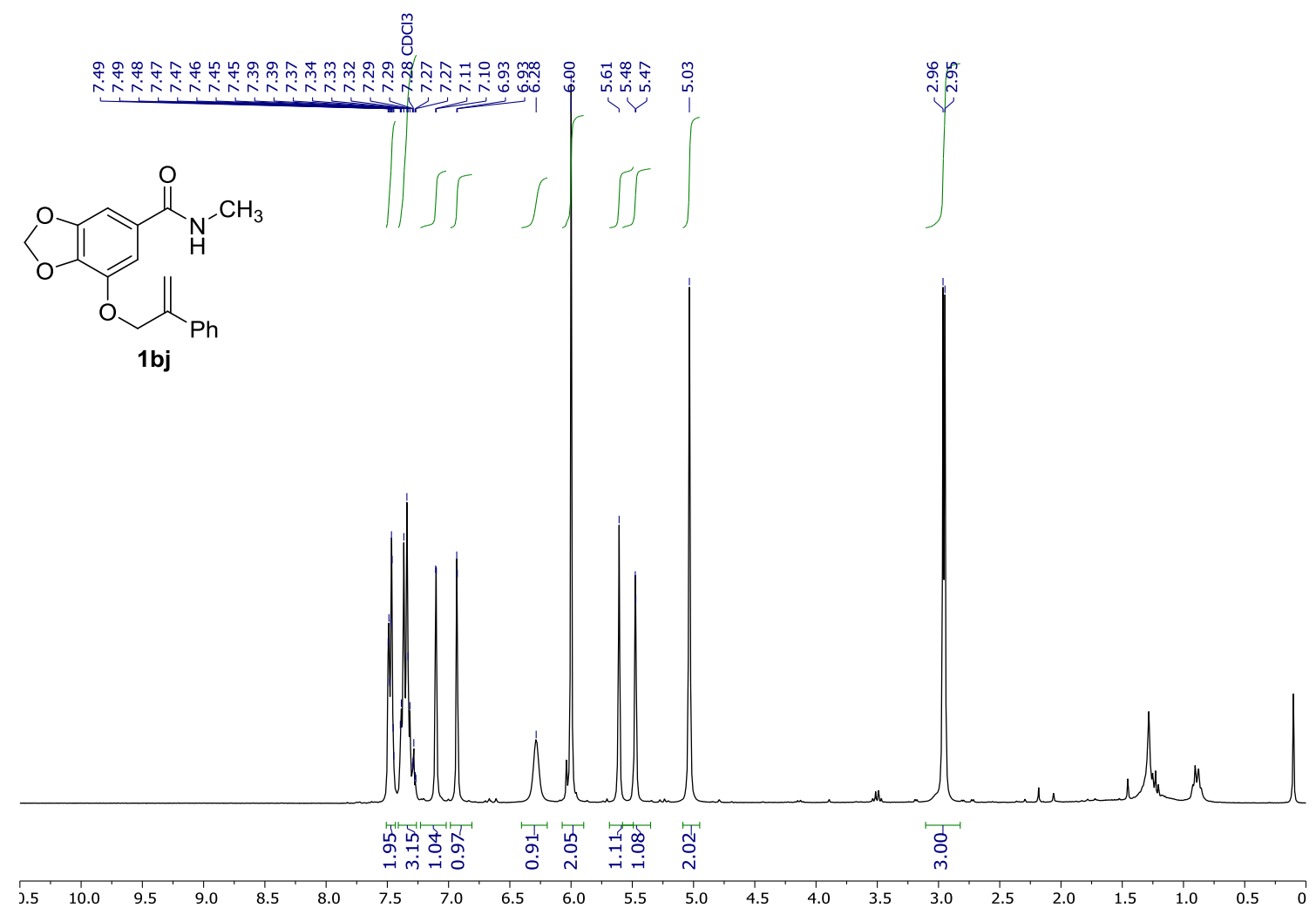




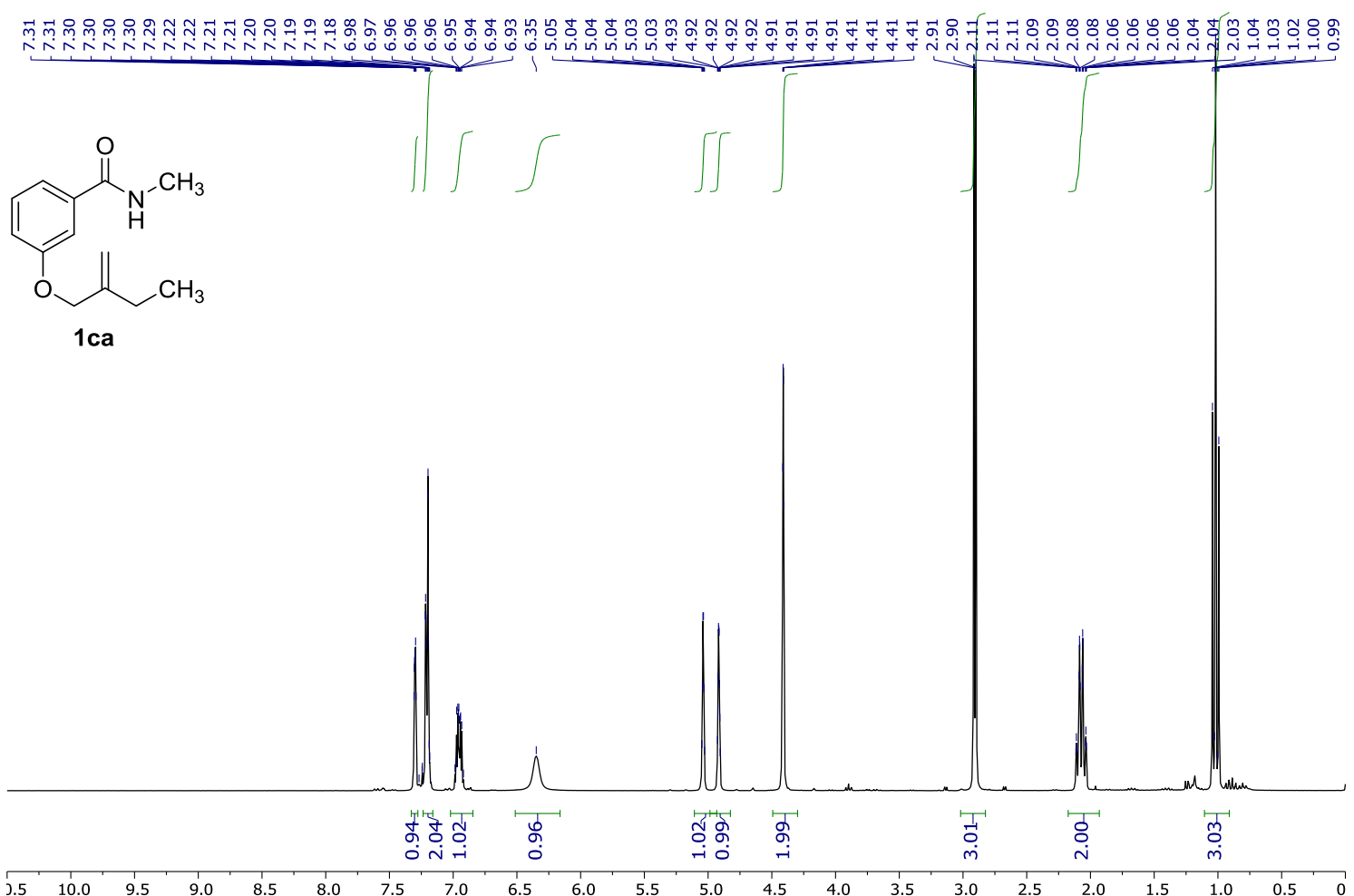

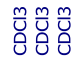

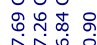

송

국ㄱ

ㄱ.

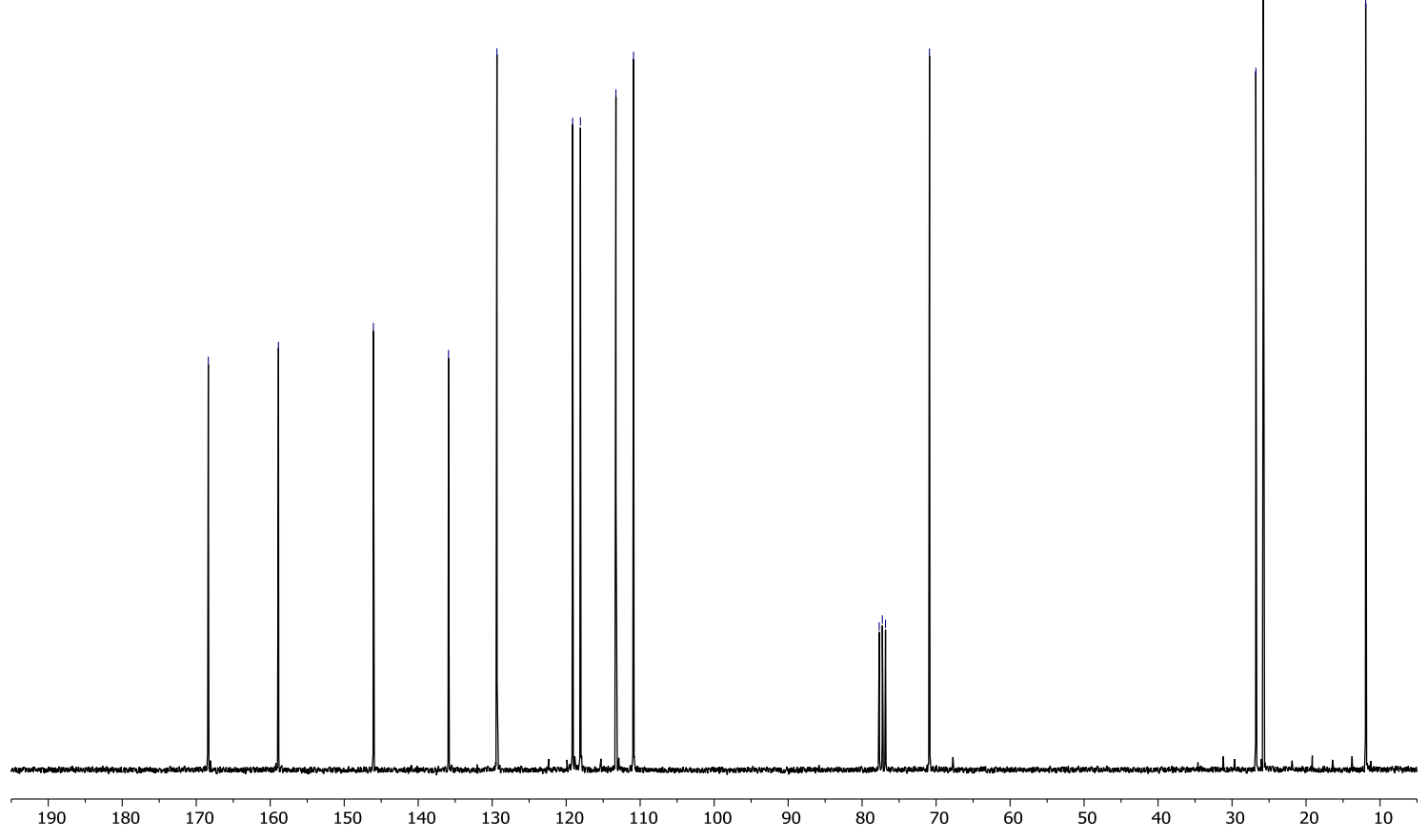



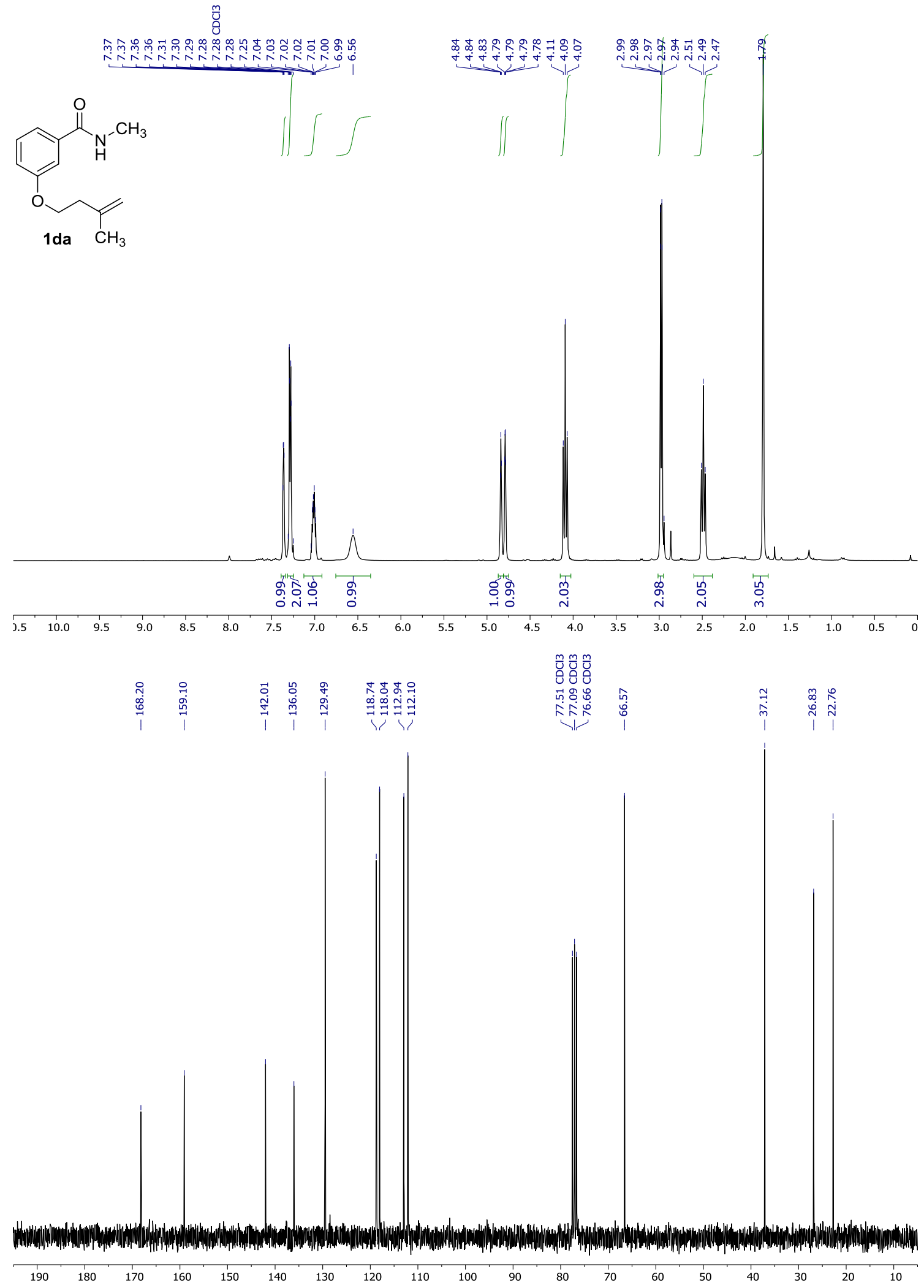

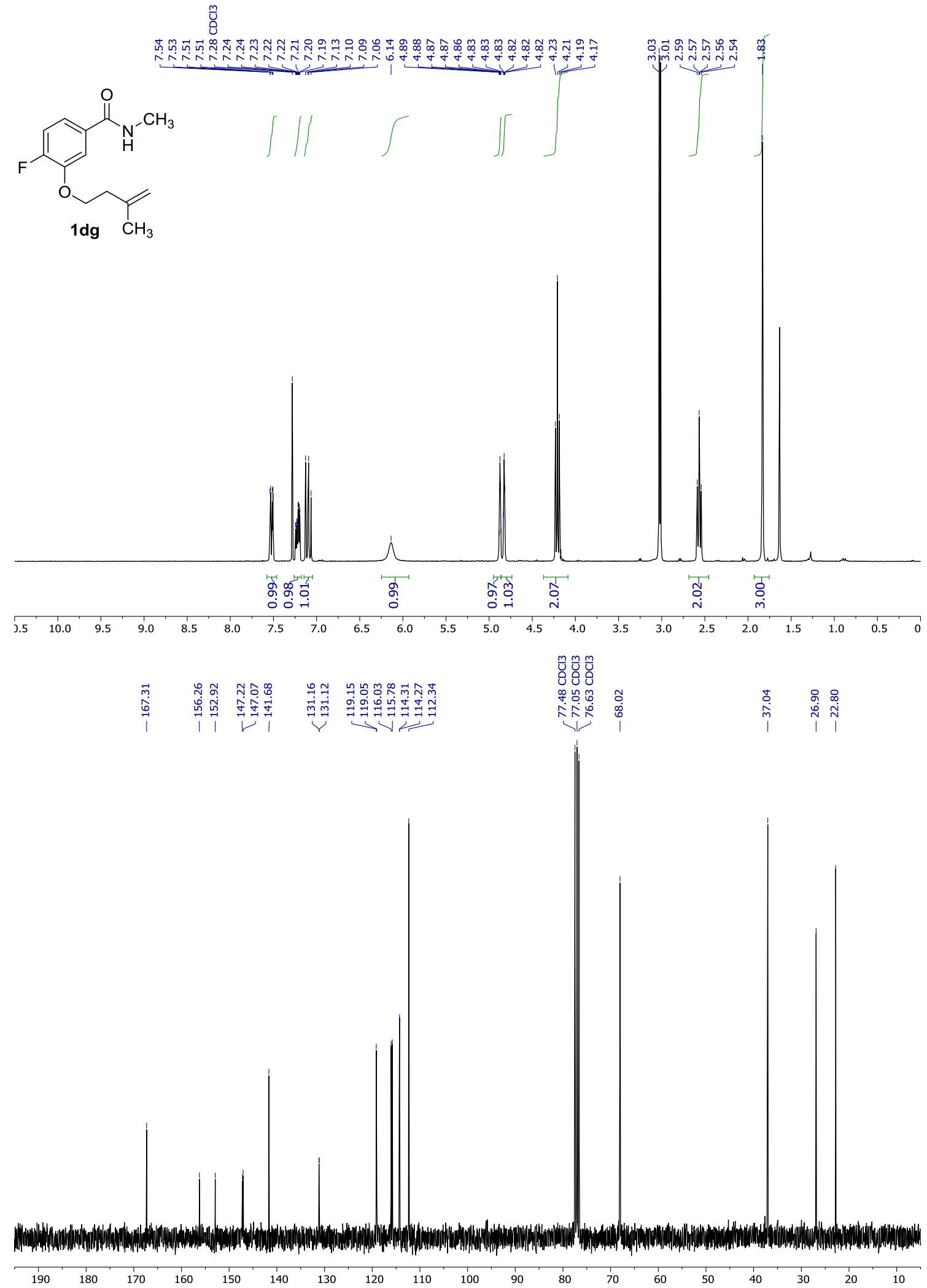

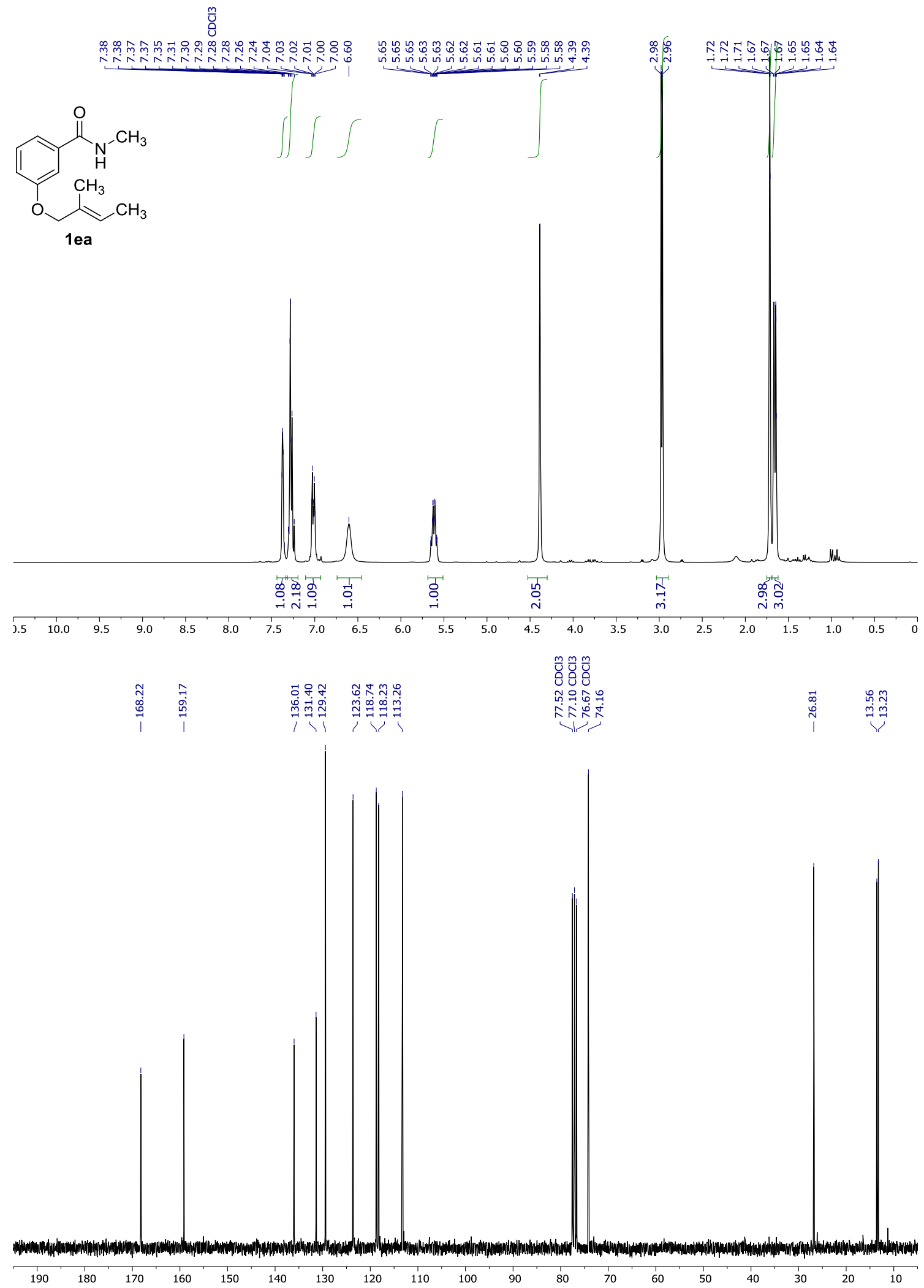
品

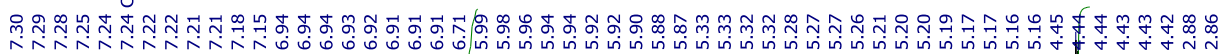<smiles>C=CCOc1cccc(C(=O)NC)c1</smiles>

$\iiint \iiint$

1 fa

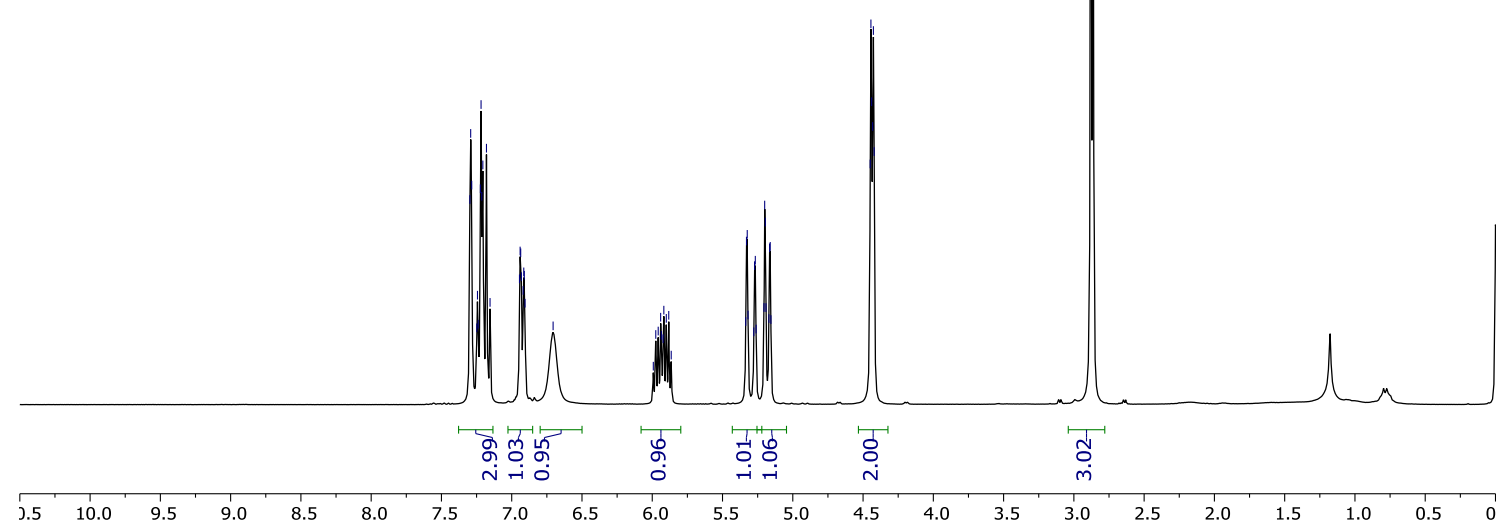

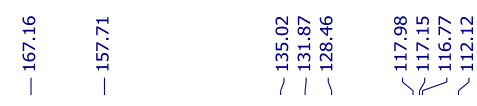

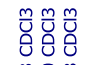

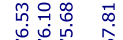

in

䓹

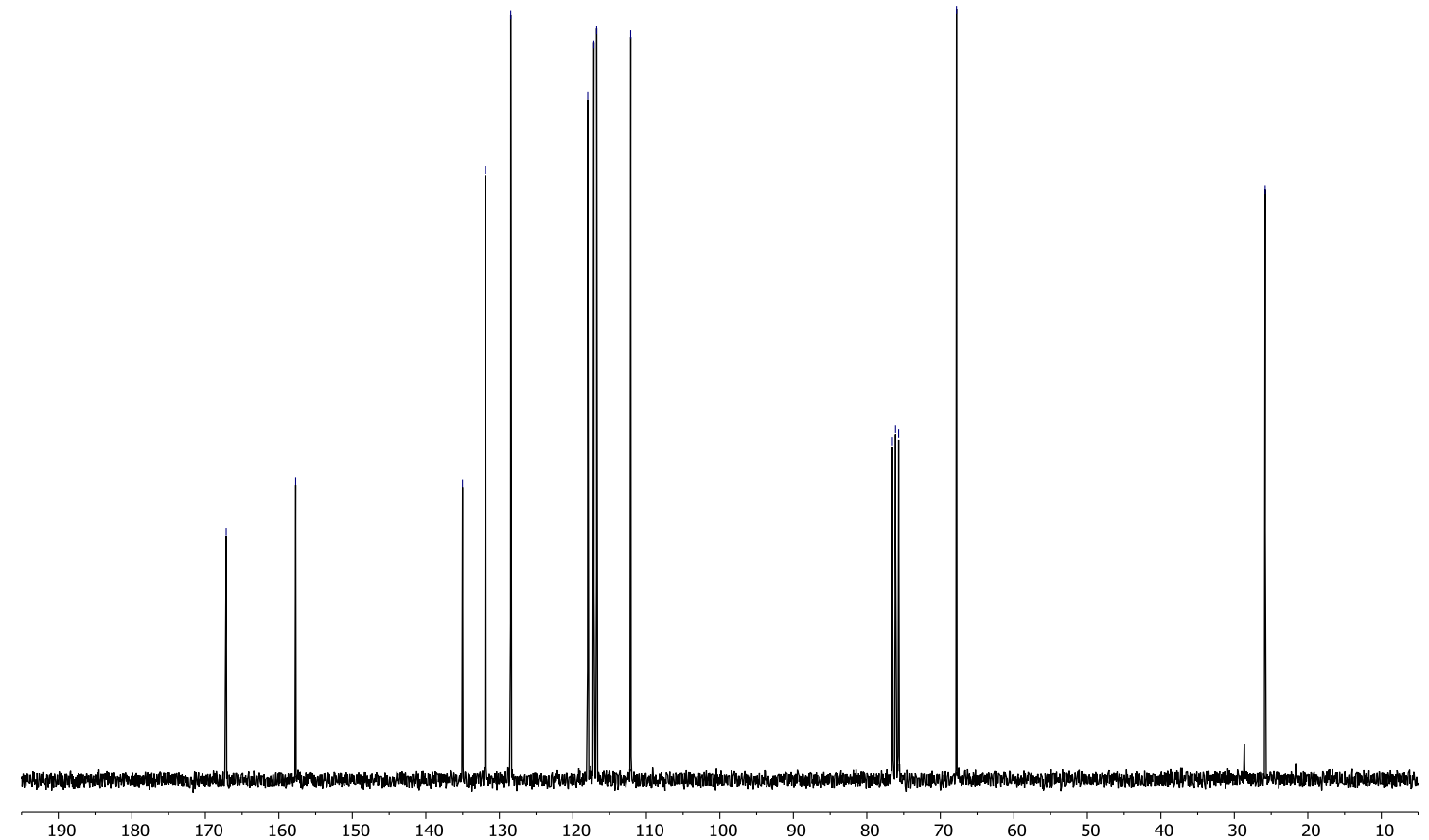




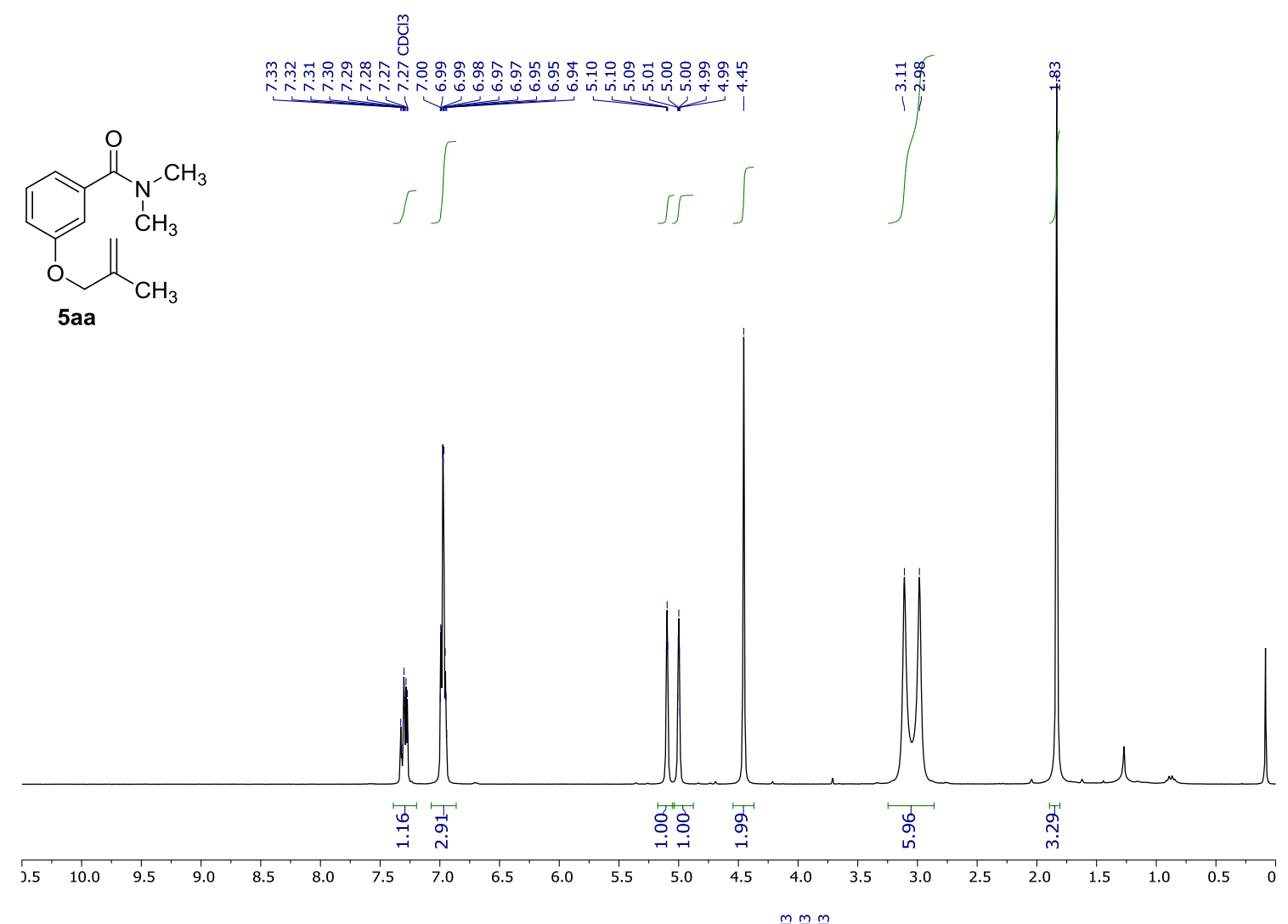



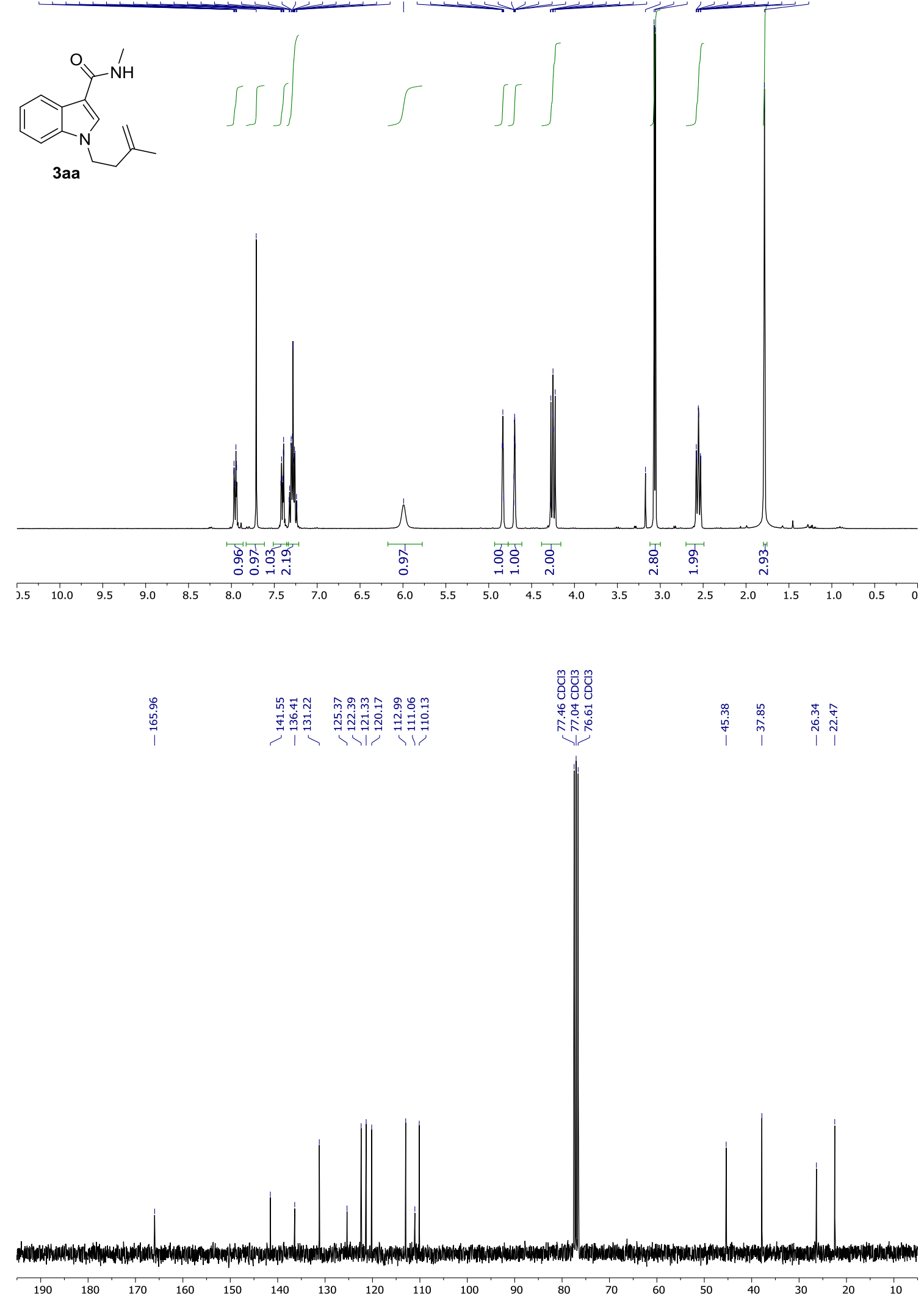
ญั

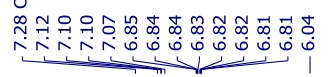

$\mathrm{CH}_{3}$<smiles>CC1(C)COc2cccc(C(=O)N[IH2+])c21</smiles><smiles>CCCCCCCCC</smiles>

2aa

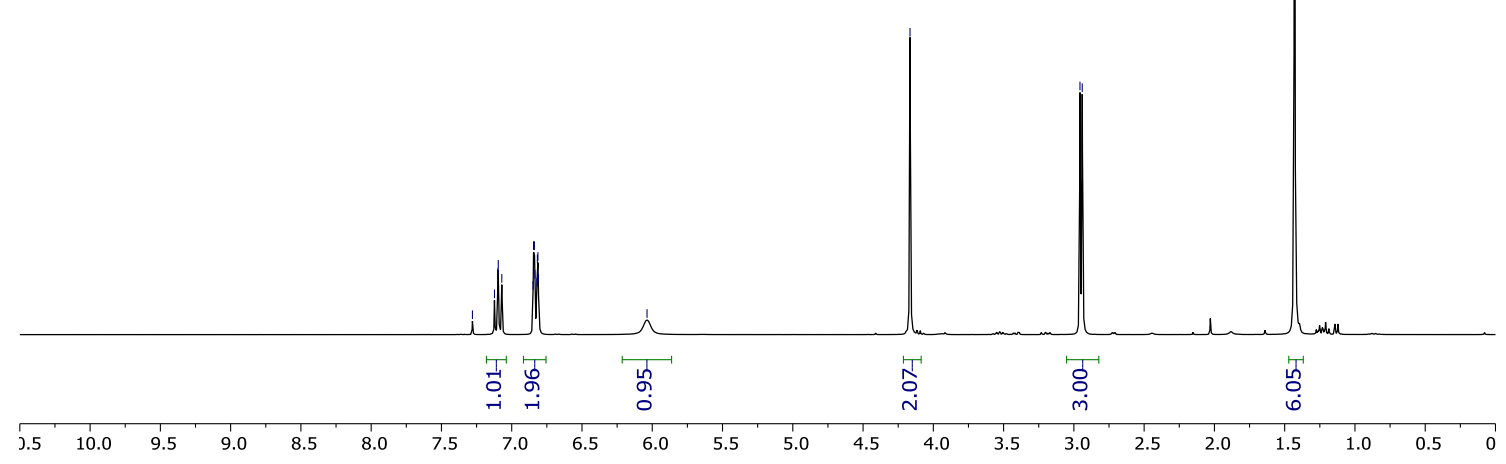

\begin{tabular}{|c|c|c|c|c|}
\hline 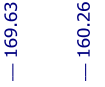 & 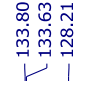 & $\begin{array}{l}\infty \\
\infty \\
\infty \\
\infty \\
\stackrel{7}{1} \\
1\end{array}$ & $\begin{array}{l}\text { } \\
\text { in } \\
-1 \\
1\end{array}$ & $\begin{array}{c}\stackrel{\mathscr{N}}{\leftrightarrow} \\
\stackrel{\infty}{\infty} \\
1\end{array}$ \\
\hline
\end{tabular}

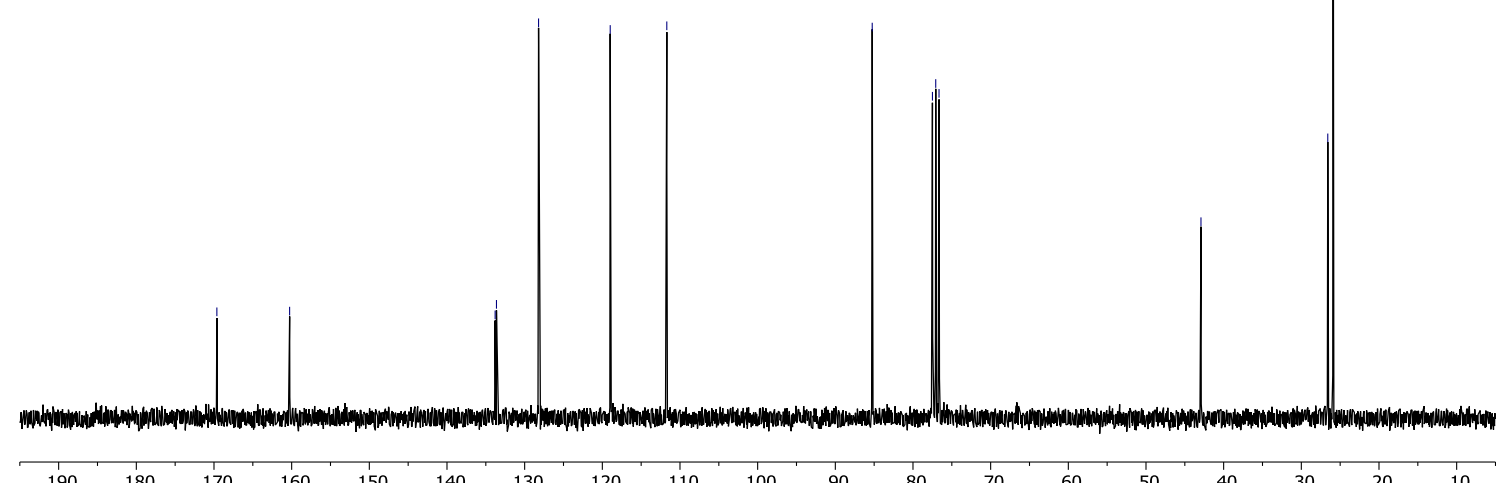




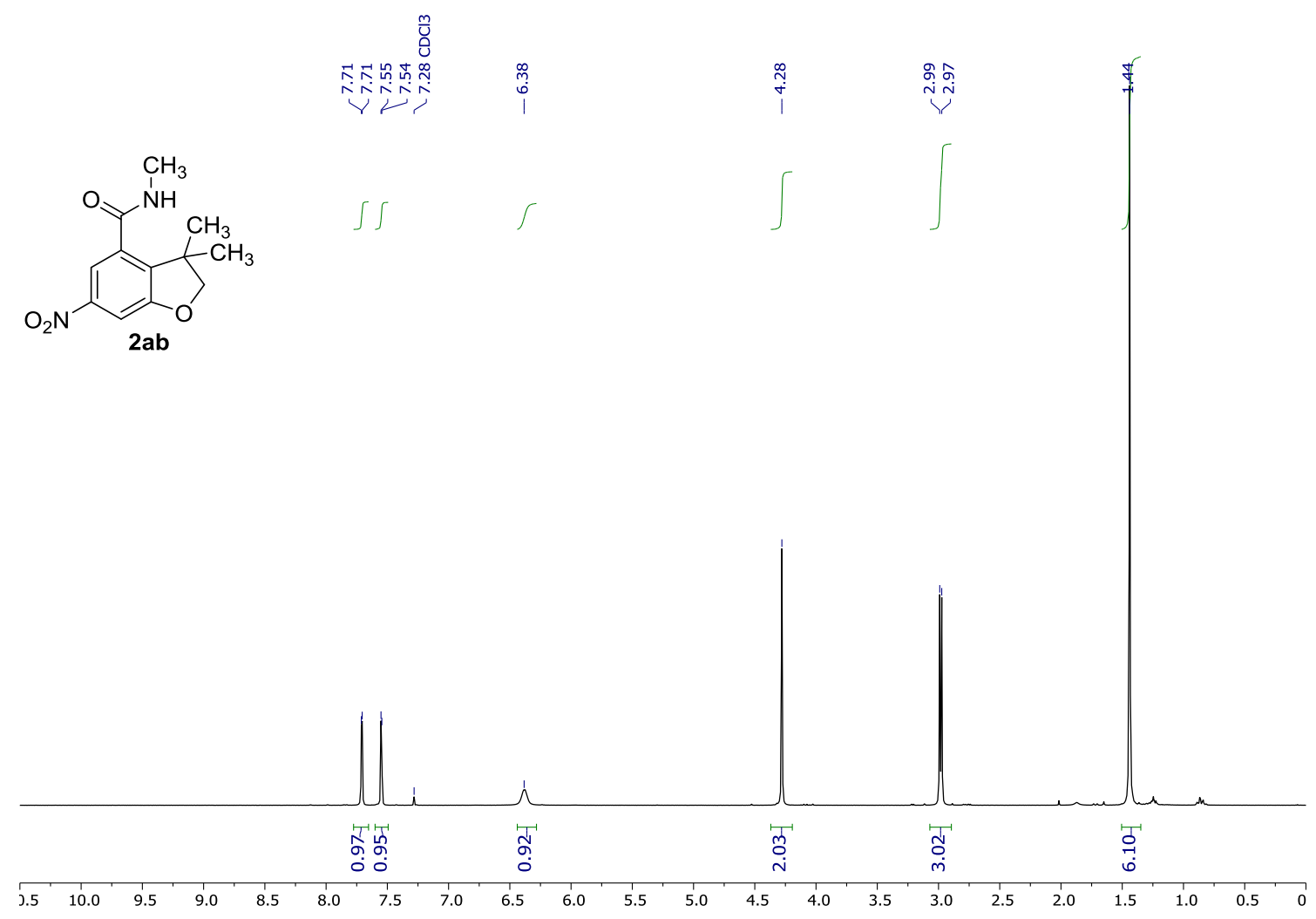

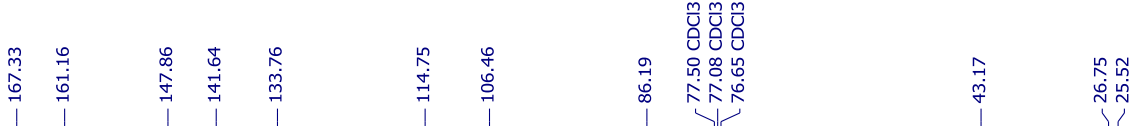

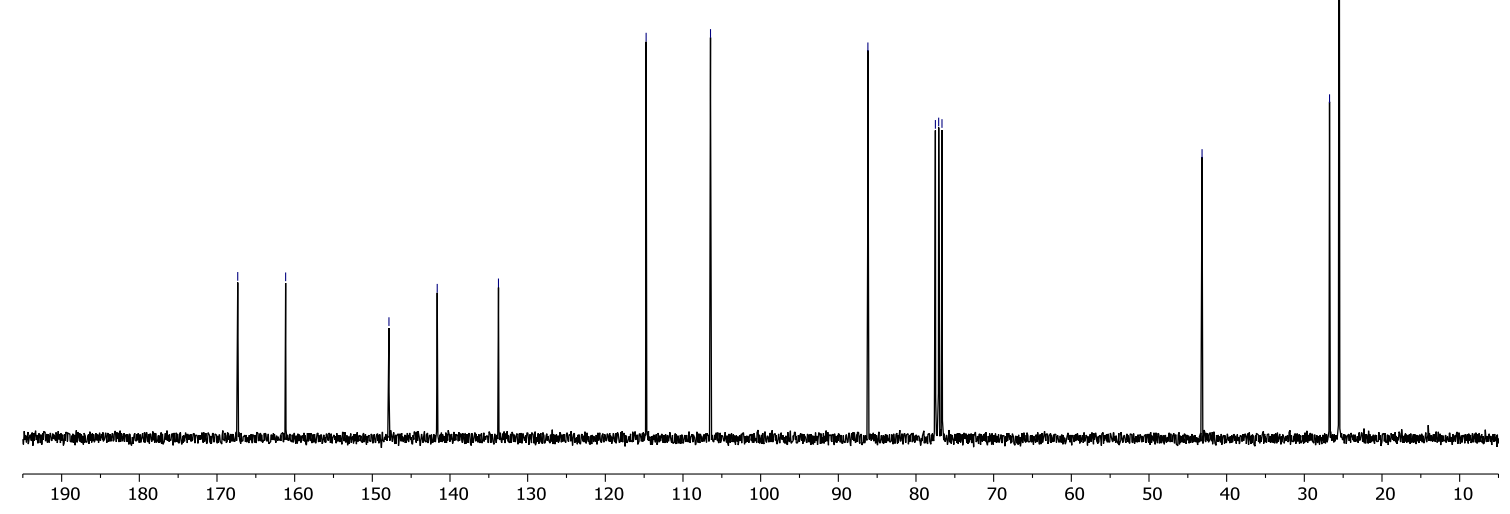




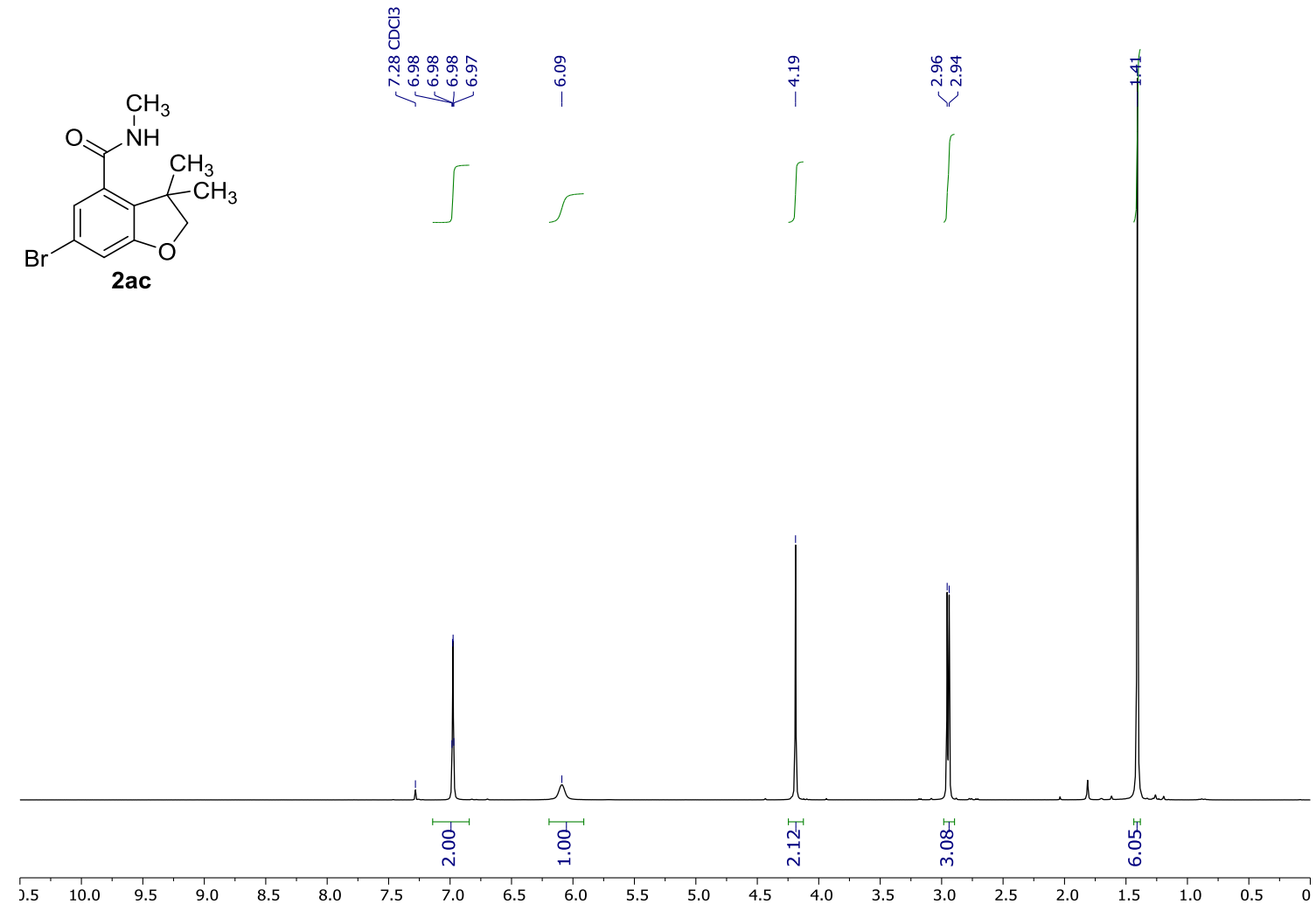

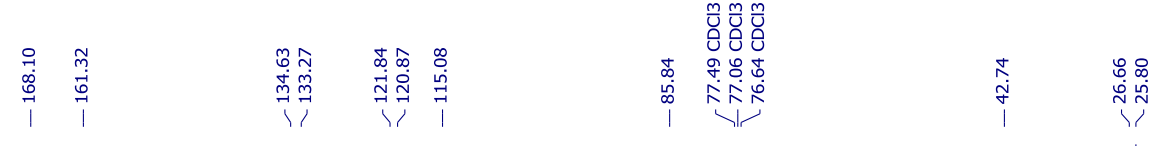

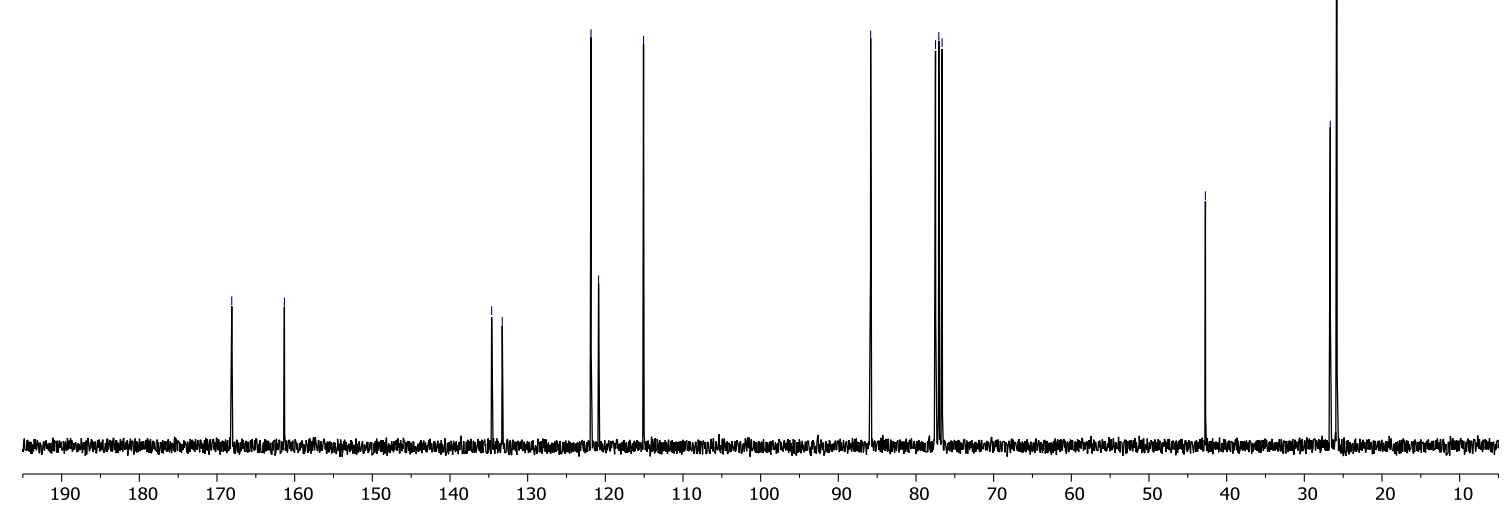




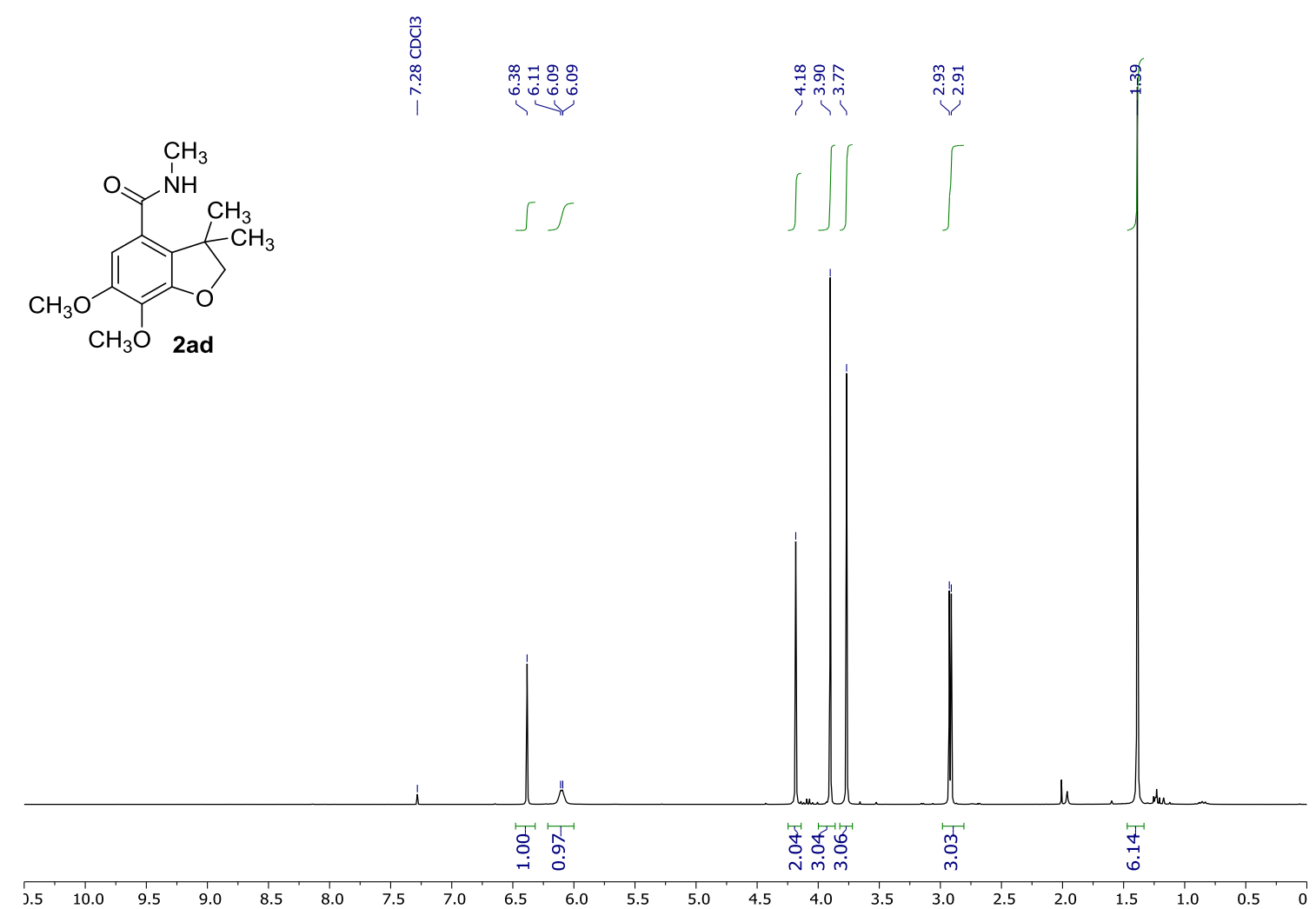

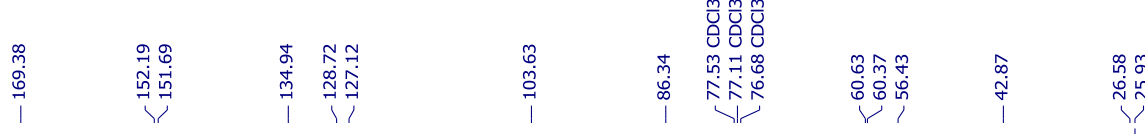




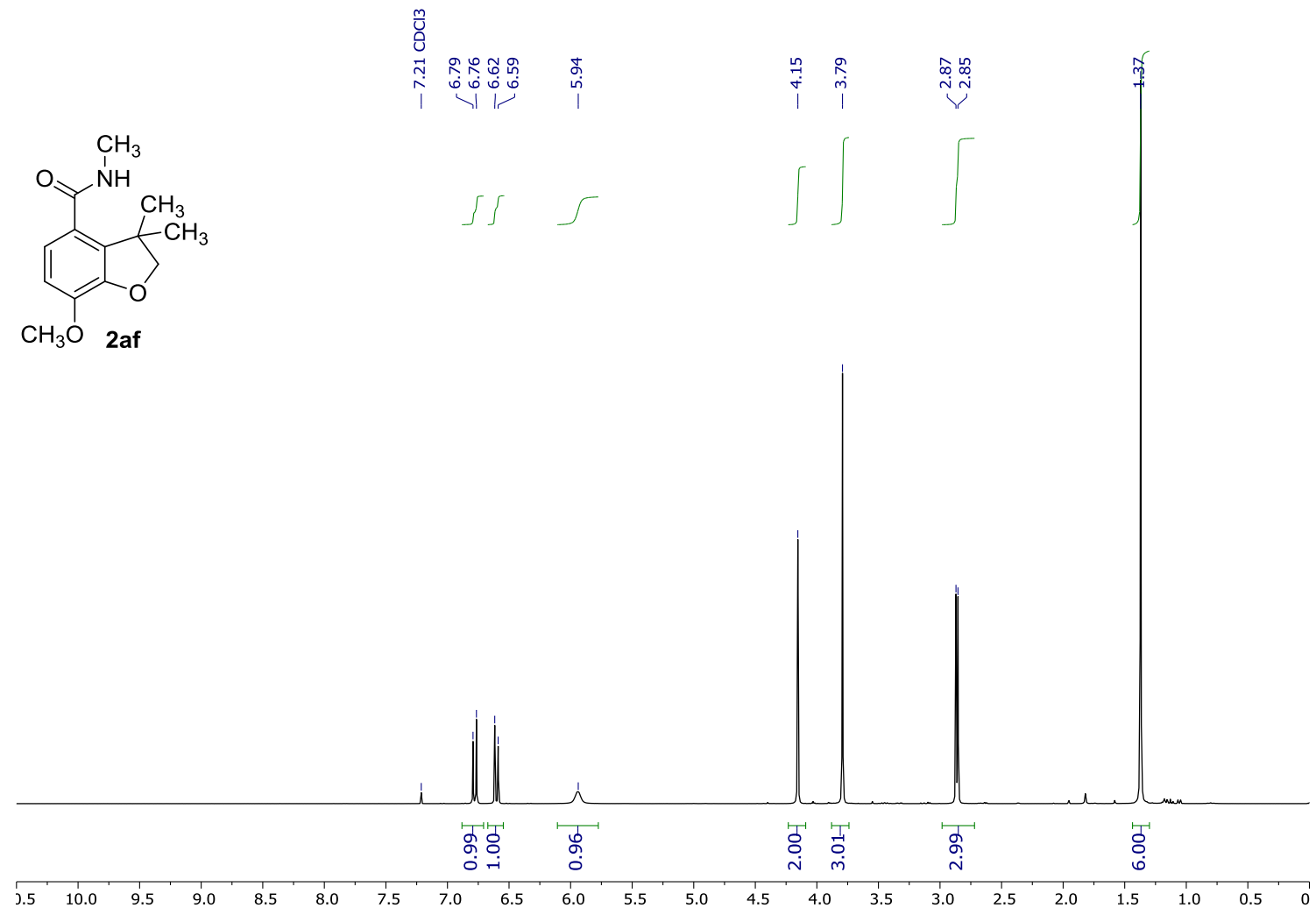<smiles>CNC(=O)c1ccc(OC)c2c1C(C)(C)CO2</smiles>

$\mathrm{CH}_{3} \mathrm{O}$ 2af

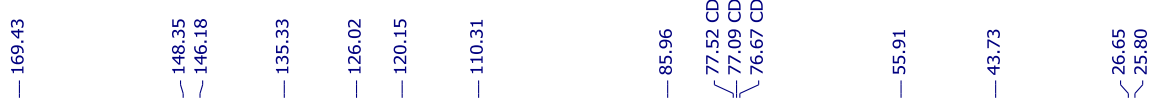

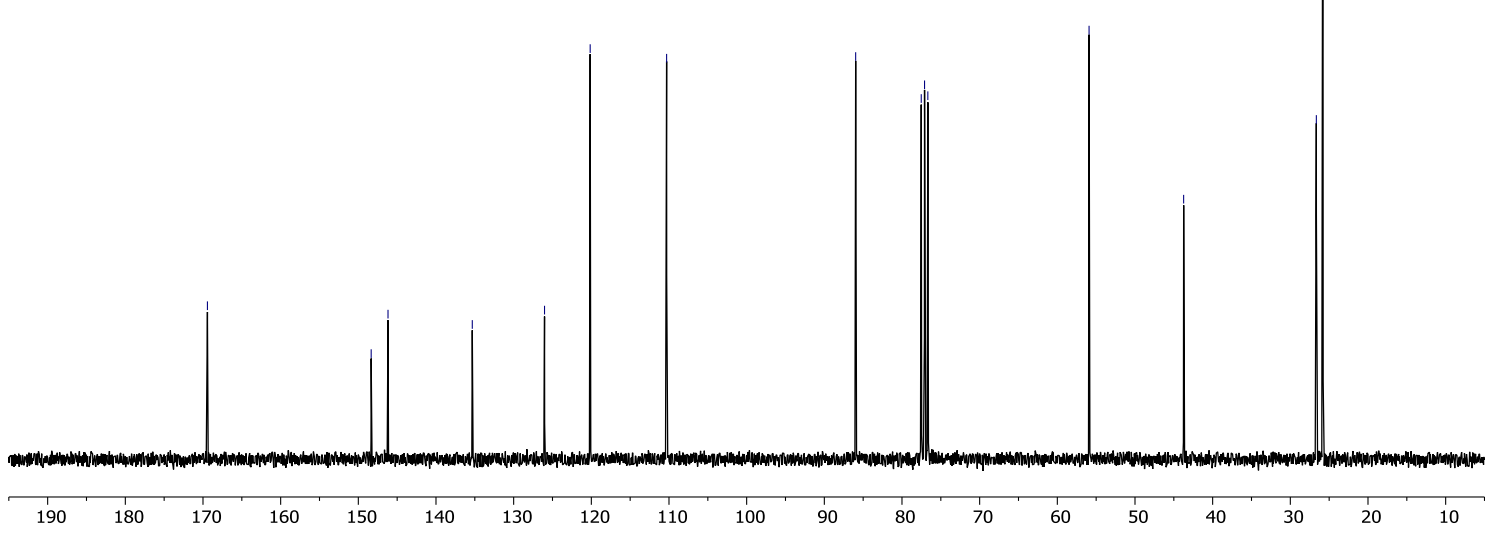


$\underbrace{1}$<smiles>CNC(=O)c1ccc(F)c2c1C(C)(C)CO2</smiles>

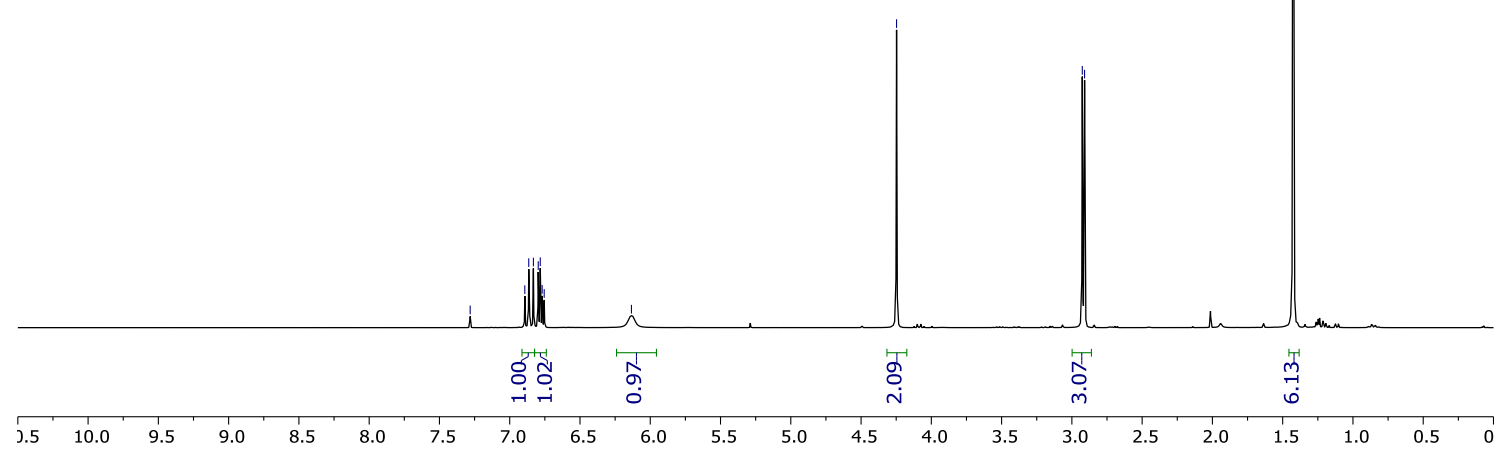

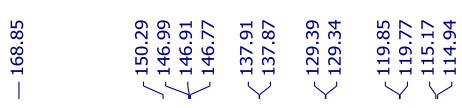

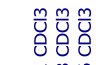

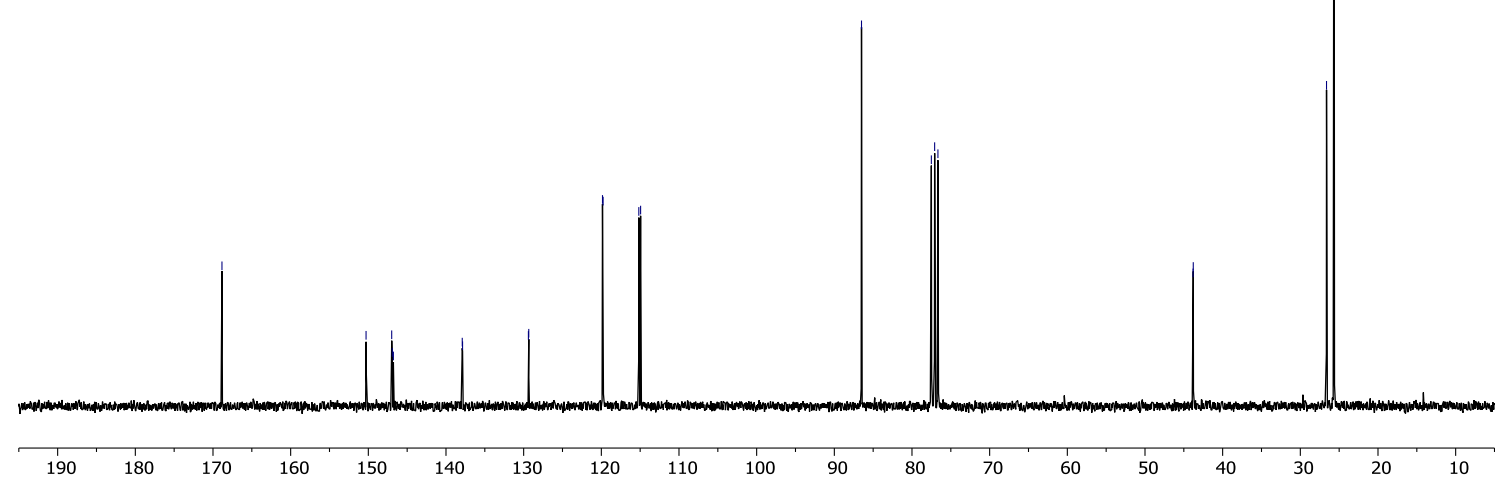




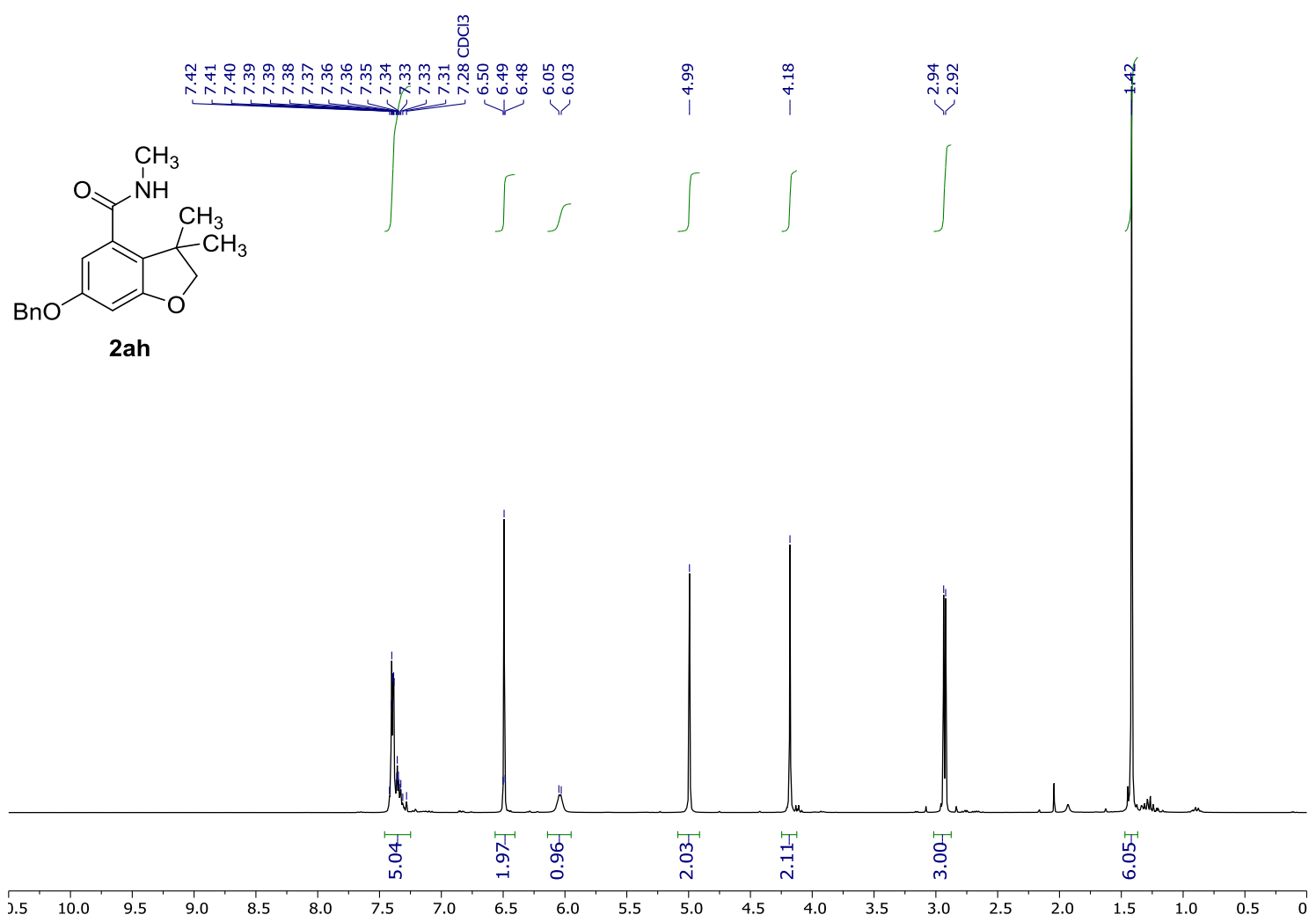

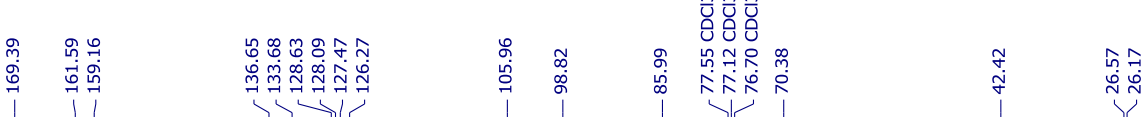

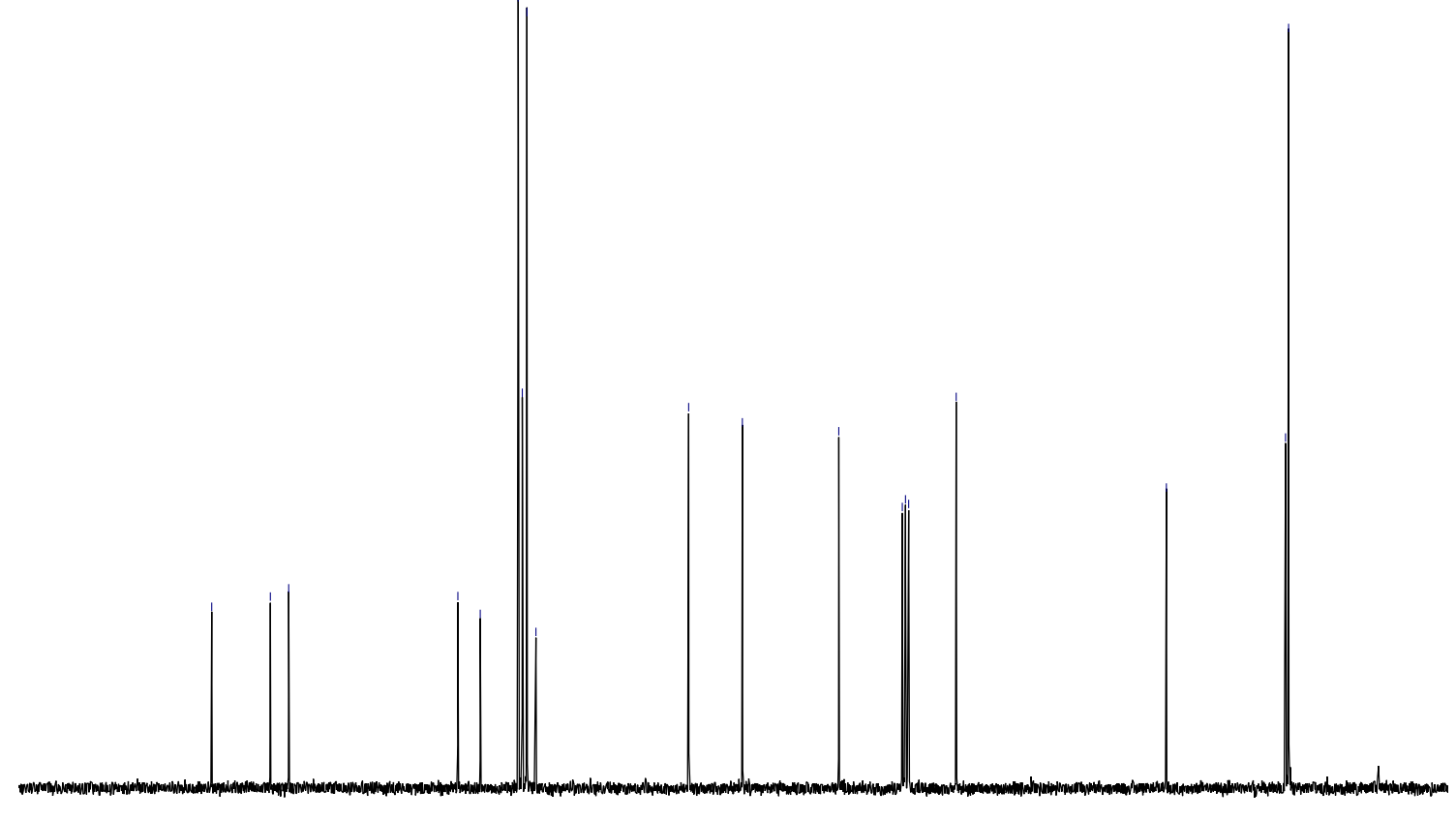

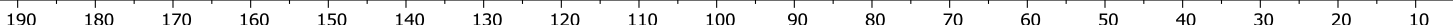




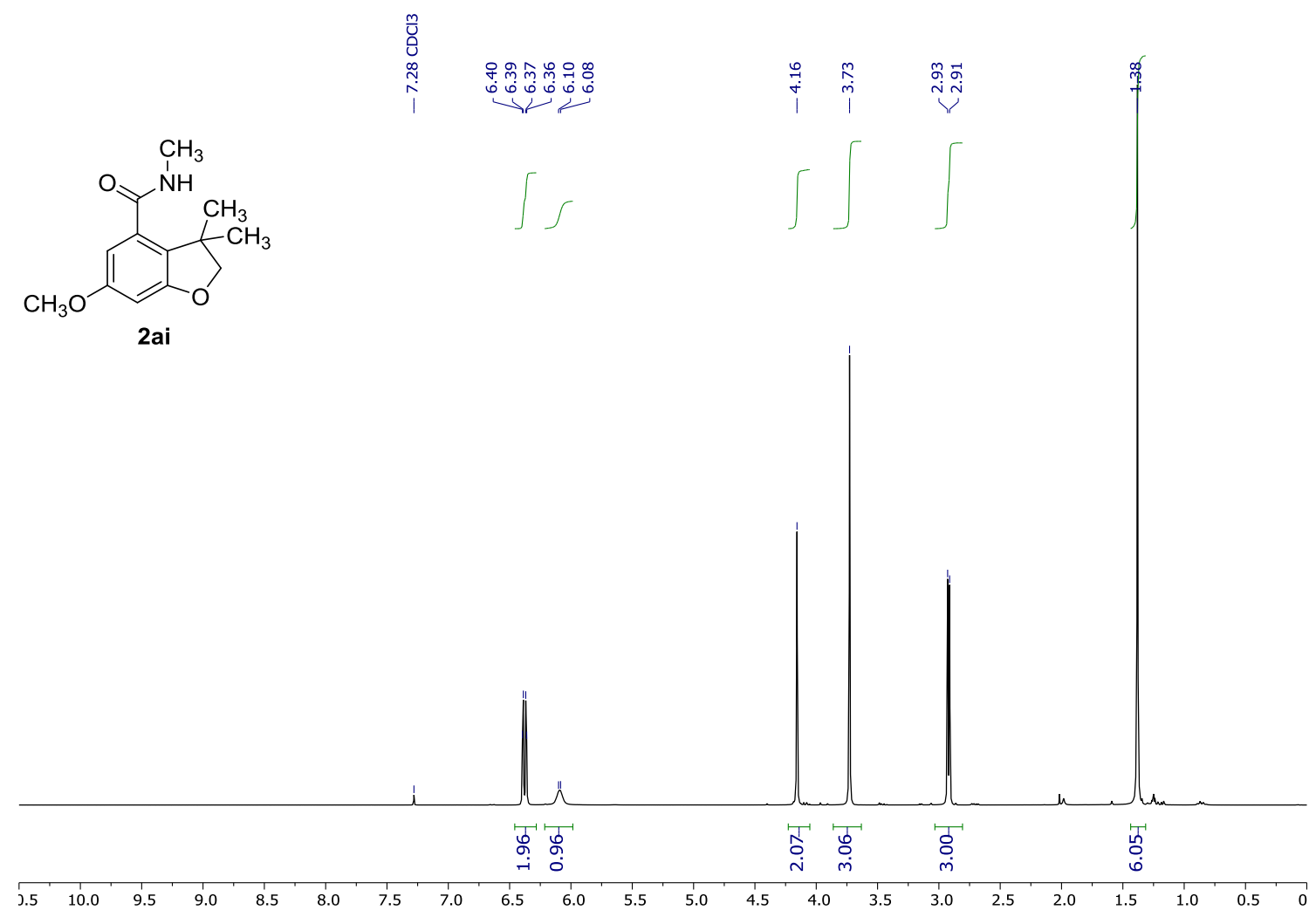

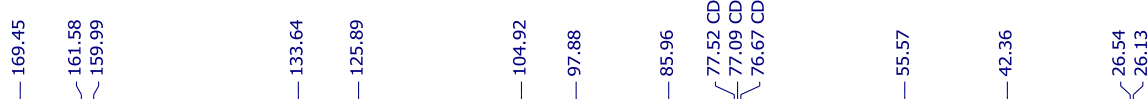

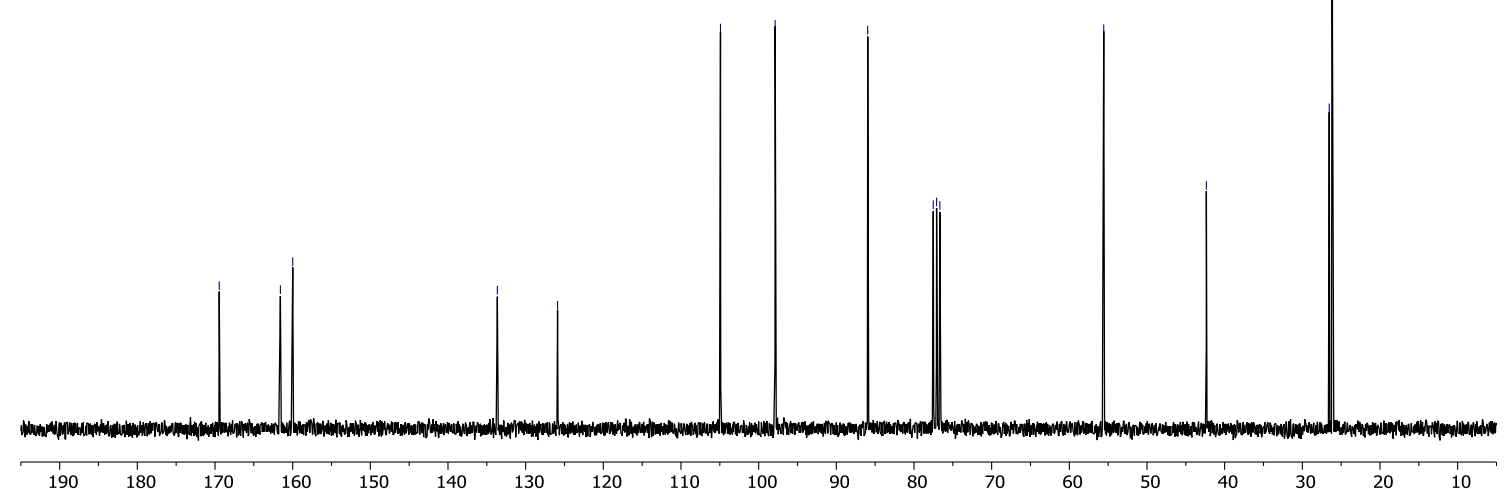




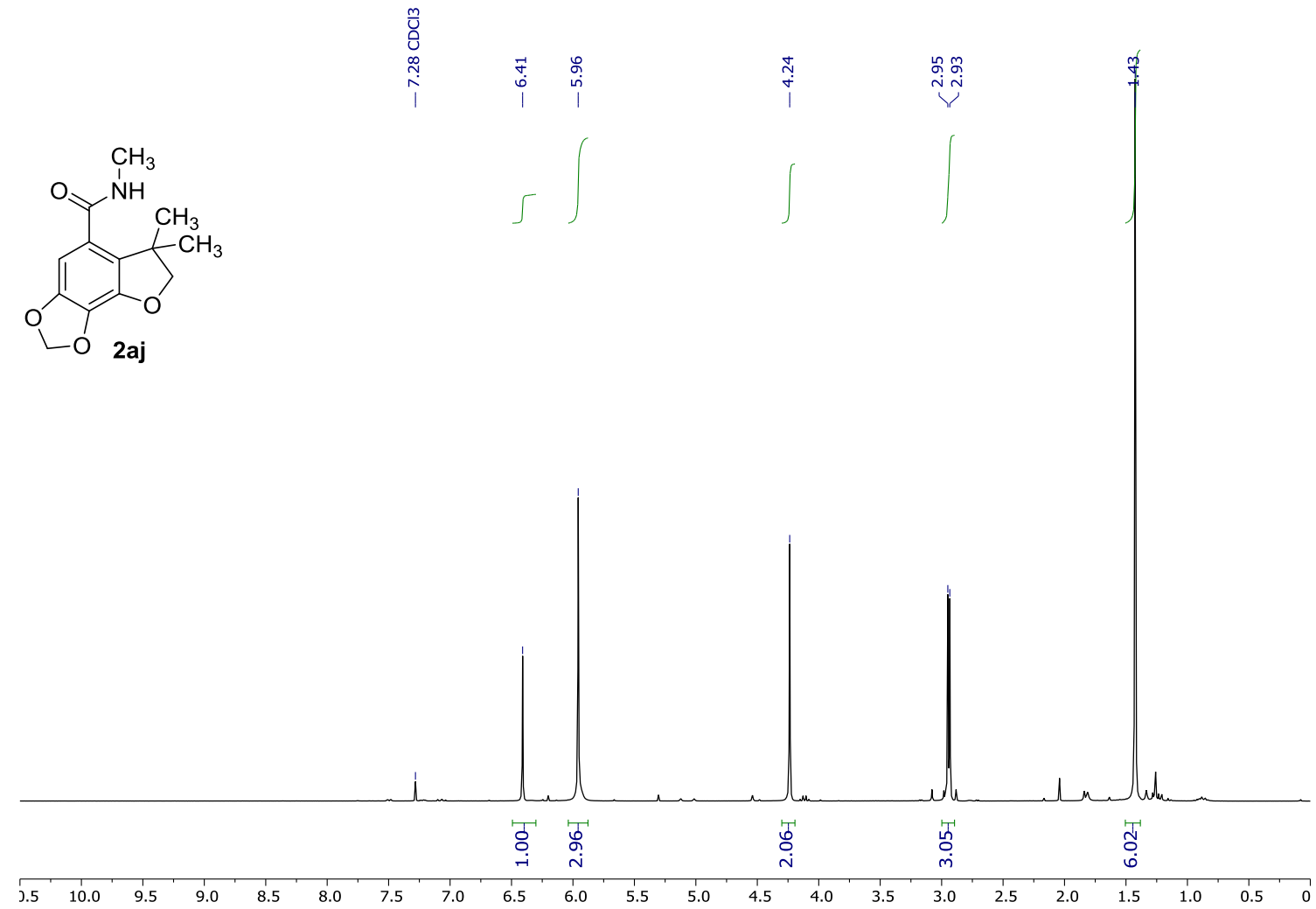

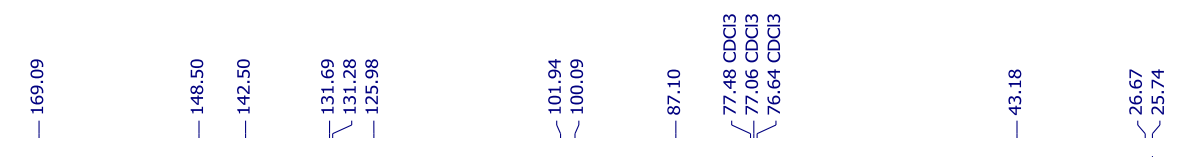

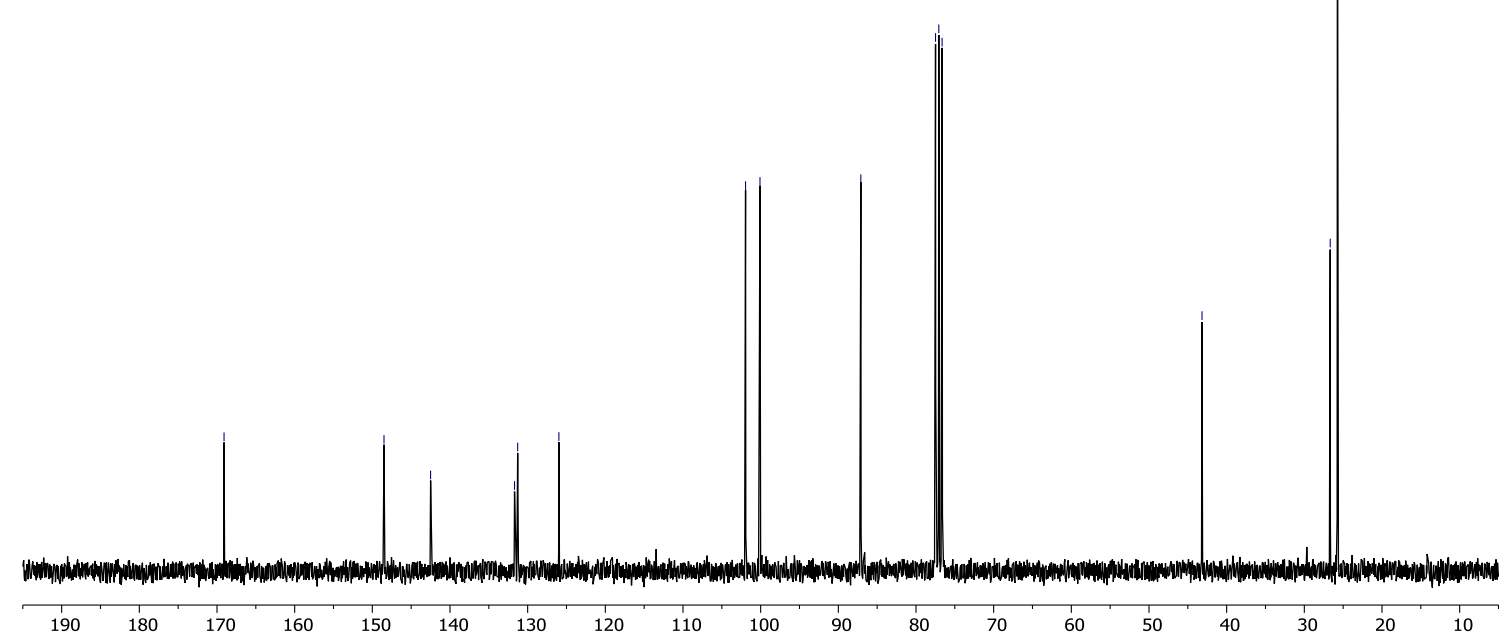



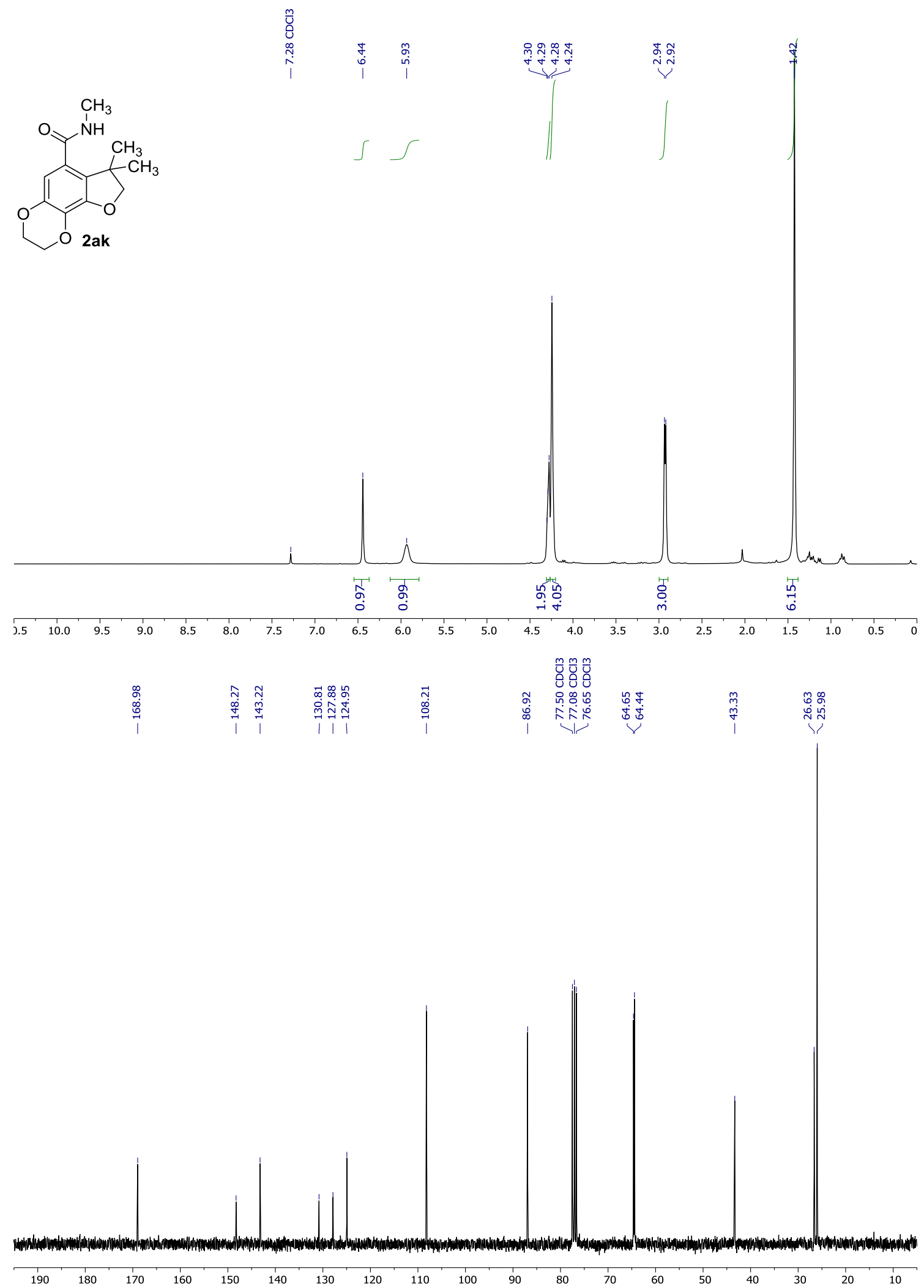


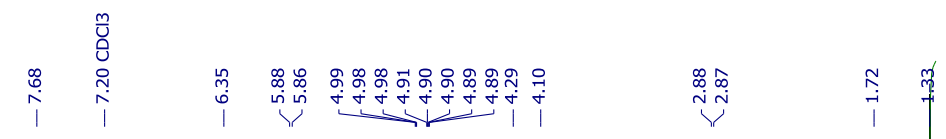<smiles>C=C(C)COc1cc2c(c(C(=O)NC)c1)C(C)(C)CO2</smiles>
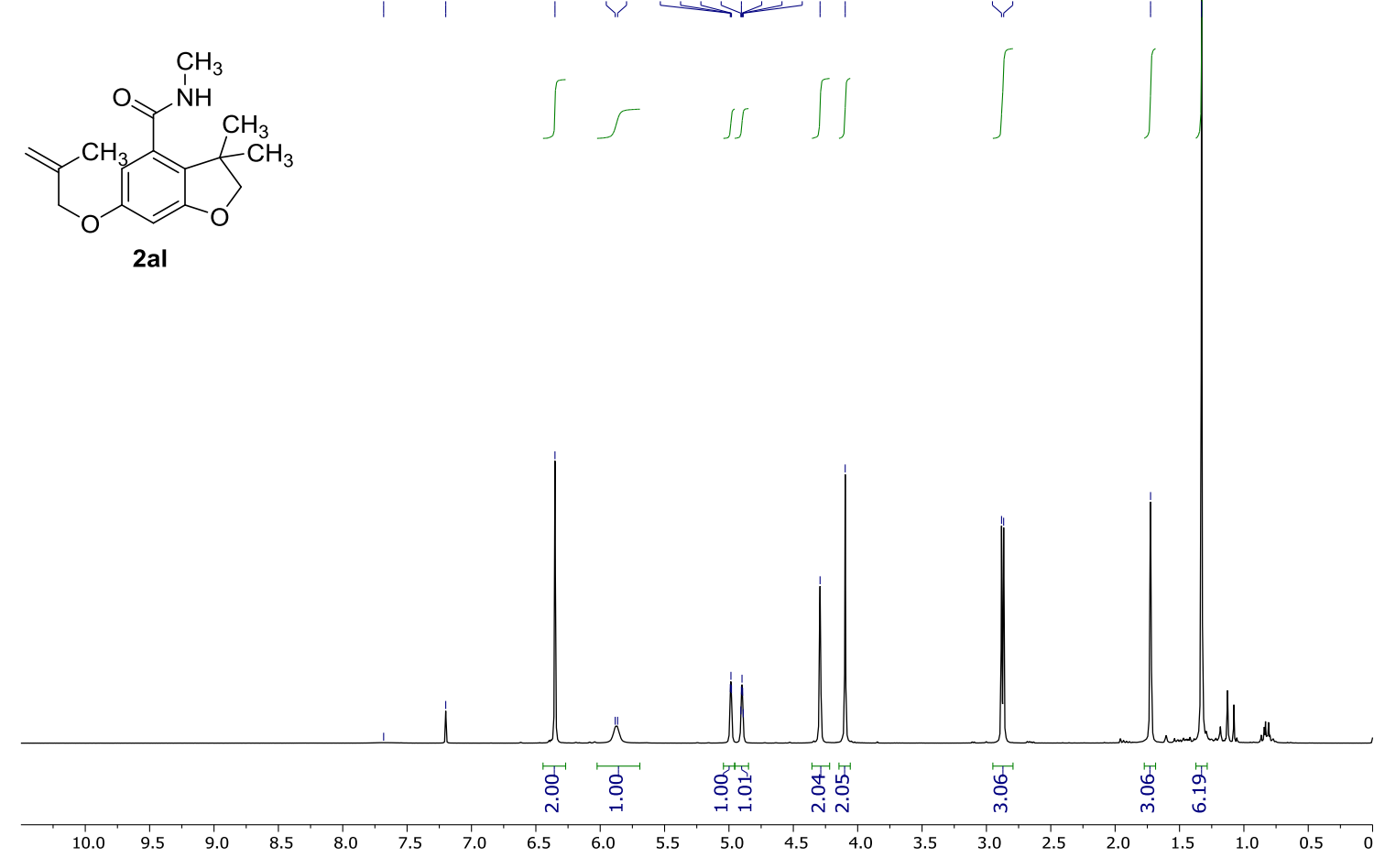

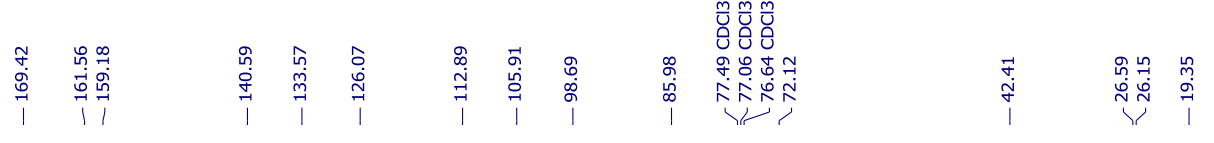

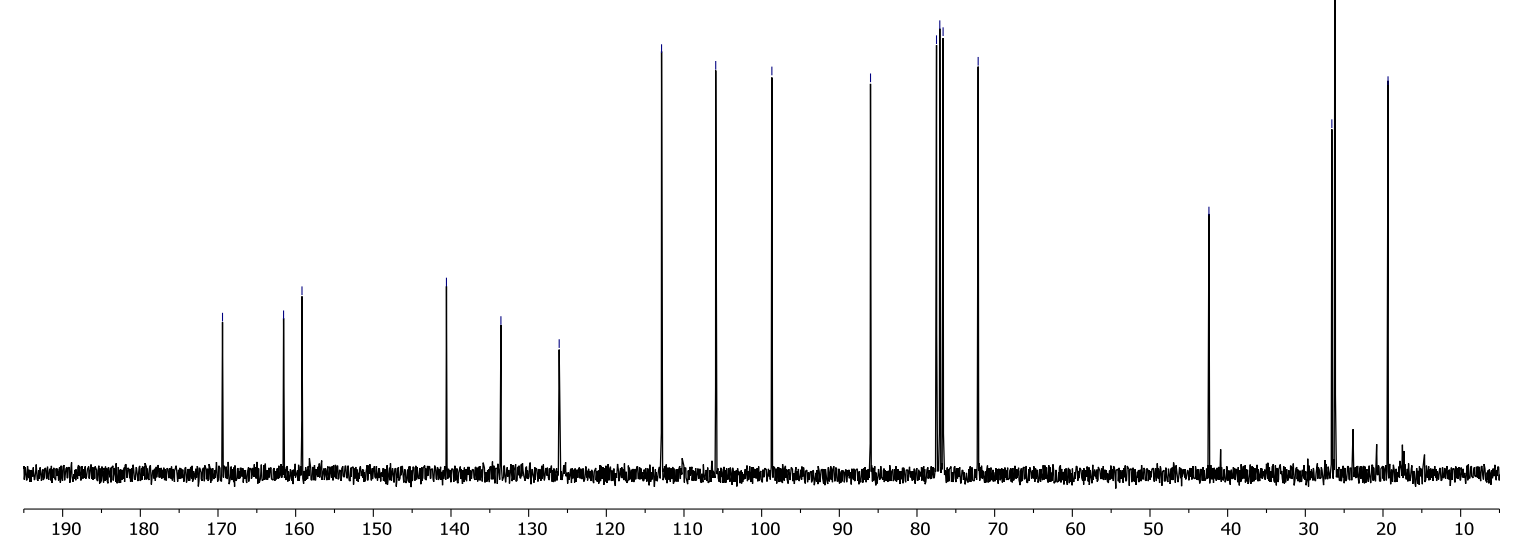



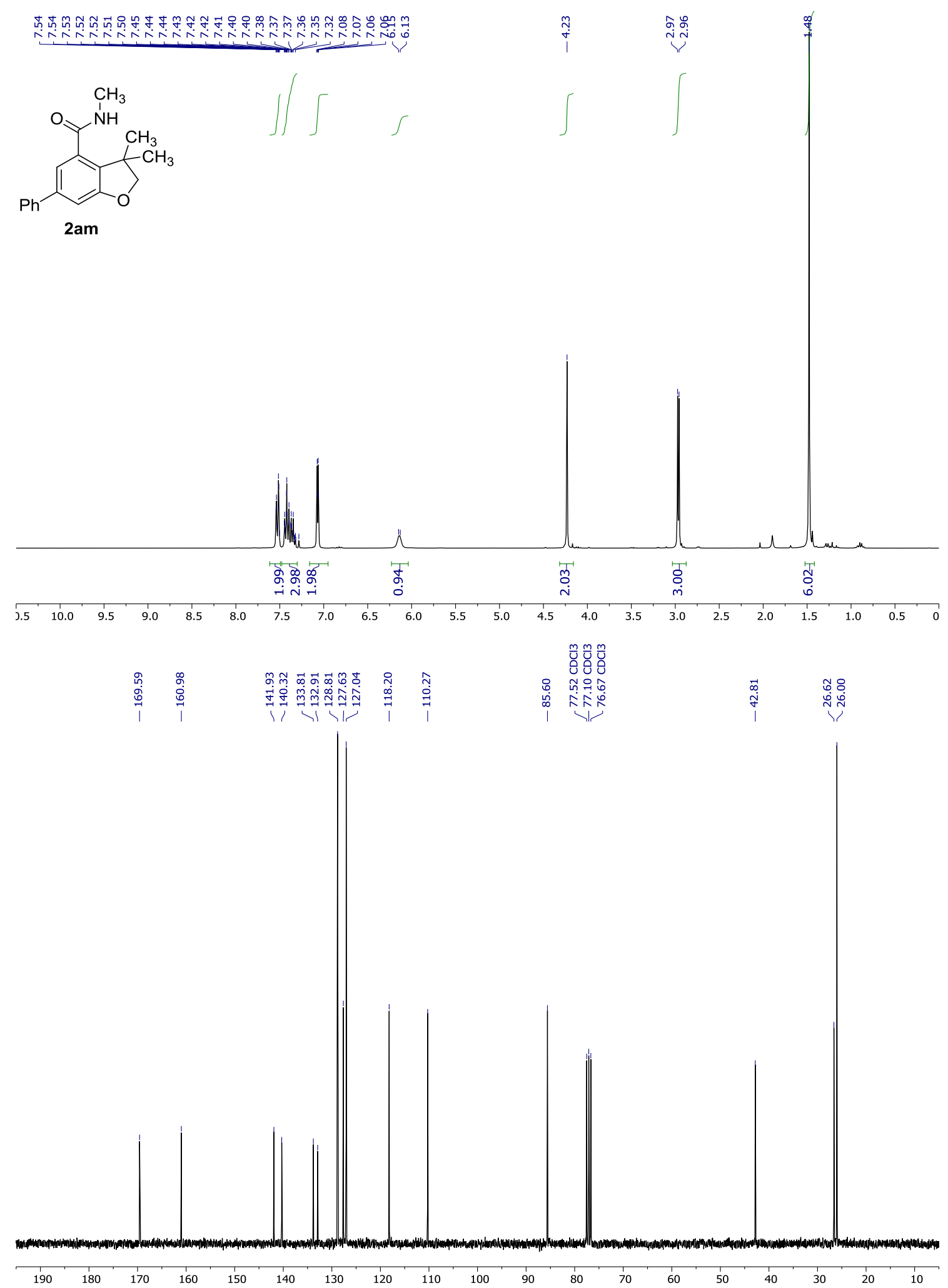

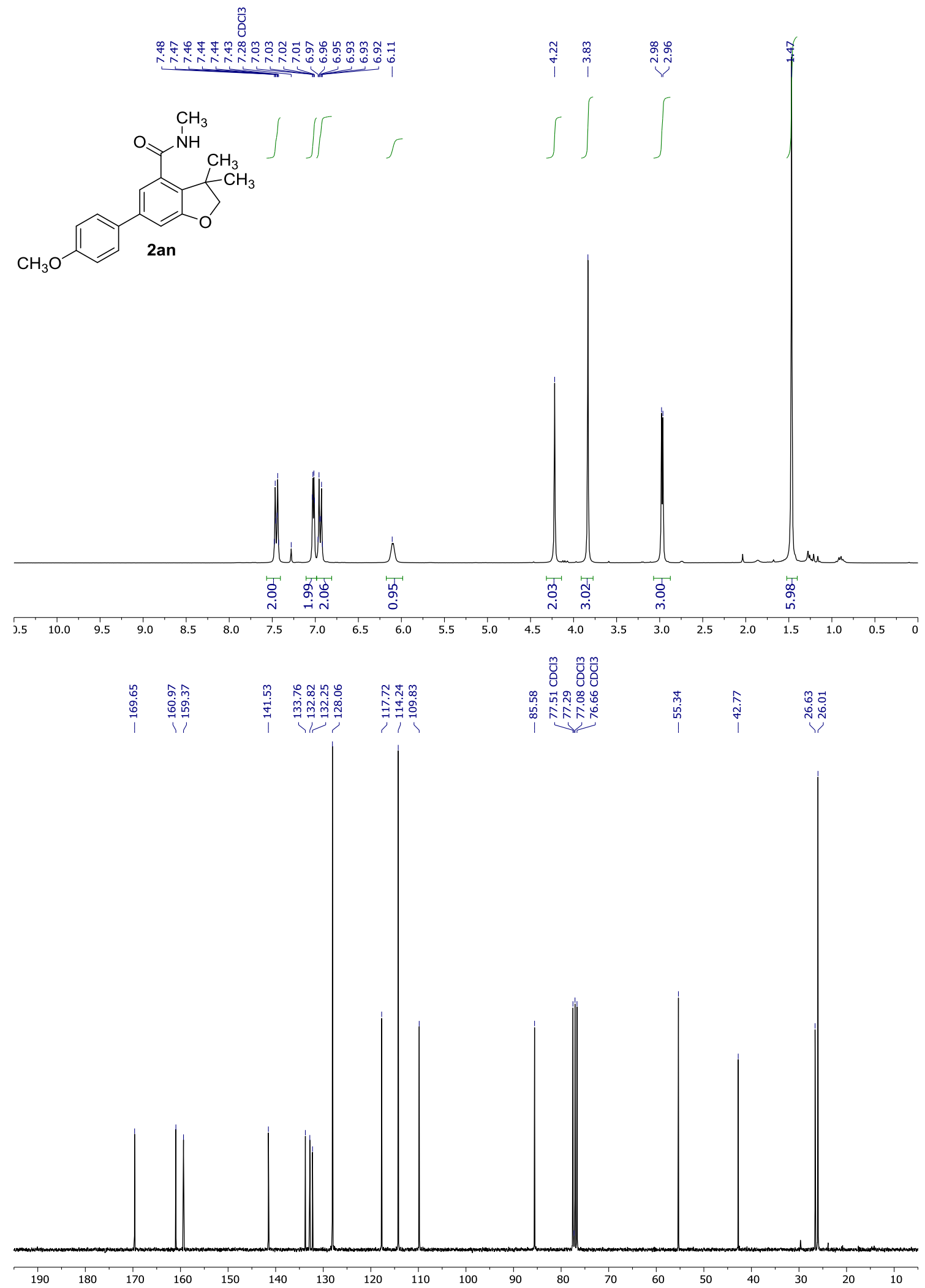


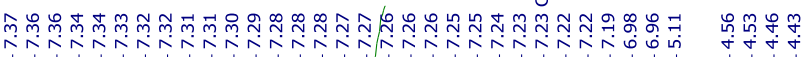<smiles>CNC(=O)c1cccc2c1C(C)(c1ccccc1)CO2</smiles>

2ba

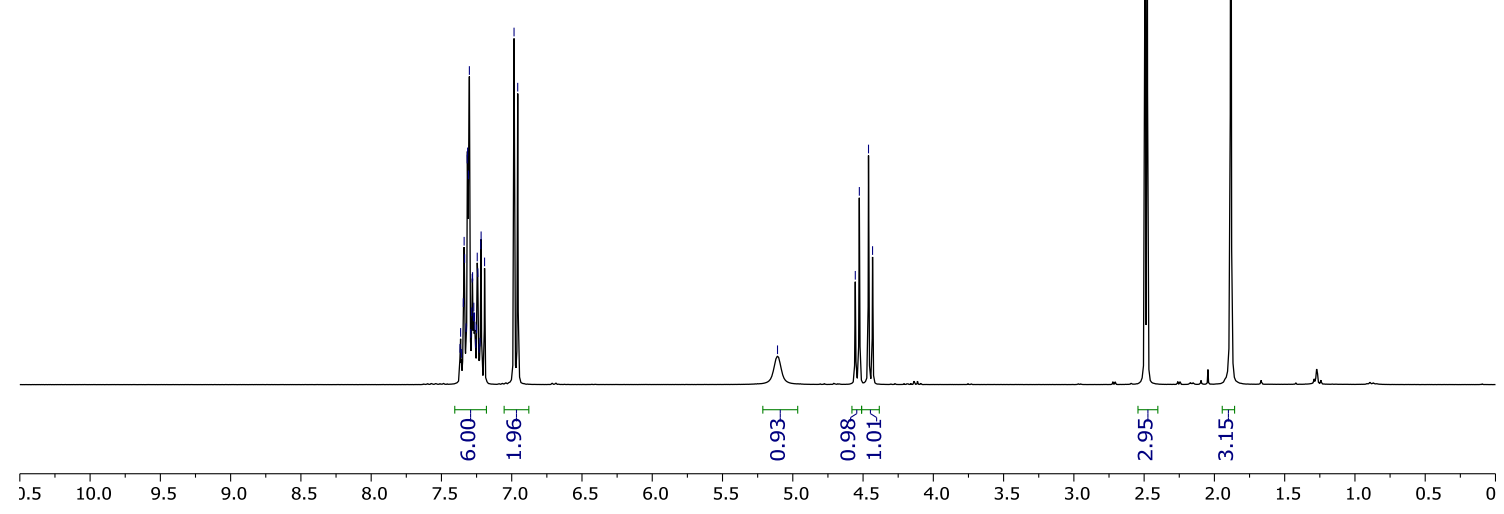

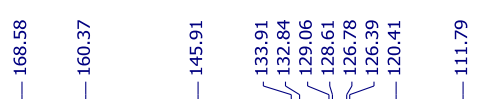
\begin{tabular}{ll}
$m$ \\
\hdashline \\
0
\end{tabular}

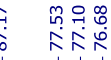

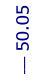

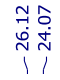

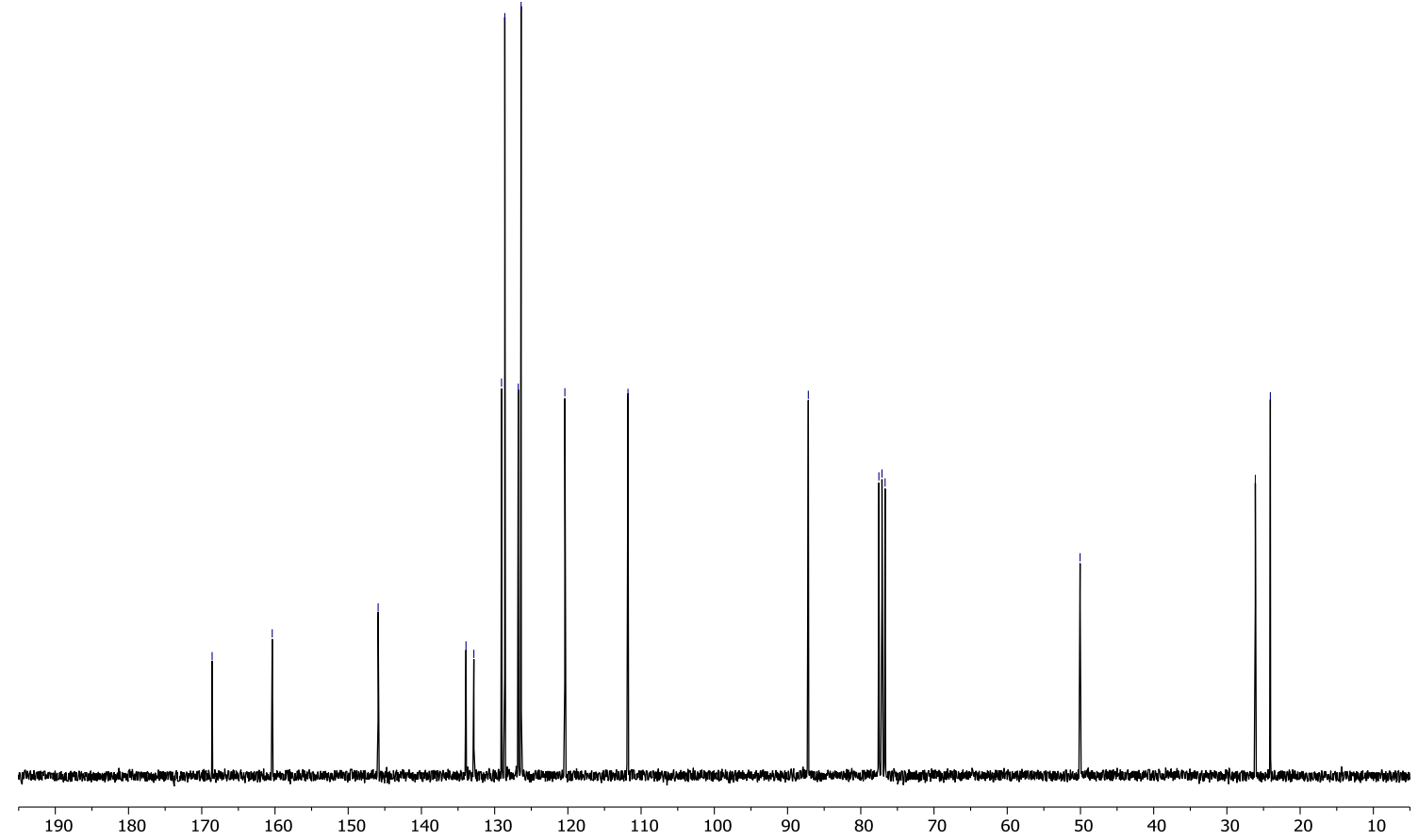



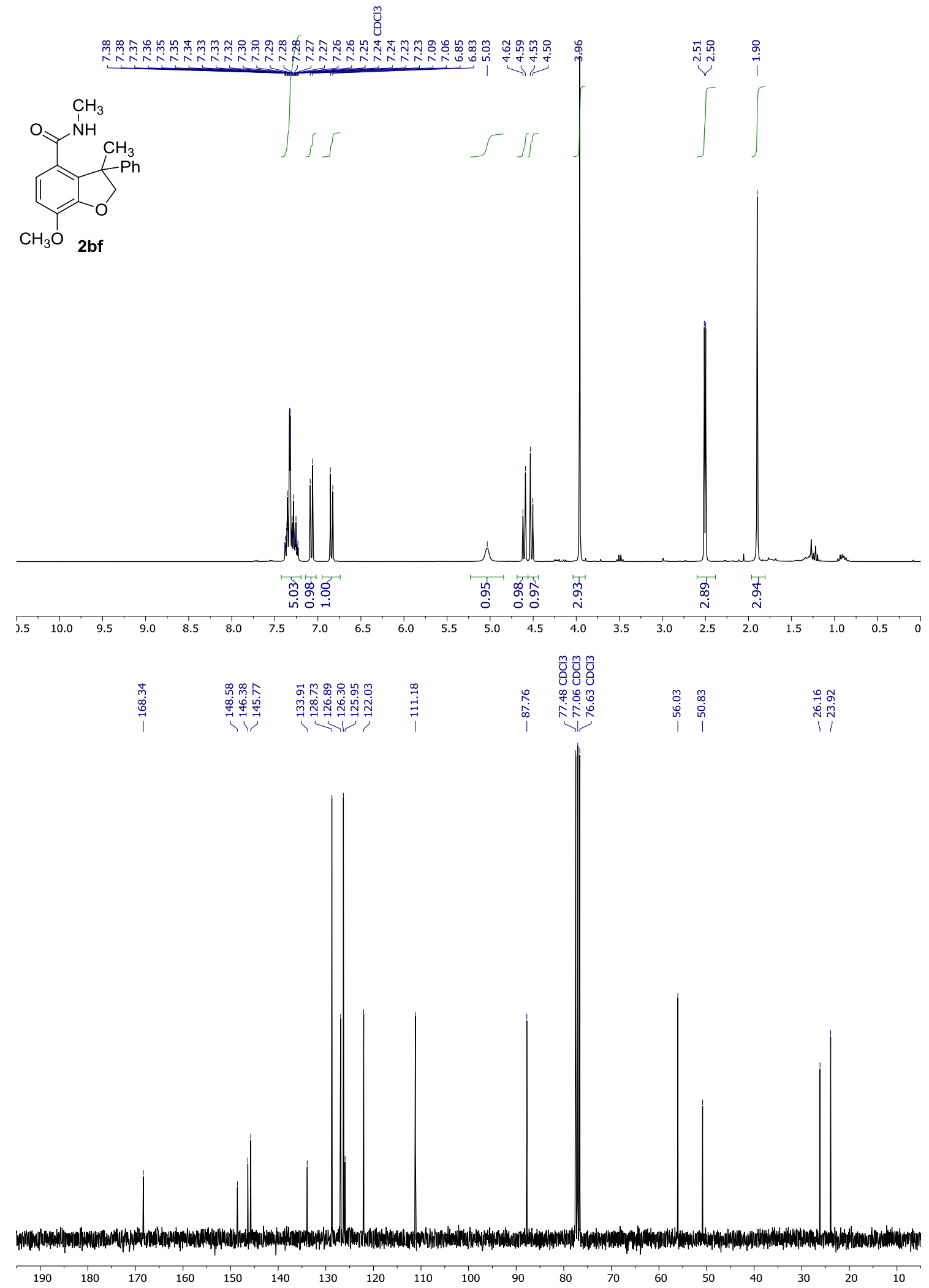

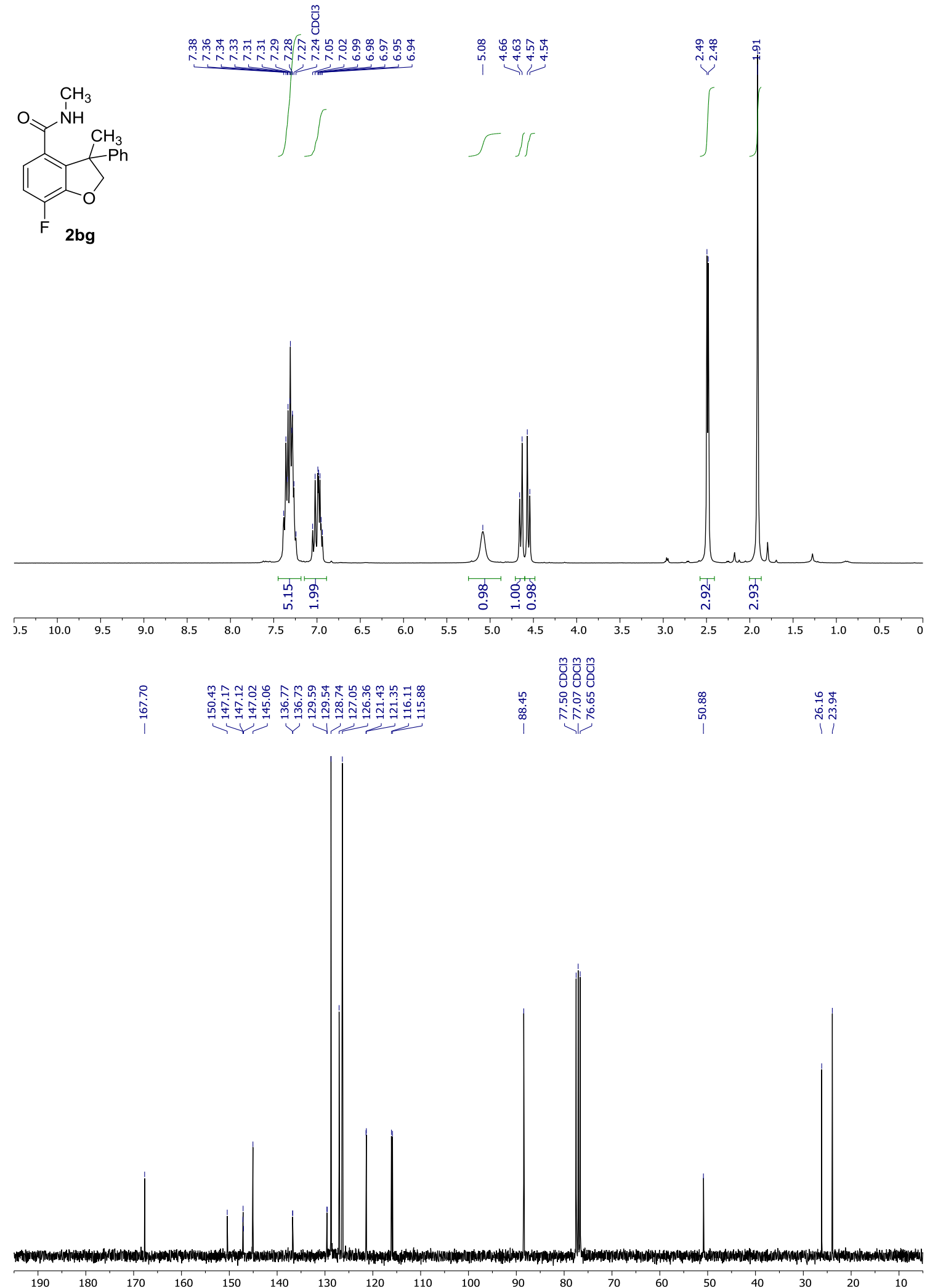
商

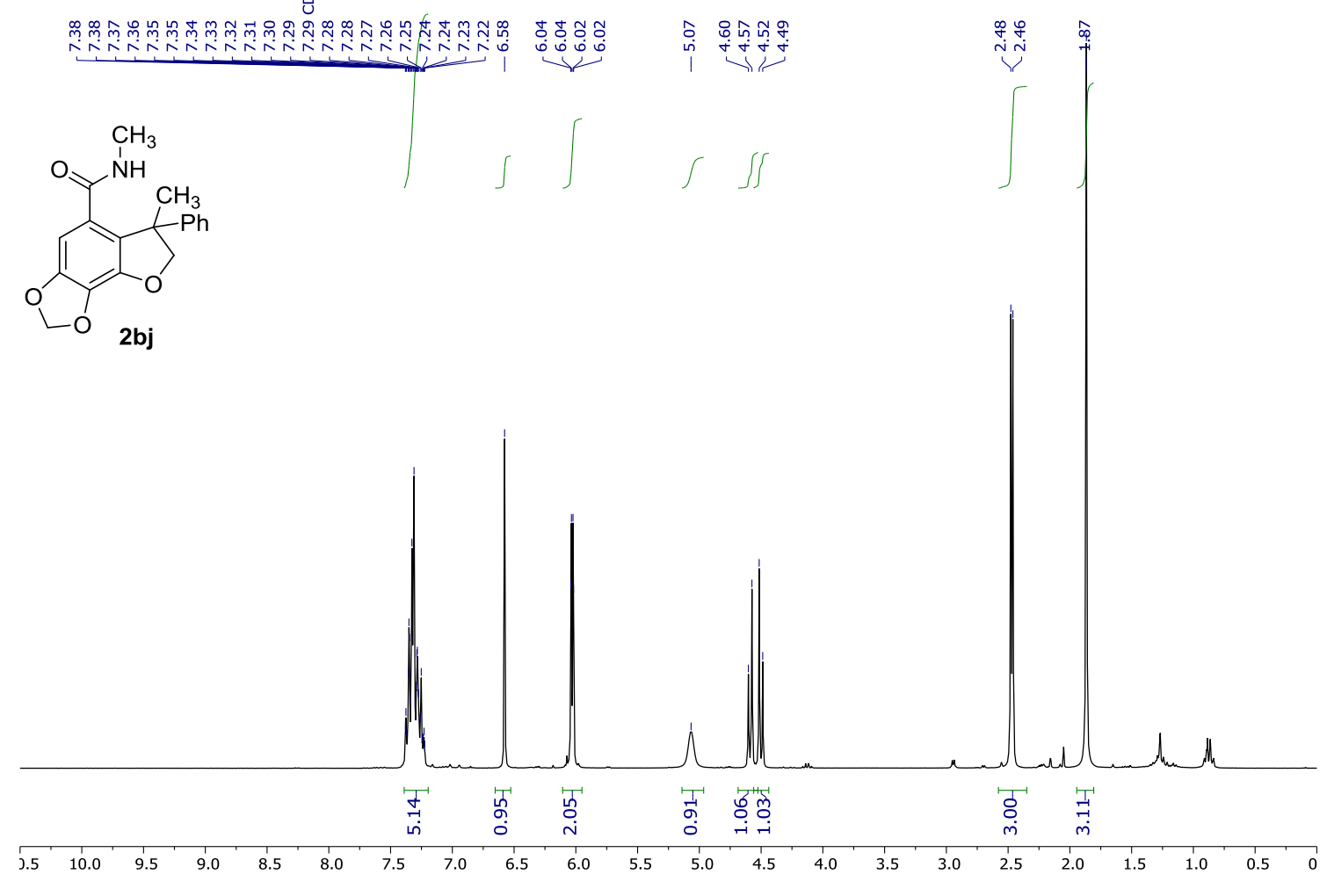

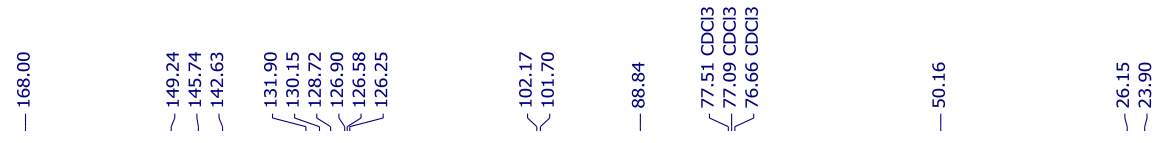

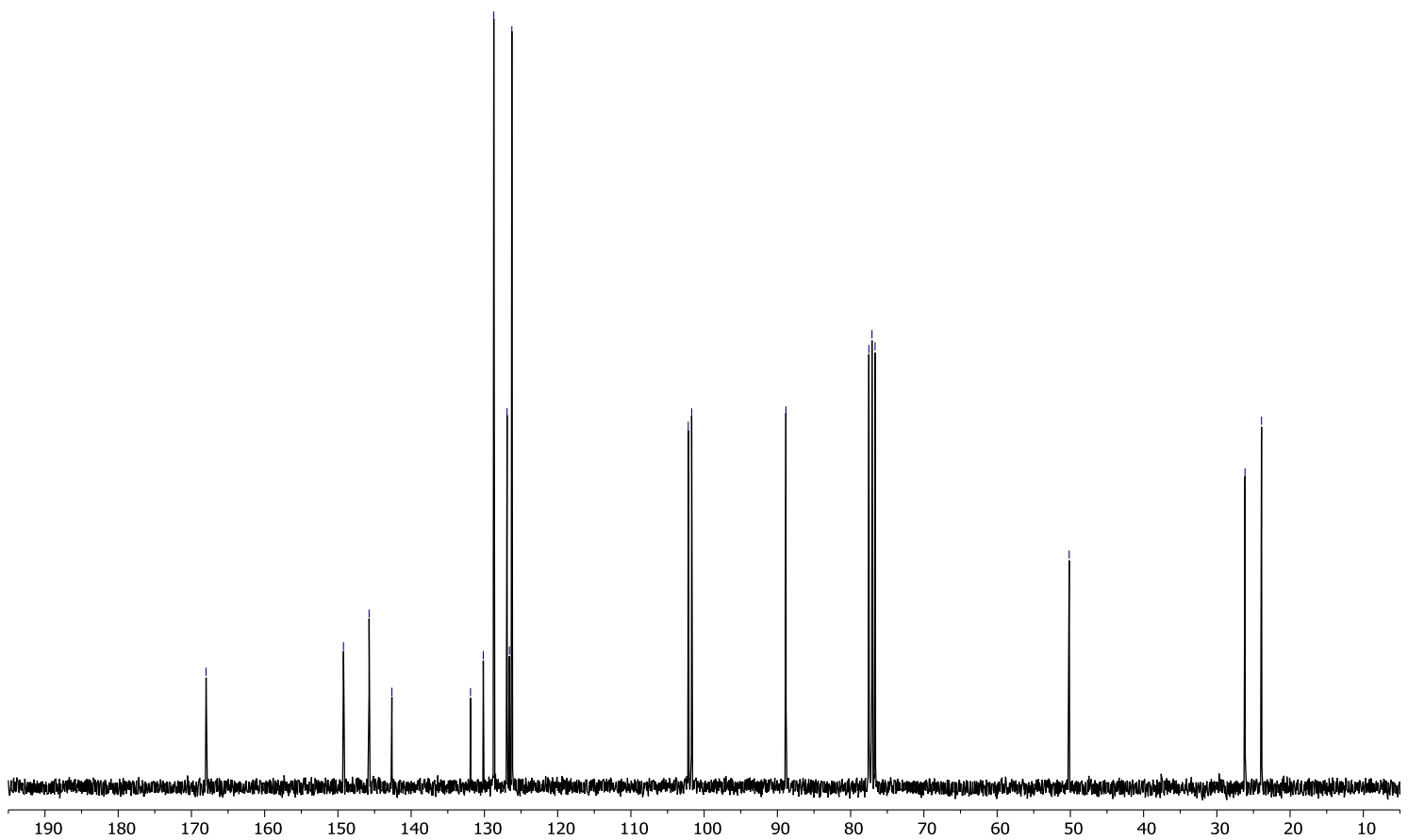



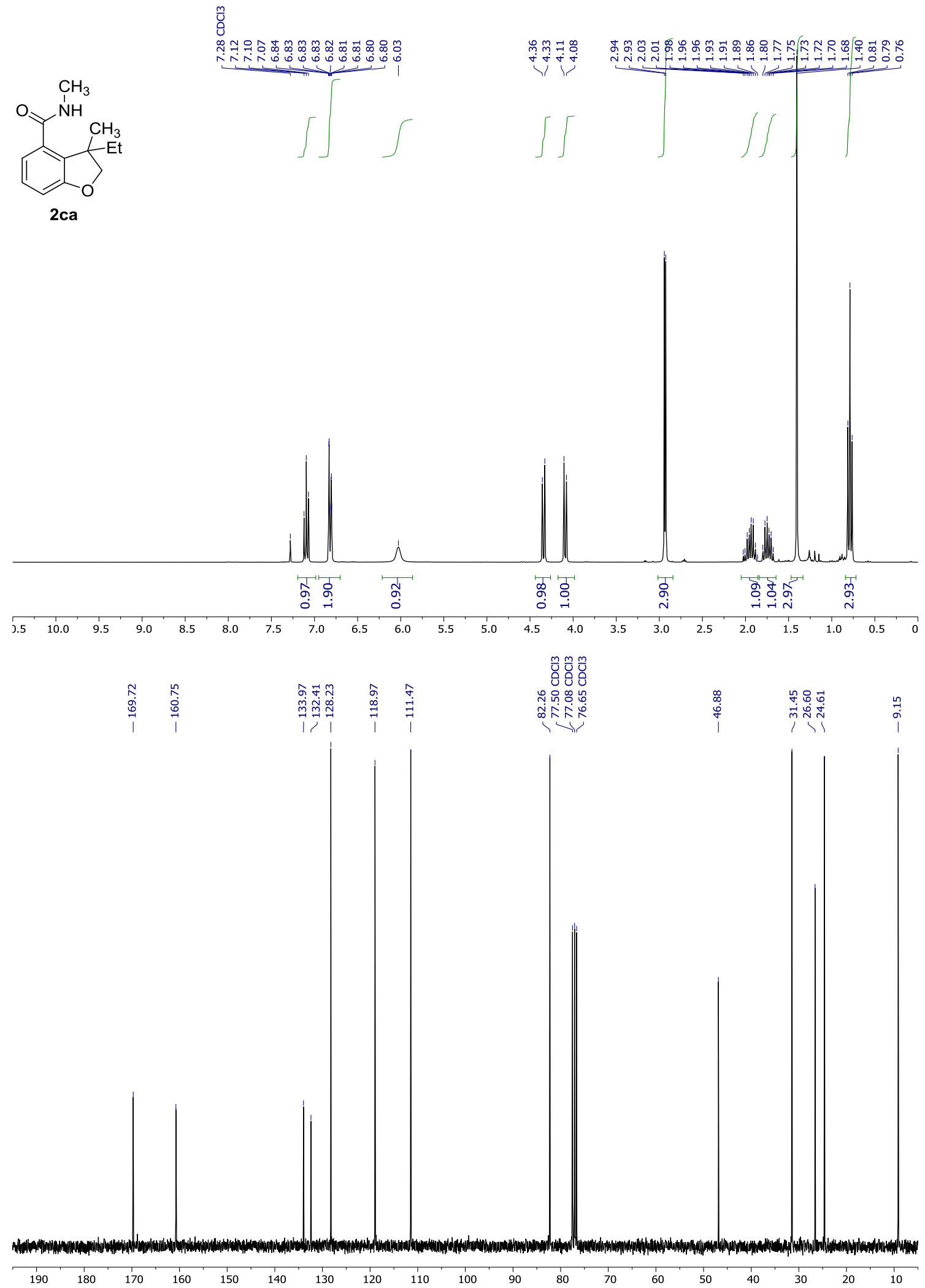

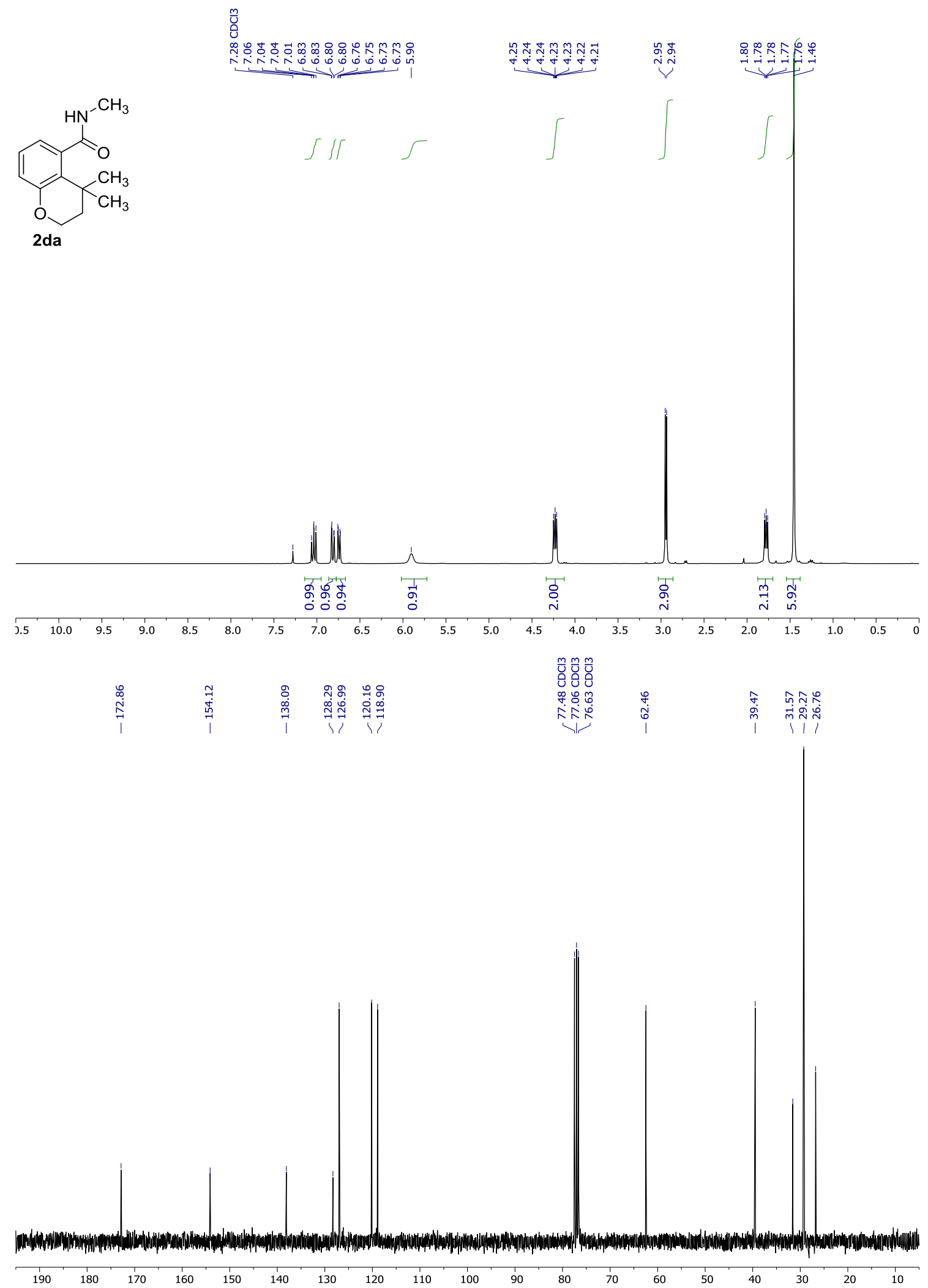

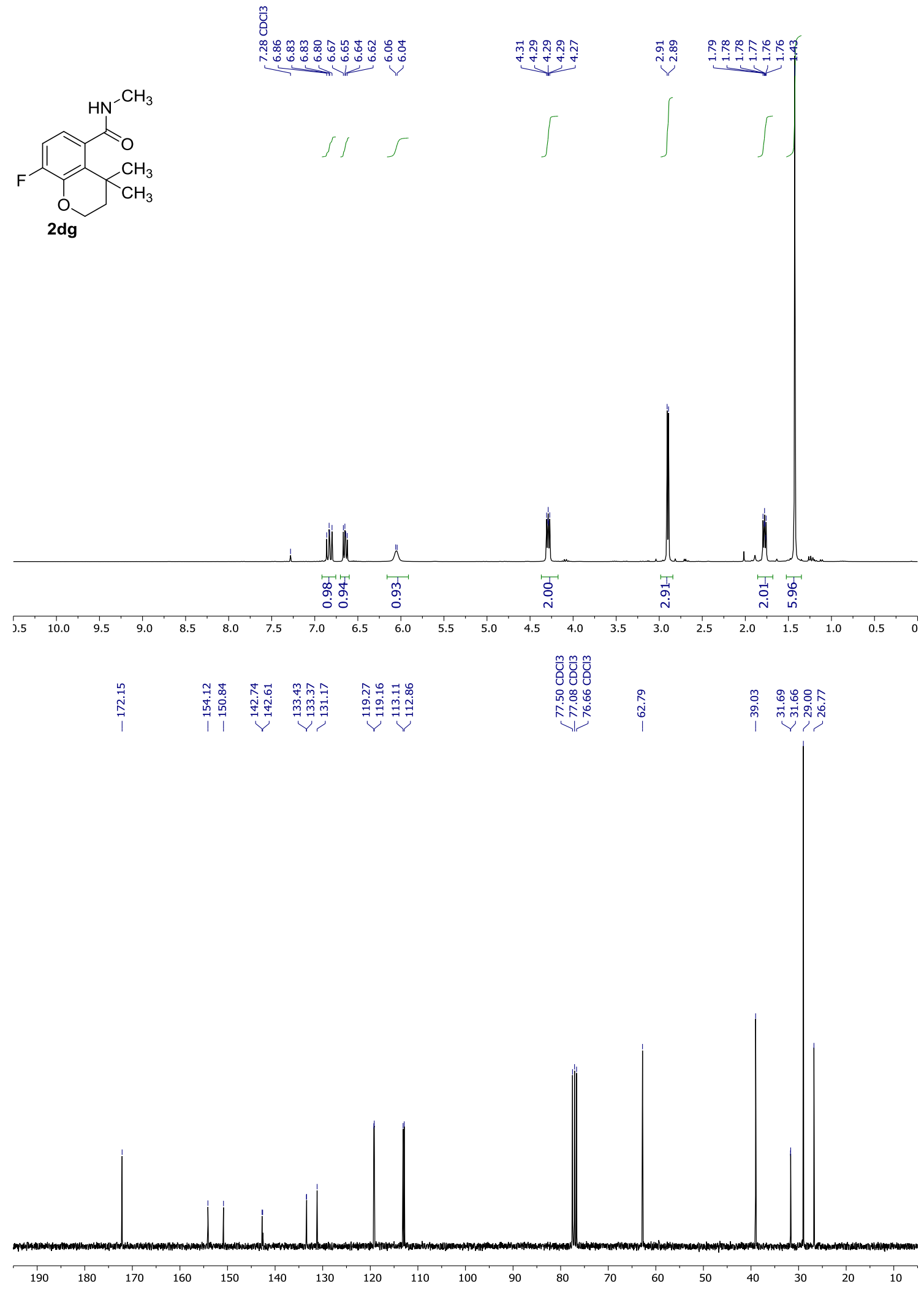

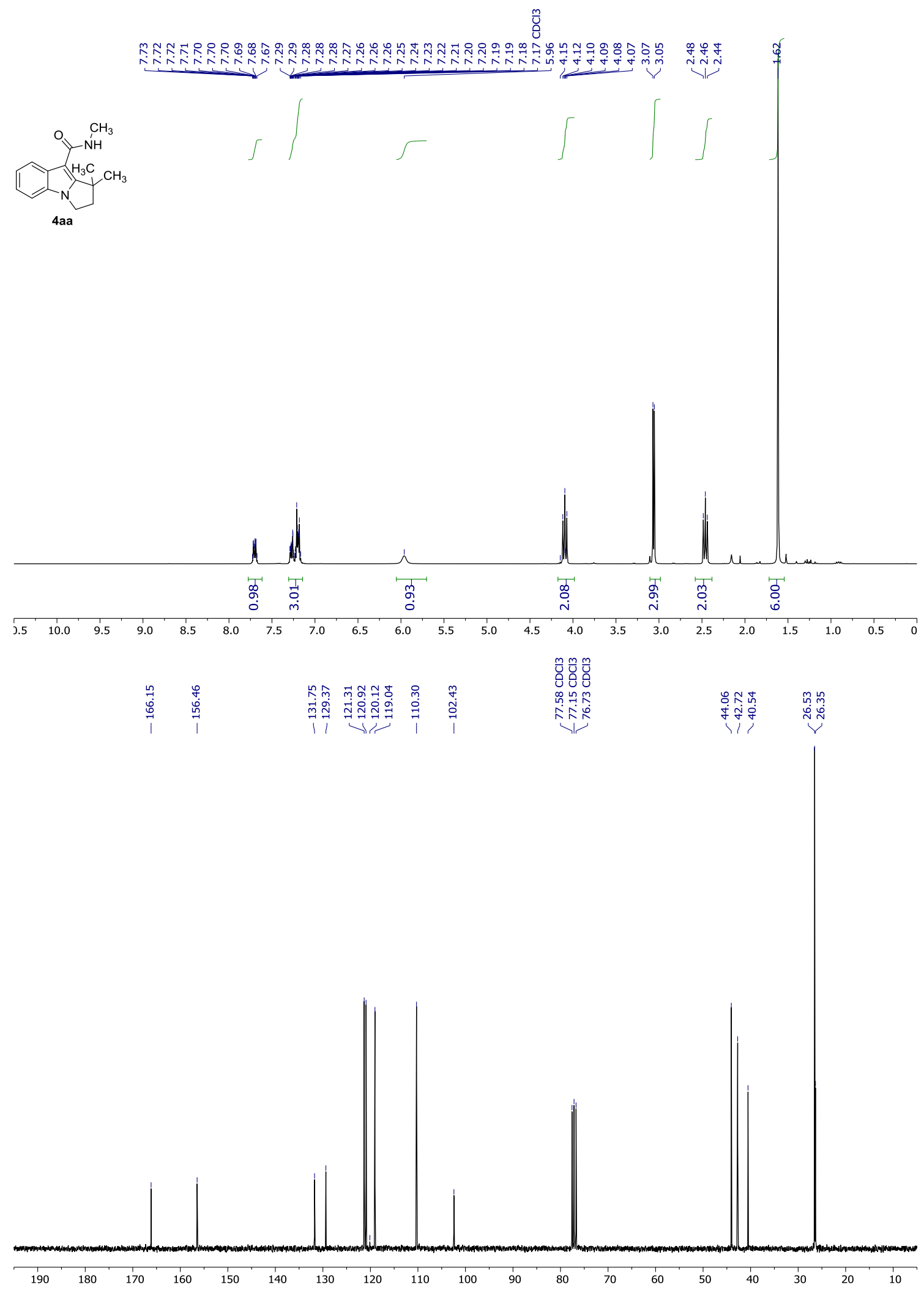


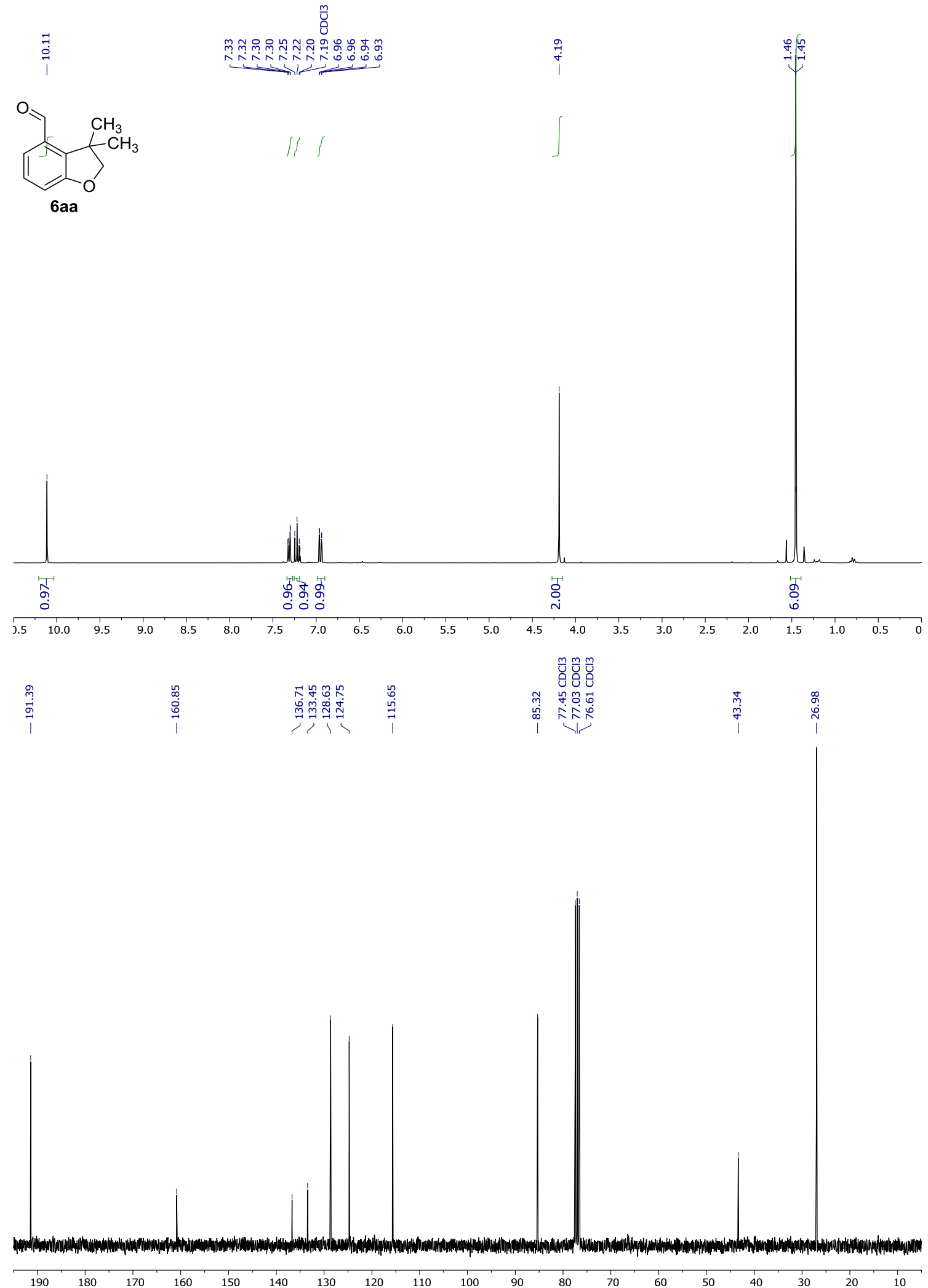

